\title{
Lapurdum
}

Euskal ikerketen aldizkaria | Revue d'études basques |

Revista de estudios vascos | Basque studies review

2 | 1997

Numéro II

\section{Histoire et onomastique médiévales. L'enquête de 1249 sur la guerre de Thibaud I de Navarre en Labourd}

Jean-Baptiste Orpustan

\section{(2) OpenEdition}

\section{Édition électronique}

URL : http://journals.openedition.org/lapurdum/1812

DOI : 10.4000/lapurdum.1812

ISSN : 1965-0655

Éditeur

IKER

\section{Édition imprimée}

Date de publication : 1 octobre 1997

Pagination : 161-235

ISBN : 2-84127-142-0

ISSN : $1273-3830$

\section{Référence électronique}

Jean-Baptiste Orpustan, « Histoire et onomastique médiévales.

L'enquête de 1249 sur la guerre de Thibaud I de Navarre en Labourd », Lapurdum [En ligne], 2 | 1997 ,

mis en ligne le 01 septembre 2010, consulté le 29 janvier 2020. URL : http://journals.openedition.org/ lapurdum/1812 ; DOI : 10.4000/lapurdum.1812 


\section{J.-B. ORPUSTAN}

\section{HISTOIRE ET ONOMASTIQUE MÉDIÉVALES L'ENQUÊTE DE 1249 SUR LA GUERRE DE THIBAUD I DE NAVARRE EN LABOURD ${ }^{(1)}$}

\section{$1^{\text {re }}$ partie : les réclamations des Bayonnais et Labourdins}

\section{Avant-propos}

Le texte de ce document exceptionnel du milieu du treizième siècle demandait à être mis d'urgence à la portée des lecteurs et des chercheurs. C'est pourquoi, après l'avoir découvert grâce à la bienveillance de notre regretté collègue Eugène Goyheneche, qui en avait fait la première transcription pour sa thèse sur l'onomastique basque médiévale, et l'avoir utilisé comme l'une des sources principales pour la documentation de notre thèse d'Etat sur les noms des maisons basques médiévales soutenue à l'Université de Bordeaux III en 1984, nous en présentons les deux parties aux lecteurs de LAPURDUM II et aux chercheurs des diverses disciplines concemées : parmi celles-ci, il y a d'abord l'histoire médiévale du Pays basque encore si insuffisamment prospectée sur nombre de points.

La première partie du document comportant les doléances du roi d'Angleterre, des Bayonnais et Labourdins, rédigée en latin, est présentée ici en traduction française. Des deux rédactions d'archives à très peu de choses près (quelques graphies des noms de personnes et de lieux) identiques, c'est la seconde qui a été retenue. L'original, écrit dans la graphie la plus soignée et la plus lisible des chancelleries médiévales du temps, contenant quelques passages écrits d'une seconde main, se contente de séparer les diverses rubriques par des blancs, sans aucune numérotation, et le détail des déclarations individuelles par des alinéas précédés des abréviations d'item habituelles et des lettres initiales mises en marge. Pour la commodité de lecture, une numérotation romaine a été ajoutée ici entre parenthèses à la tête des rubriques principales. La deuxième et demière section (la troisième en tenant compte des deux versions de la section labourdine), comportant les doléances du côté navarrais, rédigée en langues romanes, sera présentée à la suite.

C'est le document lui-même qui foumit le plus clair des renseignements sur ce conflit totalement ignoré de la "grande histoire", qui suivit de peu l'arrivée sur le trône navarrais, d'abord conteştée, de Thibaud Ier comte de Champagne, plus célèbre dans la littérature française que dans l'histoire poli- 
tique : "Thibaud le Chansonnier", le plus grand "trouvère" de son temps, lié à une prestigieuse lignée de princes poètes qui remontait à... Guillaume IX duc d'Aquitaine, le premier des "troubadours" d'oc. Neveu par sa mère de Sanche le Fort mort sans héritier en 1234, mais qui l'avait déshérité, il avait eu quelques difficultés à s'installer sur le trône de Pampelune. ll avait aussi tenté de réformer les divers "fors", textes des droits et libertés que les premiers rois de Navarre avaient concédés à la plupart des territoires du royaume. Des historiens considèrent aujourd'hui qu'il dut accepter les points de vue et les limites à son autorité que lui imposa l'assemblée des "Cortes" à laquelle tout nouveau roi de Navarre devait prêter serment, ce qui se perçoit assez clairement dans des articles comme celui des preuves de l'infançonnie ou noblesse. De là naquit le Fuero General de Navarra (1237) qui resta, avec quelques amendements partiels et conjointement à la coutume locale propre à chaque vallée, la loi navarraise jusqu'à l'annexion castillane de 1512 .

D'après les termes de l'enquête elle-même, les hostilités entre les Labourdins et les Bas-Navarais se sont développées durant ces mêmes années. Comme le rappelle le professeur Ricardo Cierbide dans une étude sur les quatre langues utilisées dans ce document (2), la situation des terres de l'actuelle Basse-Navarre (le terme ne sera pas inventé avant le XVI siècle) à l'égard de l'ancien comté de Gascogne annexé par le duc d'Aquitaine au milieu du $\mathrm{XI}^{c}$ siècle était, sinon incertaine en droit, du moins disputée, et pas seulement pour Mixe et Ostabarret qui relevaient depuis toujours de l'évêché de Dax : le comte de Leicester - c'est le fameux Simon de Montfort - représentant le duc d'Aquitaine devenu roi Angleterre depuis le mariage d'Aliénor un siècle plus tôt revendiquait aussi comme possession du duc-roi Iholdy et Armendaritz et d'autres territoires déjà passés sous suzeraineté navarraise. C'était en effet tenir pour nuls et non avenus les serments d'allégeance au roi de Navarre des seigneurs principaux, celui du seigneur de Labrit seigneur "naturel" pour Mixe et Ostabarret dès la fin du XII' siècle, celui de Gramont en 1203 etc., comme le roi de Navarre le rappellera en tête de ses propres réclamations dans la seconde partie.

La cour de Pampelune attirait depuis longtemps des nobles labourdins : non seulement Garro de Mendionde, frontalier des pays navarrais d'Ossès, de Hélette, d'Ayherre (3), mais aussi une branche d'Espelette, dont la maison éponyme du Labourd avait pourtant conservé son seigneur propre et fut incendiée par les Navarrais, et d'autres comme "Sanz de Cambo". Ainsi des Labourdins tout au moins d'origine pouvaient être dénoncés pour leurs méfaits commis contre d'autres Labourdins ou des Bayonnais, et de même pour les BasNavarrais, d'autant plus que l'enquête scellait en 1249 la fin d'une douzaine d'années d'escarmouches. Les hostilités avaient culminé, après le double siège de Garro par les Bayonnais, le premier ayant été interrompu par les Navarrais, avec le véritable raid que Thibaud en personne mena avec ses partisans pour l'essentiel navarrais et bas-navarrais, Ioin en Labourd jusqu'à Saint-Jean-deLuz et Urrugne d'un côté, Mouguerre, Lahonce, Briscous de l'autre, et l'avan- 
cée en Mixe jusqu'à Came et le siège du château de Gramont à Viellenave. Cet événement se situe en 1244.

La rédaction des doléances, de part et d'autre, foumissait l'occasion de régler bien des comptes et des mécomptes personnels, les longues années d'hostilité ayant mêlé les meurtres et les faits de guerre véritables à divers chapardages et exactions de petite envergure, avec tous les degrés intermédiaires. Si l'on en croit les destructions dénoncées, ici au détriment des Labourdins, en plus des dizaines de tués, des très nombreux hommes pris pour être ensuite libérés contre rançon selon la mode du temps, l'armée royale et les partisans de Thibaud, souvent constitués de familles et fratries de guerriers (le père et les frères Garro évidemment, mais aussi les frères Arraidu d'Ayherre, Soraburu de Saint-Esteben, Nagithurri et Leizarraga d'Ossès etc., nobles et laboureurs mêlés), avaient brûlé des centaines de maisons, nobles "aulas" ou non "domos", surtout à Hasparren et Ustaritz où se trouvaient les deux principaux "castra" ou châteaux-forts (le Gaztelu d'Ustaritz qui a hérité en basque de son nom latin castellu, celui de Zaldu, autre latinisme, à Hasparren), scié les vergers, détruit les outillages, emporté le bétail. S'y ajoutaient les dommages particuliers qu'avaient subi artisans et marchands bayonnais : prêts non remboursés, vêtements et outils impayés, denrées perdues (jusqu'à un curieux "esturgeon" !), soldes réclamés par les marins ayant transporté le roi Thibaud, ce qui ouvre aussi le chapitre des fonctions portuaires et maritimes de la ville avec ses "nefs"...

Comme tous ces dommages sont calculés en monnaie - dont la diversité signale la place des échanges extérieurs dans l'activité du port et du commerce bayonnais: morlans régionaux, sanchetes navarrais, livres bordelaises. toulousaines, tournois français, poitevins, parisis, marcs anglais... -, il est aisé d'établir une sorte de "mercuriale" du milieu du XIII" siècle : le prix, variable selon son importance et sa notoriété - mais étonnamment modeste au regard d'aujourd'hui comparativement à celui du bétail -, d'une maison avec tous ses outils, d'un moulin, d'un cheval, d'un roussin ou d'un âne, d'un bœuf, d'une vache, d'une chèvre, d'un mouton, d'un cochon et des troupeaux parfois nombreux qu'ils constituent, d'un couteau même et de divers vêtements, étoffes. fourrures et cuirs... Mention est faite des cultures, avec les vignes, les céréales. blé et froment, mil et avoine, et surtout les "pommeraies" parfois de plusieurs milliers de pieds, les pressoirs, les cuves omniprésentes, dans ce pays de cidre évoqué un siècle plus tôt par le pèlerin de Compostelle Aymeri Picaud. de la présence des volailles et des abeilles : voilà de quoi dresser un tableau de l'économie régionale qui devrait tenter les historiens.

Pour l'onomastique médiévale l'intérêt du document n'est pas moindre Les noms de personnes, surnoms et prénoms d'abord, sont sans doute les moins intéressants pour l"onomastique, basque en particulier : leur abondance permet de noter les vogues du moment, matière à comparaison avec les périodes suivantes. Il est vrai que, dans la rédaction latine de cette première 
partie présentée par la chancellerie anglo-labourdine et le comte de Leicester, ils subissent comme de règle la latinisation, non sans diverses irrégularités et apparitions de formes dialectales (par exemple Garcias, Garcia, Garcie ou Gassie, Petrus, Petri ou Per, Sancius ou San(t)z...), soit au nominatif : Anerius, Arnaldus, Comitissa, Michael, Petrus, Raymundus, etc., soit dans les divers cas de la déclinaison. Ils sont présentés ici pour la plupart en traduction française ("Comtesse, Marie, Michel, Pierre, Raymond...") ou, parfois, dans leur forme ancienne locale la plus connue : "Garcia, Sanz, Aner, Arnalt (qui a fait le français Arnaud), Johan, Eneco...". Quelques autres, de forme plus rare ou plus spécifique, sont conservés sous la forme textuelle entre guillemets, comme "Per, Petri-Santz (qui est passé aux noms locaux d'état-civil sous cette forme), Ispanus, Auria" etc.

Deux traits dominants caractérisent ces anthroponymes médiévaux du XIII ${ }^{e}$ siècle : $1^{\circ}$ la présence à peu près constante du double prénom, le second presque toujours au génitif latin et représentant alors le nom paternel (ce qui peut se comprendre toujours comme "fils de..."), usage traditionnel qui ne disparaîtra tout à fait qu' au siècle suivant ; $2^{\circ}$ la rareté relative des surnoms, alors qu'ils sont légion dans les textes médiévaux et tout spécialement dans les régions de langue basque : Esquerra "le gaucher", Chipja "le petit", Suria "le blanc" toujours très répandus dans les textes médiévaux, Estua sans doute "l'enfermé", Baque qui pourrait bien être - paradoxe dans ce contexte guerrier - la première mention de l'emprunt basque au latin pace "paix", forment, en complément aux toponymes, les seules traces visibles du parler basque ayant résisté à la traduction latine, quoiqu' on puisse aussi les trouver traduits, comme certains toponymes, en langue romane ou en latin (blanc, parvum...).

Les prénoms et surnoms sont presque tous complétés par le nom indiquant la provenance et le lieu d'origine : ce peut être la terre ou la vallée, la paroisse ou hameau, mais c'est presque toujours dans les villages basques intérieurs le nom de la maison, véritable "nom de famille et d'état-civil" de ces temps, dont l'usage quotidien au lieu de celui d'état-civil moderne même s'il est en fort recul n'a pas encore totalement disparu aujourd'hui. Ces indications peuvent renseigner sur le pays ou la maison d'origine de certains habitants installés hors de leur lieu éponyme, à Bayonne ou ailleurs. Elle permettent surtout de disposer d'un nombre considérable de noms de maisons, presque toutes parfaitement localisées, pour la première moitié du XIII' siècle : pour la plupart d'entre elles ce texte offre la plus ancienne citation documentée, les noms cités auparavant (Livre d'Or de Bayonne et Cartulaire de Sorde ainsi que quelques textes navarrais pour les XI' et XII's siècles) étant relativement peu nombreux par comparaison. Il va de soi aussi, trait commun à toutes les maisons citées dans ces documents médiêvaux, même les plus anciens, que ces maisons existent encore pour la plupart dans les mêmes lieux, sinon avec les mêmes murs - détruits, brûlés, rénovés sans aucun doute encore un grand nombre de fois depuis lors -, du moins avec les mêmes noms.

Le document latin, probablement rédigé ou réécrit par des non bascophones, fait subir bien des outrages à ces toponymes ou "domonymes", et cer- 
tains restent même à peu près méconnaissables sous leur forme textuelle. Ils ont tous été reproduits tels quels sans modification orthographique - sauf pour les majuscules, minuscules et ponctuation pour lesquelles la traduction commande l'usage actuel, ainsi que pour l'apostrophe dans les élisions après détachement de la préposition ou de l'article -, et en caractères gras à chaque première apparition, comme tous les noms de lieux d'origine. Une citation entre guillemets rappelle à l'occasion les formes du texte original.

En dehors des noms en général basques du pays intérieur ou de HauteNavarre, le document cite de nombreux noms de personnages venus des zones aujourd'hui "landaises" (le vicomte d'Orthe à la tête de sa compagnie, tué par les Navarrais au siège de Garro, en est l'exemple le plus illustre) proches de Bayonne, et de Bayonnais : parmi ces derniers beaucoup sont connus et cités dans d'autres textes du milieu du XIII' siècle, en particulier dans les listes des habitants "censitaires" de la cathédrale du Livre d'Or (4), "cens" auquel le texte lui-même fait d'ailleurs allusion à la rubrique III des réclamations bayonnaises.

Aux noms de lieux cités, en particulier ceux des pays, hameaux et maisons du pays intérieur, ont été ajoutés, entre parenthèses, la forme actuelle ou historiquement attestée (graphie basque ou romane selon l'origine) la plus correcte, attestation qui remonte elle-même parfois à des époques antérieures, contemporaines ou de peu postérieures au texte de 1249, et si possible ou si nécessaire des renseignements sur le lieu ou l'établissement nommé. Toutes les sommes d'argent et autres nombres en chiffres romains dans le texte ont été transformés par commodité de lecture en chiffres arabes.

(I)

"Voici les réclamations du seigneur comte de Leicester ("Leycestrensis") qu"il expose au nom de l'illustre roi d'Angleterre ("Anglie" désormais traduit "Angleterre"):

Le seigneur comte fait savoir que durant les trêves entre les rois, des gens du roi de Navarre ("Navarre") obligèrent le sénéchal et les gens du seigneur roi d"Angleterre à quitter le siège de Garro (château des seigneurs labourdins du même nom à Mendionde), lequel lieu est du fief et du domaine ("de feodo et dominio") du même roi d'Angleterre ; et que durant le même siège les gens du roi de Navarre précité tuèrent le vicomte d'Avorta (Orthe) avec lui un autre gentilhomme (5) et 19 hommes du même vicomte ainsi que 18 citoyens bayonnais venant par devoir pour le service du nommé seigneur roi d'Angleterre au siège précité. Et à la suite du susdit éloignement forcé il fut nécessaire que le sénéchal du seigneur roi d'Angleterre, après avoir augmenté son armée, revînt pour assiéger le dit lieu de Garro, ce pourquoi il lui fallut faire de grandes dépenses et subir beaucoup de préjudices. Le comte fait savoir aussi que durant les dites trêves le roi de Navare occupa le château ("castrum") de Monte Ferrandi (à Itxassou : le nom castral et roman Montferrand, inventé sans doute par l'administration anglo-aquitaine, a fini pas s'altérer pour faire l'actuel Mondarrain qui désigne l'ensemble de ce site montagneux) qui est du domaine du roi d'Angleterre et il le tient encore. Le comte fait savoir aussi que, guand il y avait les trêves entre les rois, Amigot de Garro alors bailli du roi de Navarre et les siens tuèrent un féal et vas- 
sal du roi d'Angleterre, soit P. Arnalt de Saut (Zaldu qui était le "castrum" ou château-fort de Hasparren) et un de ses servants, et le susdit roi de Navarre accueille ces meurtriers sur sa terre, injustement à l'égard du seigneur roi d'Angleterre et en violation des trêves.

Item le comte fait savoir que durant les dites trêves Pierre Amalt de Luxa (Luxe, le principal seigneur de Mixe) vassal et gentilhomme (6) du mentionné roi de Navarre assiégea un château du seigneur roi d'Angleterre, à savoir le château de Saut (voir cidessus), ce pourquoi le même seigneur roi fit de nombreuses et grandes dépenses et subit beaucoup de préjudices, en plus du meurtre de beaucoup d'hommes.

Le comte fait savoir aussi que durant les trêves le roi de Navarre prit le château de Camer (Came en basque Akamar(re)), qui est du fief du seigneur roi d'Angleterre, et pour le récupérer le seigneur roi dut faire de grandes dépenses.

Item le comte dit que durant les trêves Amigot de Garro et Garcia Arnalt son père avec les hommes du roi de Navarre brûlèrent environ 200 maisons et des moulins ; ils tuèrent 7 laboureurs ("agricolas") du roi d'Angleterre et dévastèrent les pommeraies du château de Saut et de son district (c'est-à-dire le pays de Hasparren) qui est du fief du roi d'Angleterre ; ils volèrent des bœufs et du bétail, ce qu'il estime à 7.000 sous morlans.

Item le comte dit qu'au temps de la guerre que le roi de Navarre menait injustement le même roi de Navarre et les siens brûlèrent le château de Saut et environ cent maisons au château d'Ustaryds (le "castrum" est constitué de l'ensemble du village ou hameau fortifié autour du château : actuelle mairie dite en basque gaztelu) et ils dévastèrent les pommeraies à Ustaryz (sic), prix 300 marcs.

Item le comte fait savoir que dans les trêves les gens du roi de Navarre brûlèrent les maisons de Sansa et de Crussyaga (Azantza et Kurutxaga deux des maisons infançonnes de Cambo), dommage qu'il estime à 100 marcs.

Item le comte dit que dans les trêves les gens du roi de Navarre brûlèrent trois maisons dans la paroisse de Sancti Johanis de Luyz (Saint-Jean-de-Luz), et volèrent 120 porcs et tuèrent un homme, dommage qui est estimé à cent marcs, le meurtre de l'homme en plus.

Item le comte dit que dans les trêves les gens du roi de Navarre volèrent quatrevingts vaches à Pierre Amalt de Saut et tuèrent un homme du même P. A. de Saut et en prirent un autre, et ils l'obligèrent à se racheter pour 60 sous morlans.

ltem le comte dit que, alors que les gens du seigneur roi d'Angleterre assiégeaient les envahisseurs de ses terres (le texte écrit par erreur "treugarum" : des trêves) et graves malfaiteurs à I'égard de lui-même et des siens, et qu'ils les réduisaient en telle nécessité qu'ils ne pussent plus se défendre longtemps, les gens du roi de Navarre et sur son ordre par menaces et terreurs les refoulèrent du siège (7) et ainsi les dits malfaiteurs s'échappèrent sains et saufs.

Item le comte dit qu'au temps de la guerre que le roi de Navarre menait injustement il prit Bastitam (cette "bastide" ne peut être Labastide-Clairence fondée par le roi de France et de Navarte seulement un demi-siècle plus tard : puisque la rubrique concerne le pays d'Ostabarret, c'est probablement Ostabat, ou bien Larceveau dont le plan ancien correspond aux modèles d'urbanisme généralement nommés "bastides") et toute sa terre qui sont du fief et du domaine du roi d'Angleterre. Item dans le même temps le même roi de Navarre prit Ostebares (Oztibar ou pays d'Ostabarret, quoique le nom désigne aussi parfois Ostabat) qui est du fief et du domaine ("feodo et domi- 
nio") du roi d'Angleterre, et les gens du roi de Navarre tuèrent en Mixe Bernard de Bauta (à moins d'une erreur pour Arraute en Mixe, ce nom peut représenter, avec l'oubli du signe abréviateur par le copiste, Berrauta, forme romane du basque Berroeta, maison infançonne à Asme) damoiseau (voir plus loin la note 17) du seigneur Guillaume B. de Samacos (pour ce Samacos correspondant à la maison mixaine de Samakoitz voir plus loin la rubrique IV : le "seigneur" de Berraute devait être Latsaga ou Laxague d' Asme et le nom pouvait en désigner le propriétaire du moment et sa maison d'origine), Raymond d'Orsahaco (pour Orsanco) meunier du seigneur de Mansbarrauta (la "salle" de Masparraute ou Martxoeta était la principale des quatre maisons nobles ou infançonnes du lieu) et un bourgeois de Mansbarrauta ; de plus ils brûlèrent les maisons, dévastèrent les pommeraies, détruisirent les moulins et causèrent d'autres ravages, ce qu'il estime à cent mille sous morlans.

Item le comte fait savoir qu'au temps où Mixa (le pays de Mixe) fut prise, le roi de Navarre prit deux paroisses du roi d'Angleterre, à savoir Hyhout (forme romanisée de Iholdy) et Armendaryz, et il les tient encore.

Item le comte dit que dans les trêves et quand les hommes du roi d'Angleterre allaient au siège du château ("obsidionem castri de Garro") de Garro, les gens du roi de Navarre détruisirent les engins (pour le siège) du roi d'Angleterre et tuèrent deux hommes et firent des dommages jusqu'à la valeur de 40 marcs et davantage.

Item le comte dit qu'au temps de la guerre que le roi de Navarre menait injustement, le même roi brûla la maison d'Espeleta (la maison seigneuriale d'Espelette, qui n'avait donc pas, comme Garro, Saut, Ustaritz, Came, le rang et la fonction de château-fort ou "castrum") et dévasta les pommeraies, brûla les moulins et les maisons et provoqua d'autres dommages : prix 5.000 sous.

Item le comte dit qu'A migot tua deux hommes du roi d'Angleterre à Hesparrena (Hasparren, dont c'est ici une des formes anciennes, et déterminée en basque).

Item le comte fait savoir que dans les trêves, des gens de Garcia Arnalt de Garro et d'Amigot coupèrent deux mâts de navire et rompirent les cordes (sans doute celles d'un navire) de Seingnoret prévôt du Labourd, c'était "Martinus Bracsa", "Johannes Ortyz", "Domingo Harraca" (pour une autre graphie de ce nom voir rubrique XVII), "Senescala".

Telles sont les demandes du comte, sauf le droit d'ajouter, diminuer, déclarer et corriger, et de poser la somme des dépenses et aussi des dommages.

Ceux-ci sont les hommes du roi de Navarre qui intervinrent dans le meurtre ou assassinat des citoyens bayonnais et du vicomte d'Orthe et des siens : Bernard d'Alsu gentilhomme (Alzu maison infançonne de Saint-Michel en Cize), Loup d'Erro (la vallée de Haute-Navarre), "Bracs" (sic) et Bernard de Sorarburu frères (Soraburu maison infançonne de Saint-Esteben), Garcia d'Arraide (Arraidu à Ayherre), Sancius d'Araide (id.), Amalt seigneur de Le Carra (la salle de Lacarre en Cize), Sanz-Anso Sanz d'Etsau (ce nom semble représenter, vu le nombre de combattants de ce nom sans lien de parenté apparent, plutôt des gens venus du quartier Etsaba ou "Exave" d'Arrossa en Ossès que la salle d'Etxauz en Baigorry), Sanz seigneur d'Alsueta (sans doute l'une des maisons infançonnes d'Alciette en Cize), Loup Sanz de Sorrossa (pas de maison de ce nom en Basse-Navarre : il doit être Navarrais) et "Petriz Esquerra" son frère. Sanz Arnalt de Le Tarsa (Latarza nom de l'un des deux quartiers anciens de Lecumberry en Cize où la plupart des maisons étaient nobles), Loup Arnalt de Caragar (nom inconnu résultant peut-être d'une cacographie : par exemple pour 
Saradar maison d'Iholdy en limite d'Irissarry ; s'il s'agissait de Çaragorri d'Ossès ce serait la première mention avant le ... XVII' siècle !), Sanz Amalt d'Etsau, Anso Sanz d'Etsau, Analt Loup "Chipya", Garcia de Herriart (pour Iriante, impossible à localiser vu le nombre de maisons du même nom en Basse-Navarre et ailleurs), "Lupus" A. d'Etsau, Arnalt Sanz de Caragar, Aner de Hyruberi (il s'agit d'Iriberri d'Ossès comme on le comprend par la suite, nom écrit ici en phonétique labourdine avec aspiration), Garcia Amalt, Bernard, Sanz de Neguytorri frères (Nagithurri de Horça en Ossès) et beaucoup d'autres.

(II)

Celles-ci sont les demandes des citoyens bayonnais ; jureurs ou taxeurs (ceux qui ont fixé les sommes dues sous serment) : P. de Rauset et Laurent de Puiana.

Bernard de Belus a subi des dommages a l'occasion de la guerre du roi de Navarte pour le cens des dîmes à l'église de Bayonne, pour 60 livres morlanes.

Bernard de Hatcha (sans doute "Ahaxe" ou Ahatsa en Cize) obtint de Pierre Amalt de Larras (peut-être originaire de la maison de ce nom à Villefranque, actuellement Arlasea : voir rubrique VIII) 65 sous pour le rachat de son frère.

Amigot détruisit le moulin de Vital de Luc : prix 50 livres.

Sanz de Cambo doit à Pierre de Senseres 50 sous moins 6 deniers pour des pains.

B. de Hatcha vola un roussin et deux conques de blé à Garcia Arnalt dels Puis : prix 50 sous.

Sanz d'Arraidu vola au même un roussin et 5 conques de froment : prix 50 sous.

"Johannes" de Sateriz (ou Satharitz maison noble ancienne d'Isturitz) et "Aneco" (pour Eneko) volèrent au même un roussin : prix 30 sous.

Le fils d'Amalt de Luiar (Elhuiarte est une maison de Hasparren) vola au même cinq conques de froment et d'autres choses : prix 15 sous.

Sanz de Cambo reçut en commande ("per comendam" : vieux français "comande" pour ce qu" on nomme un "contrat à cheptel") 30 vaches d" "Assarida" de Perer et de son mari : elle (ou : il ?) demande les vaches et leur nourriture pour les cinq ans révolus ou davantage. Sanz d'Arraidu vola au même 4 vaches : prix 40 sous.

"Gonsalvo Johannis" doit à Marie de Corneillan pour son père 14 livres bordelaises.

Guiralt de Lisserrague (Leizarraga maison ancienne d'Ahaice en Ossès aujourd'hui disparue, ou peut-être de Mendionde) et d'autres servants de Garcia Amalt de Garro brûlèrent la maison de Pierre Arnalt de Luc et volèrent des vaches : prix 35 livres.

P. de Meharren (la salle de Méharin) doit à Daunet de Herryague (Harriaga maison infançonne de Mendionde) 4 livres pour fidéjussion que son mari fit pour lui. Arnalt de Garue prêtre mit à la recommandation de Garcia Arnalt de Garro 48 vaches et trois bœufs. Il demande les vaches et les bœufs et la nourriture des vaches pour les 10 ans passés. Item il lui transmit 6 livres sur garantie et il paya pour cela à ses créditeurs quelques 6 livres et 5 sous. Item Raymond d'Ostebares (la ville d'Ostabat, ou le pays d'Ostabarret) et Arnalt B. de Garro volèrent au même une vache : prix 20 sous. Item Aneco d Arraidu et Martin son frère et $P$. de Mongelos (la paroisse de Cize du même nom) et Raymond de Londais (Londaitz maison infançonne d'Ayherre) volèrent au même 260 brebis : prix 15 livres.

Loup Aner prit Pero A. de Naner et l'obligea à se racheter pour 62 sous. 
Martin d'Arraido et Aneco son frère et leurs complices prirent Guillaume de Bordeu et l'obligèrent à se racheter pour cinquante sous.

Item ils prirent Johan de Prad et l'obligèrent à se racheter pour 25 sous.

Sanz d'Arraido prit Johan de Taron et l'obligea à se racheter pour 32 sous et 6 deniers.

Garcia A. d'Espeleta et Guillaume son fils volèrent à Jacob de Lesquira et Dominique d'Endrein (Andrein en Béarn) et B. Fierer 60 porcs, prix 12 livres.

P. dels Puis paya pour Garcia Amalt de Garro 6 livres et 5 sous qu'il lui demande.

Guillaume A. de Luc paya pour le même 6 livres et 5 sous qu'il lui demande. Item i] doit au même 50 sous pour transport. Item le même Guillaume Arnalt de Luc paya pour Amigot de Garro 30 sous qu'il lui demande.

Johan Desbor paya pour Garcia A. de Garro 6 livres et 5 sous. Item le même Amigot doit au même 30 sous et 6 deniers qu'il lui demande. Item le même Garcia Arnalt de Garro doit 6 sous à Johan Desbor qu'il lui demande.

Item Guillaume de Naubica (le nom renvoie sans doute à la maison d'Arcangues actuellement dite Albeintz, résultat d'une métathèse de l'ancien Nalbais 1083 puis par romanisation phonétique Naubeis à partir du XIII' siècle) paya pour le même 6 livres et 5 sous. Item il doit au même pour des pains 38 sous et 7 deniers.

Pélégrin de Faurgues paya pour le même Garcia A. de Garro 6 livres et 5 sous.

La femme de Guillaume de Sumset paya pour le même Garcia A. de Garro 6 livres et 5 sous.

Bernard de Hatche (château d'Ahaxe en Cize) obligea V. de Saint-Félix à se racheter pour 16 sous et lui emporta ses outils, prix 8 sous.

B. de Hatche prit Michel de Casanova et l'obligea à se racheter pour 9 livres et à cela a participé Garcia Amalt de Belsunsa (forme déterminée de Belzuntz la plus importante des maisons infançonnes anciennes d'Ayherre).

L'illustre roi de Navarre doit à Marie "Davorta" (d'Orthe) alors épouse de Maître Garcia 40 sous pour la fourniture d'un navire.

Guillaume A. de Re Labord alors mari de "Grazide" de Poyes acheta à Garcia A. de Belsunsa 8 douzaines de ruches ("bornacj") que son épouse lui demande.

Item Sanz d"Arraidu emporta une douzaine de "hubornu" au mari de la même femme, prix 60 sous. Item elle paya pour Aneco Sanz de Sateliz (Satharitz) 30 sous à Pierre de Polencs.

Sanz A. Blanc servant de Garcia A. de Garro prit Johan d'Estela (originaire de cette ville de Navarre) et l'obligea à se racheter pour 50 sous sanchets. Item Domingo de Galvensu (Guelbenzu en Navarre dont c'est ici la plus ancienne mention connue) prit le même Johan et l'obligea à se racheter pour 30 sous sanchets. Item Martin Michel obligea le même à se racheter pour 10 sous sanchets. Item le même Johan est fidéjusseur en faveur de Michel de Lerin pour 53 sous morlans et 7 livres tournoises, fidéjussion dont il demande à être acquitté.

Amigot vola 8 porcs à P.S. de Beguios (la salle de ce lieu en Mixe), prix 30 sous, et l'obligea à se racheter pour 12 sous.

Raymond d'Aragon péager du roi de Navarre emporta 70 sous toumois à Pierre Angles (surnom roman d"origine "l'Anglais" qui a pu devenir prénom "ethnique").

Amigot de Garro emporta à Pierre d'Yruber (nom ancien de Saint-Pierre d'Irube) deux vaches: 28 sous.

Sanz d'Arraydu prit Julien de Salies et l'obligea à se racheter pour 9 sous.

Petri-Sanz d'Arraidu vola une tunique à Fort-Aner de Sancto Johanne (plusieurs maisons "Saint-Jean" existent en Labourd et dans les environs, outre les paroisses du même nom) : prix 30 sous. 
Garcia "Baque" prit Guillaume Marques et l'obligea à se racheter pour 20 sous.

Aneco et Martin d'Arraidu volèrent 1 bœuf à Johan Desbor : prix 20 sous.

Item Amigot de Garro vola au même Johan Desbor une vache : prix 15 sous.

Sanz d'Arraidu doit à $R$. de Garans 14 sous pour le manteau de son épouse et 3 sous pour un dessus de tunique et il lui enleva un drap, prix 3 sous ; et il lui remit sur garantie 3 sous : il demande le tout.

Gracie de Sant Girons ("Saint-Girons" dans le pays d'Orthez probablement) épouse de Garcia Arnalt d'Arrauns demande un taureau que son mari remit à la recommandation de Sanz de Cambo.

Amigot de Garro vola 16 chèvres et le bouc à Raymond du Tremolet : prix 26 sous.

"Petri-Sanz" d'Arraidu obligea Johan de Le Fijte (pour "Lafitte") au rachat 14 sous.

Pierre et Michel Maignan (origine sans doute du nom "Maignon") doivent 11 sous à Guillaume de Sort au titre de fidéjussion.

Amalt Guillaume fils de Guillaume Escolan, Loup Amalt de Garagar (sic), Sanz son frère, Johan de Irryvaren (plusieurs maisons Iribarren en Ossès et ailleurs, aujourd' hui Iribarne), Sanz "Faber", Loup Johan, B. de Sufaratsu (pour Zuharatzu toponyme cité au XII' siècle, disparu aujourd'hui), Sanz de Sufaratsu, Arnalt de Sancta Maria (plusieurs maisons nobles de ce nom en Basse-Navarre) fils de Garcia Arnalt d'Eusees (pour "Ossès" : comme il n'y pas eu de maison "Sainte-Marie" à Ossès, le fils de ce personnage doit habiter une maison situé ailleurs, peut-être à Hélette), Amigot de Garro brûlèrent la "salle" (c'est-à-dire la maison noble, "aulam" dans le texte) de Pierre d'Arraused (maire de Bayonne : à la sortie de la ville vers Urt, l'actuel "Moulin d"Arrousets" perpétue le souvenir de son domaine) et coupèrent ses vergers. Prix 200 marcs. Item Pierre de Ferriague (Harriaga) doit au même Pierre d'Arrauset 20 sous qu'il paya pour lui à titre de fidéjussion. Item Pierre "Aleman" (prénom ethnique médiéval très répandu) d'Iruyta (outre le village du Baztan, il y a une maison Irurita à Saint-Esteben d'Arbéroue, citée encore au XIV ${ }^{c}$ siècle et parmi les 128 anoblies de 1435) (8) vola au même un bœuf : prix 30 sous; mais il subit depuis un dommage de 10 livres. Item "Petrus" Ladron vassal du roi de Navarre enleva au même un cheval qu'il détient encore.

Ceux-si sont les marins (9) qui naviguèrent sur la nef du roi de Navarre la dernière fois que ce même roi traversa la mer, et chacun d'entre eux demande son salaire : soit Raymond d'Os, Amalt de Senguinet (Sanguinet dans les Landes), Fort Aner de Faurgues, Amalt de Fort, Pierre Guillaume de Legieta (sans doute "Ligeta" nom de quartier et maisons nobles de Cize, aujourd'hui déformé en "Libieta"), Arnalt de Naubil, Raymond R. de Cimbads, Pierre de Lastres, Pierre de Seingnosa (Seignosse dans les Landes), Guillaume de Le Bruguerre (c'est-à-dire "La Bruyère"), P. d'Avorta, "Vitalis" de Monen (Monein en Béam), Salvat de Le Peruilla (une majson d'Ustaritz se nommait "Perul" ou "Peruil", actuellement Perulea), Mathieu de Seubist, Em(ile ?) Arnalt de Plaieds, Bertrand de Le Furie (sans doute pour "Lafaurie"), Guillaume Amalt deu Flis, Michel de Fort, Bertrand de Pui, Amalt de Baliros, Arnalt d'Ere (sans doute pour “Aire”), Amat de Sorrain (ce nom représente peut-être "Sorano" de Hasparren) le fils de seigneur André (par "seigneur André" nous traduisons la formule gasconne qui intervient dans le texte latin : "lo fil nandriu").

"Vitalis" de Villa fut pris par "Semen" de Beraids ("Beraitz" village de HauteNavarre) qui lui vola un paquet de marchandises, après quoi le même Vitalis fut forcé à se racheter : 68 sous sanchets.

Garcia Baque vola à $\mathrm{P}$. de Luxerror 31 broches (tiges de fer) quand il y avait le siège de Garro: prix 10 sous. 
Sanz d'Arraidu vola à Sancia (nom féminin) Arnalt d'Ossau 14 sous et demi.

Garcia Baque prit Amalt de Prad et l'obligea à se racheter 63 sous.

Pierre Arnalt de Giestars (Gestas) fut pris pas Dominique Pascal de Larressoina (Larrasoain en Navarre) qui tua son père à Bayonne.

Garcia d'Arraidu et ses frères obligèrent Guillaume Pierre de Laugar à racheter 120 porcs : 18 sous (sic).

Garcia Arnalt de Garro et les siens prirent Bernard Espert et le blessèrent de 7 blessures et lui enlevèrent ses armes. Prix des armes et des dépenses des médecins : 40 sous.

Aneco d'Arraidu et Martin obligèrent "Garcion" de Lanson à se racheter à Beios pour 3 sous.

Palatin ("Palazinus" dans le texte) perdit du fait de "Semen Sementz" 4 livres et 12 sous sanchets qu'il lui extorqua pour le rachat des poissons qu'il portait pour les vendre en Navarre. Item le même perdit du fait de R. d'Aragon à Pampelune 20 sous pour le prix d'un certain esturgeon.

Raymond Guillaume de la Fiite perdit du fait de Martin d'Arraidu et de P. Sanz et Johan de Saterids 13 sous morlans.

Pierre Johan de Mugron (originaire de ce village landais) perdit du fait de M. Periz péager de Maier (Maya en Navarte) I roussin : prix 60 sous.

Bernard de Mascarat (ce nom d'origine doit désigner une maison Amezkarate non identifiée) perdit du fait de Garcia Arnalt de Garro 1 roussin et 3 vaches, et il perdit du fait de B. d'Orcuit (ce n'est sans doute pas le village labourdin, mais la maison homonyme Urkieta d'Ayherre anoblie en 1435 : voir note 8 ) servant du même Garcia Arnalt de Garro 16 chèvres. Prix du roussin 20 sous, prix des vaches 40 sous, prix des chèvres 16 sous. Item Amigot de Garro lui retient 20 sous qu'il demande. Item "Jordana" d'Orquieta Hugon (forme plus basque du précédent "Orcuit" et désignation de l'une des maîtresses de maison impliquées dans ces rivalités ; "Hugon" prénom masculin semble ici une erreur : il faut peut-être comprendre "suson", en gascon "situé au-dessus") lui retient 20 sous qu'il demande de même.

Arnalt Sanz de Sorarburu doit à Guillaume du Tremolet 10 livres qu'il demande.

Pierre Arnalt de Goos (dans les Landes) fut pris par Sanz Amalt de Chaua (hameau d'Etsaba ou Exave en Ossès) et les siens et conduit à Garcia A. de Garro et il dépensa en allant vers le roi et en revenant sur son ordre et pour ceux qui le conduisaient 8 livres. Item le même fut spolié par B. de Hacha (Ahaxe) qui lui prit 25 sous.

Pierre Arnalt péager retient à Pascal Cordaler (ou "le cordelier") 10 livres morlanes. Item Dominique fils de M. Cordaler lui retient 6 livres et 6 sous. Item Johan d'Autefalle lui retient 4 livres de sanchets et 10 sous pour ses dépenses.

Pierre Maignan et Michel son fils doivent à Guillaume A. de Pagasu (cette maison était située à Saint-Jean-de-Luz) et à son épouse 12 livres morlanes.

Sanz chapelain du seigneur évêque de Bayonne perdit du fait de Sanz Arnalt d'Espeleta et des siens et de Johan Ortytz et des hommes de Garcia Amalt de Garro 13 vaches : prix 8 livres morlanes.

Sanz Amalt de Maverned perdit aussi du fait des mêmes un bøuf et une vache.

Guillaume Bergoin fut blessé par Garcia Amalt de Garro et les siens et subit un dommage de 20 livres.

Amalt Garcia de Bisaudun subit de la part de Garcia "Ochoa" alors bailli de Roquefort (c'est-à-dire gouverneur du château royal de Rocafort dont il reste encore une tour en ruines au-dessus des grottes d'Oxocelhaya) un dommage de 30 sous.

Bemard Guillaume de Bagneires (nom d'origine : Bagnères) prêta à Loup Arnalt de Meharren (Méharin) et $\mathrm{S}$. Loup son fils 10 livres et demie qu il demande à Pierre de Meharren. 
Bartolomé de Stella (sans doute Estella en Navarre) demande 36 sous moins 2 deniers à Bon Ami le marchand qu'il paya pour lui. Item il demande 11 sous 3 deniers à Johan Sanz de Saint-Jean-Pied-de-Port.

Le précepteur de Saint-Jean du bout du pont de Bayonne (le Sancti Johannis in capite pontis Baione du texte nommant l'établissement des hospitaliers de Saint Jean de Jérusalem correspond à l'actuel Saint-Esprit) perdit du fait de "Lope Ochoa" alors bailli de Camer (Came) 5 vaches : prix 4 livres morlanes, et il demande pour les dépenses faites sur cela 40 sous morlans.

Pierre de Saint-Nicolas clerc perdit du fait de P.S. d'Arraidu 1 couteau : prix 20 deniers.

Guillemat de Garans demande à Fortaner de Mendilla harsu (Mendilaharsu maison franche d'Isturitz) pour des douelles (planches pour faire des tonneaux) 15 livres morlanes.

Pierre Amalt de Lescum (nom du village béarnais Lescun) retient à Michel de Mangs 71 livres morlanes qu'il demande, excepté qu'il reçut de lui une fourrure blanche de lapin.

Johan d'Aiossa (peut-être pour Aziotz maison infançonne de Macaye) fut pris par M. d'Arraidu et obligé à se racheter pour 20 sous morlans.

Garcia Arnalt de Belsunsa doit à Pélégrin de Saubaignag (pour Sauvagnac) et Johan de Sordua (nom de l'abbaye de Sorde) une douzaine et demie de "huborn";

Loup Brasc qui demeure à Saint-Jean-Pied-de-Port doit à R. de Larreula (nom d'origine : Larreule en Béarn plutôt que La Réole) 10 sous morlans.

Pierre de Meharren doit à Johan de Sordua (idem) 4 sous 4 deniers pour une tunique d'estamine (un tissu léger en laine ou coton) forte.

Pierre Sanz et Eneco d'Arraidu prirent Guillaume de Laurhontan (aujourd'hui Lahontan) dans son verger pendant les trêves et extorquèrent au même 12 sous morlans.

Johan A mbazedor (titre "ambassadeur" devenu nom de personne plutôt que fonction de ce personnage) doit à la femme du bailli ("baillencs" dans le texte, au sens de "gouverneur") d'Ortes (Orthez) 26 sous morlans et demi qu'elle paya pour lui au titre de fidéjussion.

Sanz d'Arraidu et Arbeu (forme gasconne de "Arbel" qui doit être un surnom) son frère volèrent à Bénévent de Pui à Anurt (cacographie probable avec finale romane pour Ahurti c'est-à-dire "Uñ") 20 sous morlans.

Johan de Pinu neveu de Johan "Beu" (semble une forme romane irrégulière pour "Bel" sumom) doit à "Baillargue" de Pinu 5 sous.

Sanz d'Arraidu et Michel son frère extorquèrent à B. d'Agremont (forme ancienne et altérée de Gramont, mais cité ici comme marchand et bourgeois bayonnais) tant en numéraire qu'en vêtements 12 sous.

Esclarmonde de Mangs demande à Per Ortitz 15 livres et 15 sous sanchets qu il devait à P. de Baded en ce temps-là son mari. Item elle demande à Dominique Pusque 4 livres sanchètes qu'il devait à son dit mari.

Arnalt de Claromonte (Clermont) demande à Arnalt de Lelherreguy (semble une cacographie pour Leherregi sur leher "pin" base de plusieurs toponymes basques anciens) alors bailli (représentant du roi qui deviendra plus tard le "mérin") dou Sees (Ossès) pour "Martinco" Pascal 10 douzaines de cercles (de barriques), que le même bailli brûla: prix 40 sous.

Ferrand muletier de Sancto Leone (Saint-Léon quartier de Bayonne) demande à Guillaume d'Espeleta fils de Garcia Amalt d'Espeleta 1 roussin, du froment et une tunique neuve, toutes choses qu'il lui confisqua. Prix du tout 4 livres et demie. 
Guillaume Amalt demande quatre livres à "Peirona" de Faiet au nom de "Troite" son épouse et 9 sous morlans que sa dite épouse paya pour la même Peirona à Pierre de Villa en fidéjussion.

Bernard de Tissaul demande à Guillaume B. Huil de Taichon 2 bœufs qu'il vola de la cabane d'Alsueta (le nom Alzueta est, entre autres, celle d'une maison de Hasparren, la "cabane" étant ce qu' on nomme aujourd" hui une "borde") : prix 40 sous morlans.

Johan de Lesgor (doit correspondre au toponyme Laskor documenté en Cize et Mixe, mais non en Labourd ; peut-être aussi forme ancienne et altérée pour Lescar, de même étymologie que le précédent, nom d'origine de plusieurs censitaires bayonnais cités en 1266 au Livre d'Or) demande à M. d'Arraidu 1 couverture qu'il lui vola : prix 18 deniers.

Raymond Guillaume Terreberd demande à Arnalt d'Orinsu 12 sous qu'il lui doit pour ses poissons, qu'il apporta à Mayer (Maya) aux hommes du roi de Navarre.

Pierre "Blanc" et "Araldus" d'Amor demandent à Garcia Amalt de Garro 15 sous. Item ils demandent à Sanz de Cambo 15 sous pour un bouf qu'il leur vola.

B. de Mosserrole perdit du fait de Garcia Baque a Aurt (Urt) 6 sous 4 deniers.

Jordan de Salias demande à Ochoa Sanz 10 sous moins une obole pour les poissons qu il lui vendit.

Amigot de Garro prit A. de Lissabe (pour Elizabe nom de maison peut-être située à Bardos et connue aussi en Soule médiévale) et le conduisit à Sees (l'une des nombreuses cacographies du texte pour "Ossès" où les seigneurs de Garro étaient possessionnés par les rois de Navarre) et l'obligea au rachat pour 4 livres et 4 sous.

Garcia Arnalt de Belsunsa et ses compagnons, Pierre Sanz d'Arraidu et Arbeu ("Arbeui") et les leurs volèrent aux frères de la maison de Saint-Félix 117 grands porcs, des étoffes et d'autres choses et prirent un de leurs hommes et le forcèrent à se racheter pour 15 livres morlanes et demie. Prix de tout cela avec le rachat de l'homme : mille sous morlans.

(III)

Celle-ci est la plainte de la communauté bayonnaise. Jureurs : P. de Rauset et Laurent de Puiana.

Le maire et la communauté bayonnaise disent qu'eux-mêmes étant au siège de Garro sur l'ordre de Nicolas de Molis en ce temps sénéchal de l'illustre roi d'Angleterre leur seigneur, les gens du roi de Navarre en grand nombre les couvrirent de coups étant à l'armée, blessant certains d'entre eux, en tuant d'autres. Et avec toute larmée ils les molestèrent tant qu'ils durent revenir du siège sans avoir pris la dite maison de Garro. C'est pourquoi ayant augmenté l'armée avec d'autres fidèles du seigneur roi d'Angleterre il leur fallut revenir une autre fois à main armée au lieu susnommé, en quoi ils firent de grandes dépenses et encoururent de graves dommages. La maire et la communauté bayonnaise susdits font savoir aussi qu'eux-mêmes se trouvant au premier siège de la dite maison de Garro, les gens du roi de Navarte tuèrent 18 de leurs concitoyens venant au siège pour le même devoir et blessèrent gravement beaucoup d'autres de leurs concitoyens, et ils tiennent encore sous mainlevée 4 de leurs concitoyens qui furent pris par eux en ce temps. Estimation des dépenses et des dommages reçus pour revenir assiéger la dite maison de Garro : 100 livres qu“ils demandent leur être restituées, en plus des tués au sujet desquels ils demandent que leur soit faite juste réparation. Le maire et la communauté bayonnaise disent aussi que quand leurs conci- 
toyens et le vicomte d'Orthe furent tués ils perdirent tant en bêtes, armements, cordages, vêtements qu'en deniers et pains et autres préparatifs de guerre pour la valeur de 100 livres morlanes ou au-delà, en exceptant les morts pour lesquels ils réclament et requièrent que réparation leur soit faite.

Ceux-ci sont les meurtriers qui participèrent au meurtre et à l'attaque à l'épée des citoyens bayonnais et du vicomte d'Orthe et des siens, à savoir : Garcia Arnalt de Garro, Pierre "Estua" (voir l'Avant-propos) son fils, les frères Loup Garcia et Bernard de Suiars (nom sans doute déformé et qui apparaît sous diverses graphies), Amalt seigneur de Lecarra (Lacarre) et son frère, Bemard d'Alsu et son fils qui détient encore les armes du vicomte d'Orthe, Lope Sanz Sorrossa, Aneco Sanz de Larrassa (il n'y a pas de maison Larratz documentée en Cize au Moyen Age, mais à Villefranque : voir rubrique Il et VIII) et son fils qui demeure en Cize, Semen de Lecharrague (autre graphie pour Leizarraga déjà cité) et son frère qui demeurent en Ossès, les trois frères de Naguituri qui demeurent en Ossès, Aner de Villanova (traduction de Iriberri cité plus haut) qui demeure en Ossès, Bernard Guillaume d'Orcuit (pour Urkueta) qui demeure à Beelhoritz (Belhoritz nom ancien de Saint-Martin d'Arbéroue), Dominique d'Espila (il n' y a pas de maison de ce nom documentée par la suite à Armendaritz) qui demeure à Armendaritz, lequel ayant abandonné le roi d'Angleterre se mit sous l'autorité du roi de Navarre, Loup d'Erro (vallée de Haute Navarre), Johan d'Orbare et son frère et les leurs, Sanz d'Amaide, Garcia Baque, Aneco, Martin, Raymond d'Arraidu et les leurs, Sanz de Cambo et deux fils d'Arnalt Sanz de Hatche (Ahaxe), à savoir Garcia et Raymond avec les complices et les servants du dit seigneur de Hatche et son frère, qui tous au siège de Garro attaquaient les fidèles du roi d'Angleterre de jour et de nuit. Furent aussi présents dans le dit meurtre plus de deux cents hommes qui tous, exceptés 15 , sont et étaient du domaine du roi de Navarre.

Item le maire et la communauté bayonnaise disent que le roi de Navarre perçut de la maltote (10) qu'il mit à Mayer (Maya) sur eux et leurs marchands 20.000 sous morlans qu'ils demandent leur être restitués.

Item le maire et la communauté bayonnaise disent qu'à cause du règlement que la cité et le bourg de Pampelune ("burgus pampilonensis") firent à leur préjudice et grief, à savoir que celui qui apporterait des poissons à vendre à Pampelune ("Pampilinam") les en ferait sortir le jour suivant celui où il serait entré dans la cité ou le bourg susdit, ils ont subi un dommage de 10.000 sous morlans qu'il demandent leur être restitués.

Ils font ces demandes sauf le droit d'ajouter, diminuer, corriger et fixer les sommes des dépenses et des dommages.

(IV)

Celles-ci sont les plaintes du vicomte de Tartas.

Le vicomte de Tartas fait savoir que lorsque le seigneur roi de Navarre à l'occasion de la guerre qu'il menait injustement contre le seigneur roi d'Angleterre attaqua la terre qui se nomme Mixe, le même roi et les siens tuèrent B. d'Arraute gentilhomme (voir plus haut rubrique I : les deux maisons nobles d'Arraute, forme officielle romane issue du basque Arrueta, sont Elizaitzin et Elizetxe), Guillaume B. de Samacoidz (une maison Samacoitz est citée à Charritte en 1551) et Guillaume Garcie de Mazberraute (Masparraute), Amalt son frère, Bemard de Mazberraute, Guillaume molier (ce "meunier" occitan est peut-être déjà un nom patronymique) de Mansberraute (cette forme est la plus conforme aux textes les plus anciens, mais le premier élëment pris au latin mansum commence à s'altérer au XIIl` siècle), Amalt Garcie de Sosaute (de Sussaute, en basque Zozueta, dont la maison noble portait le nom de 
Galos) et Raymond d'Orzanquem (forme latinisée d'Orsanco). Et le dit roi avec son armée brûla une église avec tous ses ustensiles, à savoir les livres, les vêtements et, malheureusement, avec l'eucharistie. De plus ils anéantirent beaucoup d'autres églises avec les livres, les vêtements et les autres omements. En plus de cela le dit roi de Navarre avec son année détruisit les bourgs, les villages et les moulins et ils anéantirent les salles ("aulas") des gentilshommes et des clercs et incendièrent les maisons ("domos") des laboureurs ("agricolarum") (11), et aussi scièrent les vignes, les pommiers et les arbres fruitiers. A côté de cela ils leur firent des dommages soit en bétail, en blé et autres choses pour la valeur de cent mille sous, en plus du meurtre des hommes. Et il est prêt à le prouver tant par des gentilhommes que par des clercs et des agriculteurs ("agricultores") et d'autres dignes de foi.

Ils font (sic) ces demandes sauf le droit d'ajouter, de diminuer, de déclarer, de corriger et de fixer la somme des dépenses et des dommages.

La dame de Bedaumes (nom apparemment altéré, ressemble à Behaune nom de quartier de Lantabat) veuve demande à Amigot de Garro 202 porcs à elle qu'il lui vola quand il était bailli du roi de Navarre, avant que le même roi de Navarre entrât en Mixe.

Item elle demande au même Amigot de Garro 230 sous morlans qu'elle lui paya pour le rachat de cinq hommes, et elle est prête à le prouver par des clercs, des gentilhommes et des ruraux ("nuricolas").

\section{(V)}

De la paroisse d'Ustaridz.

Aner d'Aldave (maison Aldabea) juré dit que le roi de Navarre avec son armée lui enleva la maison, le pressoir, une cuve et du mil : prix huit livres morlanes.

"Per" de Guerre (pour Aguerre) juré dit que le roi de Navarre lui enleva deux toits, des cuves et du cidre et beaucoup d'autres choses: prix 8 livres et dix sous morlans.

Comtesse de Gusquieguia (forme déterminée, aujourd'hui Iguzkihegia maison située à Jatxou) jurée dit que le dit roi lui enleva la maison et des cuves avec du cidre, et des coffres et du froment : prix 8 livres morlanes.

Sanz de Hyrigoien (maison infançonne) juré dit que le dit roi lui enleva la maison et des cuves : prix 70 sous morlans.

Pierre de Hyspirue (Aizpurua ou Haizpurua maison au hameau d'Hérauritz) juré dit que le dit roi lui enleva la maison et deux bœufs : prix 70 sous morlans.

"Eneco" de Hyrigoien juré dit que le dit roi lui enleva une maison, des coffres et deux bœufs : prix 70 sous morlans.

Arnalt de Landalda (Landaldea à Hérauritz, maison infançonne) dit que le dit roi lui enleva la maison et un bcuf et des coffres et des cuves : prix 4 livres.

Marie de Gelos (maison Jelosea) jurée dit que le dit roi lui enleva un bœuf : prix 20 sous morlans.

Garcia de Saraspe (à Hérauritz) juré dit que le roi lui enleva la maison et d'autres choses : prix 30 sous morlans.

"Per" de Hyriart (Hiriartea) juré dit que le dit roi lui enleva la maison, des coffres et des cuves : prix 30 sous morlans.

Johan de Marrituri (nom d'état-civil à Jatxou écrit Marithurry à l'époque moderne) (12) juré dit que le dit roi lui enleva une maison et d'autres choses: prix 20 sous morlans.

Tous ces jurés donnèrent leur témoignage chacun à son tour.

Item de la paroisse d'Ustaridz deux taxeurs jurés : Martin de Iruber et B. de le Lana ("Le lane" ou "Lalanne" traduit le nom basque Larrea maison infançonne). 
Johan de Saut (nom d'origine extérieur à Ustaritz : voir Hasparren) gentilhomme perdit une maison du fait de Garcia Arnalt de Garro et des siens, trois vaches du fait de Garcia Amalt d'Espelete, un cheval du fait de Garcia d'Arraidu : prix de toutes ces choses 11 livres et demie.

Martin d'Yruber gentilhomme perdit du fait de l'armée du roi de Navarre lui étant présent une maison avec ses outils et du cidre : prix 500 sous.

Pierre B. de le Lana perdit du fait de l'armée du roi de Navarte lui étant présent une maison, les outils et le pressoir : prix 300 sous.

Martin de Juncars (maison infançonne dont le nom apparaît toujours sous la forme romane, correspondant au basque lhitz ou Ihitzaga) perdit du fait de l'armée lui étant présent une maison, les outils, le pressoir et les cuves : prix 700 sous.

Aner de Surayda (nom d'origine pour Souraide, dont c'est l'attestation la plus ancienne connue à ce jour) perdit deux maisons du fait de l'armée du roi lui étant présent : prix 100 sous.

Garcia Guillaume perdit une maison du fait de l'armée du roi : prix 8 livres.

Sanz d'Auryotz perdit un bœuf et une vache du fait de Dominique Estremil et "Otsoeta" (ce nom de lieu pour anthroponyme semble une erreur) de Berroeta (nombreux lieux et maisons de ce nom partout : la forme non romanisée en "Berraute" semble indiquer une localisation en Navarre), et 33 porcs du fait d'Arnalt Loup d'Etsava et Amalt Loup le petit ("parvum" dans le texte) et Sanz de Chava (sic) et Loup Amalt Belhare (la maison Belhar est documentée à Urdos en Baigorry, le mot au sens "face, devant, front" paraissant aussi ailleurs dans divers composés : Elizabelhar, Iguzkibelhar...). Prix du bouf et de la vache 42 sous; prix des porcs : 68 sous.

Porquet perdit deux bœufs et une vache, les bœufs du fait d'Amalt B. dit Pied de chèvre (le sumom est donné en gascon: "pei de crabe"), la vache du fait de Sanz d'Issuri (Ixuri l'une des sept maisons infançonnes anciennes d'Ayherre). Prix des bœufs 40 sous; prix de la vache 10 sous.

Garcia de Cambo perdit du fait de l'armée du roi lui étant présent une maison avec ses outils et du cidre, prix 100 sous.

Bernard de Naguilha (diverses maisons de ce nom en plus de celle d'Ustaritz) perdit du fait de l'armée du roi de Navarre lui étant présent une maison avec ses outils et 5 porcs du fait de Johan de Sombilh : prix de la maison 130 sous; prix des porcs 20 sous.

Arnalt Fortin de Hariza (sans doute le nom de la principale maison noble d'Ustaritz, Haitz ou sous forme déterminée ancienne Haitza documenté ainsi partout ailleurs, qui apparaît ici réécrit par confusion avec haritz "chêne") (13) perdit du fait de l'armée du roi lui présent une maison avec ses outils, deux ânes du fait d" "Arsisart do Sees" (sic), un bœuf du fait d'Arnalt de Bidart (maisons nombreuses en BasseNavarre et ailleurs), et un âne du fait d'Amigot de Garro dans l'armée de Garro (sans doute celle qui alla assiéger Garro). Prix de la maison et des outils 100 sous ; prix des deux ânes 12 sous, du bœuf 16 sous, du troisième âne 8 sous.

Bernard Aner de Garraut (normalement ce nom reproduit en phonétique romane Garralcle) perdit du fait de l'armée du roi lui présent deux maisons avec leurs outils : prix 4 livres.

Bernard de Hahistura (semble une cacographie pour Haizpurua : voir plus haut) perdit du fait de l'armée du roi une maison avec ses outils : prix 30 sous.

Pierre Garçie (sic) perdit du fait de l'armée du roi lui-présent une maison avec ses outils : prix 20 sous. 
Garcia Fortin de Lachalda (pour Latsalde avec une palatalisation qui se retrouve dans Latchalde 1256) perdit du fait de l'armée du roi lui présent une maison avec ses outils et du cidre : prix 4 livres.

Arnalt "Xemen" perdit du fait de l"armée du roi lui présent une maison avec ses outils : prix 30 sous.

Marie Johan de Surueta (pour Soroeta dite Sorta maison infançonne) perdit du fait de l'armée du roi lui présent une maison avec ses outils et du cidre : prix 40 sous.

Aneco de Larçebau (romanisation de Larzabal nom d'origine) perdit du fait de l'armée du roi lui présent une maison avec ses outils et du cidre : prix 9 livres.

"Petri-Santz" de Hiryberri (ici nom de maison) perdit du fait de l'armée du roi lui présent une maison avec ses outils et du cidre : prix 30 sous.

Arnalt Sanz d'Estubil (les graphies divergent pour le nom de la maison Ustubil) perdit un cheval du fait de Garcia d'Arraidu et de ses frères, trois vaches du fait de Garcia Amalt d'Espeleta, trois autres vaches du fait de Sanz d'Amaide, deux bœufs du fait de Loup d'Erro et 26 porcs du fait de Sanz d'Arrade. Prix du cheval 9 livres, des vaches 45 sous, des trois autres 40 sous, des deux bœufs 30 sous, des porcs 50 sous.

Pierre Sanz de Briscoz (nom d'origine : Briscous et sans doute la salle de ce lieu) perdit du fait de l'armée du roi une maison avec ses outils : prix 25 sous.

Pierre de Larrande (maison Larranda) perdit du fait de Garcia Arnalt de Garro qui le prit et l'obligea à se racheter 60 sous et un double ("unius ancipitris": monnaie). Il perdit aussi 10 brebis du fait de Guillaume de Murua (ancienne maison de Honza en Ossès) : prix des brebis 10 sous.

Santz d'Ustaridz perdit du fait de l'armée du roi une maison avec ses outils : 30 sous.

Marie B. perdit dans l'armée de Garro un âne : 8 sous.

Comtesse femme de Guillaume perdit un bœuf du fait de Guillaume de Ratsu (Erratzu en Bastan) : prix 20 sous.

Désirée Sanz perdit du fait de l'armée du roi lui présent une maison avec ses outils : prix 30 sous.

Marie de Hesperru (pour Haizpuru : voir plus haut) perdit du fait de l'armée du roi lui présent une maison avec ses outils : prix 25 sous.

Sanz Johan de Berasu perdit du fait de l' armée du roi lui présent une maison avec ses outils : prix 40 sous.

Pierre Bernard de Peruil (actuellement Perulea) perdit du fait de l'armée du roi lui présent une maison avec ses outils : prix 40 sous.

Sanz de Ferriague (graphie hypercorrective romane pour Harriaga) perdit du fait de l'armée du roi lui présent une maison avec ses outils : prix 300 sous. Item il perdit deux bœufs du fait de Garcia Arnalt de Larsebau (pour Larabal maison d'Ayherre anoblie en 1435) et Sanz de Bastan et 17 porcs du fait de Sanz de Cambo. Prix des bœufs 40 sous ; prix des porcs 30 sous.

"Lobet" (diminutif roman de "Lup" ou "Loup") de le Salda (pour Latsalde : voir plus haut) perdit du fait de l'armée du roi lui présent une maison avec ses outils : prix 41 sous.

Comtesse de Subieta (Zubieta) perdit du fait de l'armée du roi lui présent une maison avec ses outils : prix 30 sous.

Johan Arnalt perdit 14 sous du fait de Garcia Amalt de Belsunsa ; et 3 porcs : prix 6 sous.

"Ispanus" (prénom ethnique correspondant à "Espagnol") de le Lana perdit du fait de l'armée du roi lui présent une maison avec ses outils : prix 100 sous. 
Amalt Loup de Villanova (traduction de Iriberria précédemment cité) perdit du fait de l'armée du roi lui étant présent une maison avec ses outils : prix 15 livres. Et 20 porcs du fait de Garcia Arnalt de Belsunsa, et 2 bceufs. Prix des porcs : 40 sous ; prix des bœufs : 40 sous.

Aner de Bidart (forme romanisée habituelle de Bidarte) perdit du fait de l'armée du roi lui présent une maison avec ses outils, des cuves et le pressoir : prix 15 livres. Item il perdit deux bœufs du fait de Garcia Arnalt d'Arraidu et A.S. et leurs frères : prix 40 sous.

Bernard de Castaingnada (la version basque est Gaztenaldea) perdit du fait de l'armée du roi lui présent une maison avec ses outils et des cuves : prix 150 sous.

Arnalt d'Arrauts (pour Arrauntz) perdit du fait de l'armée du roi lui présent une maison avec ses outils : prix 4 livres. Item il perdit un bouf et demi ("unum bovem et dimidium" sic !) du fait de Garcia Amalt de Belsunsa : prix 28 sous.

Arnalt de Heguio (sans doute pour Hegia sinon Hegito quoique le suffixe -o soit bien attesté dans d'autres toponymes anciens) perdit du fait de l'armée du roi lui présent une maison avec ses outils : prix 30 sous.

"Auria" de Torobyz perdit du fait de l'armée du roi lui présent une maison avec ses outils : prix 150 sous.

"Maria" Johan perdit du fait de l'armée du roi lui présent une maison avec ses outils : prix 30 sous.

"Jordana" de Harauriz (quartier Herauritz) perdit du fait de l'armée du roi lui présent une maison avec ses outils: prix 15 sous.

Comtesse Arnalt perdit du fait de l'armée du roi lui présent une maison avec ses outils : prix 10 sous.

Arnalt de Mespa (doit représenter Amezpea) perdit du fait de l'armée du roi lui présent une maison avec ses outils : prix 100 sous.

Marie de Berria perdit du fait de l'armée du roi un tonneau et un coffre : prix 3 sous.

"Gaieta" perdit du fait de l'armée du roi une maison avec ses outils : prix 100 sous.

Daunet d"Aranseta (le nom de maison Arhantzeta "lieu de prunelliers" est très répandu) perdit du fait de l'armée du roi lui présent une maison avec ses outils : prix 100 sous.

Pierre B. de le Lana perdit du fait de Arnalt Loup le petit ("parvum") 6 porcs : prix 24 sous.

Pierre R. perdit du fait de Sanz Amalt de Naguyturri 2 vaches et 6 sous, prix des vaches 32 sous. Item il perdit du fait de l'armée du roi lui présent 1 bœuf, deux porcs et demi (sic) : prix 30 sous.

Amalt de Chavahen (forme altérée avec mécoupure romane pour Etxabarren. forme ancienne correcte devenue aujourd'hui Etxebarne) perdit du fait de l'armée du roi lui présent une maison avec ses outils : prix 4 livres.

B. "Faber" de Jatsu (vu les troupeaux possédés il ne s'agit sans doute pas du "forgeron de Jatxou", et le nom de métier faber ou son héritier roman local faure doit être utilisé comme nom de personne) perdit du fait de G.A. de Garro 24 grandes vaches et 22 petites ("peguillos", des mots romans apparaissant au milieu du latin : le sens se déduit de l"opposition avec "maiores") qu"il demande avec leur nourriture.

(VI)

De la paroisse de Saint-Etienne de Pagandurua (c'est-à-dire : Macave) (14)

Pierre de Pagandurua (la maison noble principale de Macaye) gentilhomme per- 
dit du fait de Garcia Arnalt de Garro et Loup d'Erro et Loup Garcia de Syvars (ce nom étrange répété semble l'altération romane avec mécoupure de Etxebertze : nombreuses maisons en Basse-Navarre et ailleurs) 34 porcs et 34 sous pour le rachat de sa porcherie (le troupeau de porcs) : prix des porcs 100 sous. Item il perdit une maison avec ses outils du fait d'Amigot de Garro : prix 7 livres. Item il perdit du fait des hommes de Garcia Amalt et Amigot de Garro deux ânes et des étoffes de son épouse : prix 20 sous. Item Garcia Amalt de Garro lui doit pour emprunt garanti ("ex mutuo") 50 sous. Jureurs pour cela : Garcia Amalt d'Uhalda (Uhaldea maison de Macaye) et Amalt Sanz de Hyrygoien (actuellement Irigoinia). Item il perdit du fait de G.A. de Garro 19 porcs : prix 30 sous.

\section{(VII)}

De la paroisse d'Arcangos (Arcangues, en basque moderne Arrangoitz)

Arnalt Johan de Naubeis (voir plus haut rubrique ll Naubica) juré dit que "Johannes" de Sancto Petro (la maison noble Saint-Pierre Donapetria de l'actuel Saint-Jean-le-Vieux est citée depuis le XII' siècle et le raid de Richard Cœur de Lion qui la détruisit alors ; parmi d'autres du même nom celle d'Armendaritz qui n'avait pas le statut de noblesse) alors compagnon de Sanz de Cambo lui prit 20 porcs et les mena en Cize : prix 8 livres morlanes. Et Martin "Chuste" (sans doute un sumom : il rappelle les formes basques ichusco/ichusto très répandues dans les documents de l'époque) lui enleva 1 bœuf et 1 vache : prix 40 sous.

\section{(VIII)}

De la paroisse de Biela franque (Villefranque : portait le nom basque Bazter "bord" documenté du Xle siècle au XIII").

Raymonde de Sancto Martino (l'une des nombreuses maisons nobles Saint-Martin en basque Donamartea est à Villefranque et nomme comme très souvent la paroisse du lieu) jurée dit que Sanz de Cambo lui enleva 29 porcs et un âne dont le prix est (espace blanc dans le manuscrit) 3 sous morlans. Et Sanz d'Arradu (sic) 25 brebis : prix 20 sous. Et Garcia Amalt de Belsunsa 29 porcs : prix 9 livres et 15 sous. Et Pierre Sanz d'Arraidu 3 porcs : prix 14 sous. Garcia Amalt d'Espeleta lui enleva 4 vaches : prix 4 livres.

Arnalt Guillaume juré dit que Bernard de Hatche (Ahaxe) et Pierre B. de Sancto Martino (il s'agit ici de Bas-Navarrais : les deux maisons nobles Saint-Martin étaient à Lecumberry en Cize, dont une actuelle maison-tour datant de ce temps) le blessèrent et l'emmenèrent lié et le tinrent en captivité 11 semaines et l'obligèrent à se racheter pour 48 sous. Et les hommes de Garcia Amalt de Garro et Amigot lui enlevèrent deux bœufs : prix 40 sous. Et Sanz d'Arradu avec ses compagnons lui enleva un bœuf : prix 28 sous.

Et le dit B. de Hatche et P. B. de Sen Martin (sic: forme romane du nom) prirent Bonet et l'obligèrent à se racheter pour 68 sous.

Guillaume Pierre de Tismar (cette maison est nommée Chimar en 1690) juré dit que Sanz de Cambo lui enleva 5 sous, et Guiralt de Lissarrague lui prit 7 sous. Pierre Amalt d'Irrissarri (nom d'origine qui peut désigner aussi bien un habitant de ce village que le commandeur de l'hôpital) lui retient 9 sous. Les compagnons de Garcia A. de Garro lui enlevèrent 2 bœufs : prix 25 sous.

Guillaume Amalt de Larras (maison nommée Arlas en 1690) juré dit que P. Estua et Guiralt de Lissarrague et Martin de Sancto Johane (sans doute de Saint-Jean-Pied- 
de-Port : pas de maison Saint-Jean documentée en Basse-Navarre) lui volèrent deux boufs et d'autres choses : prix 47 sous. Item Arnalt Loup d'Exagoe (vu le contexte peut représenter l'une des maisons Etxagoien d'Ossès ou ailleurs plutôt que "Etsaba", mais semble plus proche du nom du village navarrais d'Echagüe) et Garcia Arnalt de Harismendi (maison infançonne d'Ossès) lui volèrent un bœuf : prix 25 sous.

Tous ces jurés donnèrent leur témoignage sur ces choses chacun à son tour.

\section{(IX)}

De la paroisse de Saint-Jean-de-Luz ("Luis" avec diphtongue héritée de Lohitzun)

La dame Valence de Jaldai (ancienne maison noble Jaldai) perdit du fait de Pierre Gonsalvo de Bastan 70 porcs : prix 8 livres et 15 sous.

Aneco de Santz (plus loin écrit Sansu, nom de maison infançonne) perdit du fait de Garcia Amalt d'Espeleta et des siens une maison avec ses outils : prix 10 livres.

Johan Sanz de Sansu perdit du fait de Garcia Arnalt d'Espeleta une maison avec ses outils et 25 porcs et 30 chèvres et 17 abeilles (c'est-à-dire "ruches"). Item il perdit du fait de Johan Peires mérin du roi de Navarre 2 vaches. Item il perdit du fait de Garcia Arnalt d'Espeleta 12 conques de froment et 10 d'avoine et 60 de mil : prix de la maison avec ses outils 100 sous ; prix des porcs 75 sous ; prix des abeilles 17 sous ; prix des vaches 30 sous; prix du froment 20 sous; prix de l'avoine 8 sous ; prix du mil 50 sous ; prix des chèvres : 30 sous.

Aneco de Sansu perdit du fait de Garcia Arnalt d'Espeleta et des siens une maison avec ses outils et du blé : prix 9 livres. Item il perdit du fait de Johan Peires mérin du roi de Navarre 6 vaches : prix 4 livres.

Arnalt Johan de Pagandu (nom écrit Pagueundo en 1257, ce qui suppose Pagondo "près du (des) hêtre(s)" plutôt que "tronc de hêtre", mais Pagandu "souche(s) de hêtre" n'est pas impossible) perdit du fait d'Amalt B. d'Orcuit un bœuf : prix 20 sous.

Tous ces jurés donnèrent leur témoignage sur les choses susdites chacun à son tour.

Pierre de Sansu perdit du fait de Garcia Amalt d'Espeleta 59 porcs : prix 15 livres moins 5 sous. Item le précité Garcia Arnalt d'Espeleta tua son frère et il perdit du fait du même G. A. des vêtements et des armes : 8 livres. Arnalt de Naubeis jura pour cela.

\section{$(\mathrm{X})$}

Bernard B. prieur du Paradis ("prior paradisi" : voir la rubrique XXVI) (15) juré dit qu'il perdit du fait de Garcia Almoravid et des siens 100 brebis et 32 porcs : prix des brebis 150 sous morlans; prix des porcs 8 livres morlanes.

Frère Pierre B. prieur de le fonsa (écriture romane hypercorrective et latinisante avec "f" pour "h" pour l'abbaye de Lehuntz ou "Lahonce"), ayant juré sur l'âme de son abbé et la sienne propre, dit que "Gassie" Baque et Sanz d'Arraidu et ses frères volèrent de l'abbaye de le fonsa 6 vaches et 7 porcs et 1 bœuf : leur prix 106 sous morlans. Item il dit que dans la capture de ses hommes et le vol de ses autres biens les malfaiteurs susdits grevèrent la dite abbaye de 4 livres morlanes et demie. Item il dit que Garcia Amalt de Garro obligea Sanz, homme de la dite abbaye, à se racheter pour 6 livres et 12 sous morlans. Item il dit que Sanz de Yssuri leur vola 2 porcs : prix 15 sous morlans.

Espagne ("Hispania") d'Orcuit (il s'agit ici du nom d'origine du village voisin d'Urcuit) jurée dit qu'elle perdit du fait de la famille de Martin Enecotz (sic) 100 moins 2 (sic) porcs : prix 35 livres. 
$(\mathrm{XI})$

De la paroisse de Sancti Johanniz de Biudz (nom roman ou romanisé ancien de Mouguerre) (16)

Johan de Sancto Johanne (nom d'une maison noble Saint-Jean, disparue depuis, qui avait dû fonder la paroisse, ou nom d'origine de Hasparren) juré dit que Garcia Arnalt de Garro prétextant injustement de fidéjussion lui vola 13 vaches : prix 9 livres et deux sous.

Arnalt de Heriart (actuellement Iriartea) juré dit que Raymond d'Espilla (plusieurs maisons Erspila ou Espila en Cize et Baigorry) et ses familiers le prirent et l'obligèrent à se racheter pour cent et 20 sous morlans et lui enlevèrent 12 porcs : prix 48 sous. Item il perdit du fait de $S$. d'Araide un bøuf : prix 20 sous.

Raymond de Lariat (doit être le nom Larrarte) juré dit qu'il perdit 2 boufs du fait des servants du vicomte de Baigur (forme semi-romanisée avec chute de voyelle finale de Baïgorn') et d'Arnalt Arnalt et Sanz de Naguitori : prix 40 sous.

Arnalt d'Onderiz (la maison Underitz ou Honderitz moderne Hondritz était à Anglet ; à Mouguerre deux maisons portent le nom Irundaritz et il y a probablement confusion) perdit un bceuf du fait de Garcia Amalt de Garro : prix 20 sous.

Johan d'Onderiz perdit du fait de Raymond d'Espilla 16 porcs : prix 55 sous.

Tous ces jurés donnèrent leur témoignage sur ces choses chacun à son tour.

(XII)

De la paroisse d'Espeleta.

Garcia d'Espeleta perdit du fait d'Amalt Loup le petit et "Gassia" de Heriart et Sanz Amalt d'Etsau 39 porcs : prix 4 livres moins 2 sous et 6 deniers. Item il fut racheté par (sic : pour "fut obligé à se racheter") Michel Garcia de Lerin (val de HauteNavarre) 18 sous et 6 deniers. Item il perdit du fait de Sanz Arnalt d'Etsau 7 chèvres : prix 9 sous. Jureuse pour cela : "Gracia" de Berindoz (maison noble à Anglet actuellement Brindos) sa femme.

Raymond Amalt chapelain (c'est-à-dire "curé") d'Espeleta perdit du fait des compagnons d'Amigot de Garro 1 bœuf : 24 sous. Jureurs pour cela Aneco d'Uxainda (sous cette forme correspond à Otxanda, mais c'est sans doute une erreur pour Uxavida) et Lope d'Organvede (pour Orgambide). Item le chapelain ayant juré sur l'âme d'Arnalt de Gortairi (nom aujourd'hui partout altéré en Bortairi), comme il parle sur son ordre, demande pour le même Arnalt de Gortairi 1 bœuf qu'il perdit du fait de Martin Baratsa (forme probablement raccourcie pour une maison Baratzearte) compagnon de Guillaume d'Espeleta : prix 25 sous. Item le chapelain ayant juré sur l'âme de Sanz seigneur d'Espelete (la maison noble ou salle dont dépendait toute la paroisse), comme il parle en son nom, demande pour le même Sanz le paiement des moulins d'Espeleta et de la salle et des celliers d'Espeleta et des outils et du cidre, de 100 brebis brûlées et de deux mille pommiers dévastés et des dommages portés à son épouse qui lui succéda comme héritière, du fait du roi de Navarre et des siens et de Loup d'Erro et des siens : prix de tout mille sous.

Aneco Uxavide (c'est-à-dire Otsabide) perdit 40 porcs du fait d'Amalt Loup de Chaga (peut-être pour l'actuel Echagiie en Navarre) et ses compagnons. Item il perdit une maison du fait de Loup d'Erro et ses compagnons et les outils de la maison : 4 livres : prix de la maison et des (objets) contenus : 100 sous.

Jureur pour cela le chapelain susdit, lequel chapelain fut admis à la place des susdits Amalt de Gortharri (sic) et Sanz d'Espelete (sic) parce que, selon lui, ils n'osaient pas entrer dans Bayonne. 
(XIII)

De la paroisse de Hetsa (pour Ahetza).

Pierre de Herenbillague (pour Haranbilaga avec mouillure notée et étendue dans ce type de nom) perdit du fait de Loup Aner et ceux d'Espeleta (ceux de ce nom du parti navarrais) 8 têtes de bœufs et de vaches ("capita boum et vaccarum" se retrouve exactement aussi dans l'expression basque courante pour le compte du bétail idiburu, behi-buru etc.) : prix 6 livres.

Jureurs pour cela Johan Arnalt et Bernard de Carreta (semble une altération de Lakarreta ou Agerreta), ses voisins ("vicini ejus").

\section{(XIV)}

De la paroisse de Hyruber (forme attestée depuis le XII siècle pour l'actuel "Saint-Pierre-d'Irube", ce qui peut laisser entendre que l'ancien composé était fait sur -berri "neuf").

Arnalt de Hytsa (maison Ihitz en forme déterminée) perdit du fait d'Aneco Sanz et de Sanz de Viura frères 9 porcs : prix 19 sous. Il perdit du fait des mêmes 1 bœuf qu'il leur racheta 8 sous. Item il dit qu'il dépensa pour chercher les dits porcs 8 sous.

Garcia Amalt de Leichague (pour Elizaga avec palatalisation caractéristique du labourdin côtier qui passera aussi au gascon bayonnais) perdit du fait d'Aneco d'Arraide et Martin son frère et des leurs 59 brebis. Item il perdit du fait d'Amigot de Garro 41 sous avec lesquels il racheta 9 têtes de bœufs et de vaches : prix de toutes les brebis 78 sous moins 3 deniers.

Pierre de Huhagon (pour Uhagun nom qui se trouve aussi à Ayherre) perdit du fait d'Amigot de Garro 3 vaches : prix 29 sous. Et il lui racheta deux autres vaches 16 sous. Item il perdit du fait de Garcia Arnalt de Garro une vache : prix 16 sous. Item il perdit du fait d" "Aossa" (sic : erreur probable d'écriture) Sanz de Viura et Arnalt Guillaume dou Sees une vache : prix 16 sous.

Tous ces jurés donnèrent leur témoignage sur les choses susdites à tour de rôle.

(XV)

De la paroisse de Briscos (forme romane qui a donné l'officiel Briscous). Jureurs et taxeurs : Arnalt Sanz de Garat et Fort Guillaume de Firiart (pour Hiriarte).

Amalt Sanz de Garat (maison Garatea) perdit du fait d'Amigot de Garro et des siens, et il sortit de "Rupe forti" (Garro sortit du château navarrais de "Rocafort" - ici latinisé - pour faire ce coup de main), une maison et ses outils : prix 20 livres morlanes.

Item il perdit du fait de Sanz de Cambo 110 sous morlans et il le ("ipsum" qui désigne normalement le spolié, mais semble renvoyer plutôt à l'argent) mit à le Carra (Lacarre).

Fort Guillaume de Firiart perdit 24 porcs du fait de Sans d'Arraidu : prix 60 sous morlans.

Arnalt Sanz de Hiriague (romanisation de la finale et cacographie pour Harriaga) et Guillaume son frère perdirent 200 sous morlans du fait d'Amigot de Garro et des siens et il (Garro) sortit de "Rupe forti" et il retouma avec eux (les sous) à "Roque Fort" (sic : voir plus loin). 
"Sorbe" de Hirumberri (doit comespondre à Hiriberria, la nasalisation devant -b- s'étant perdue depuis) perdit du fait d'Amigot de Garro et des siens une maison et ses outils : prix 10 livres ; et Amigot sortit de Rupe Fort et retouma à Roquefort (sic pour le mélange linguistique). Item elle perdit du fait de Johan d'Orsasenete deux ânes : prix 20 sous morlans ; et il (ce demier) demeure à Orsoe (Urzua désignant sans doute ici le village d'Arizcun où se trouve la fameuse maison plutôt que celle-ci) en Bastan.

Navarre de Guerre (maison Agerrea) perdit du fait d'Amigot de Garro et des siens une maison et ses outils : prix 10 livres morlanes; et Amigot sortit de "Rupeforti" et il y retouma.

Navarre d'Olhatse (maison Olhatzea) perdit du fait d'Amigot de Garro et des siens une maison et ses outils : prix 11 livres morlanes ; et Amigot sortit de Rupe forti et y retourna.

Navarre d'Olhatse perdit du fait de A.B. Pied de chèvre un bøuf : prix 10 sous.

Navarre de Guerre perdit du fait de P. Sanz d'Araidu (sic) un bøuf : prix 18 sous.

Pierre de Paganduru (cette maison était à Macaye et c'est peut-être ici un nom d'origine, ou une erreur d'écriture pour Pagadoi) perdit du fait de Garcia A. de Naguiturri 6 porcs, prix 30 sous ; et il (ce dernier) demeure à Ossees.

Sorbe d'Errimberri (sic : il est curieux de retrouver au XIII' siècle des variantes de ce nom rappelant des citations de l'Antiquité) a été obligée à se racheter par Fort Arnalt de Mendilleharsu pour 100 sous et il (celui-ci) demeure en Arbéroue ("Arberoe").

"Messeriat" de Paganduru perdit du fait de G.A. de Garro et des siens 14 porcs et 16 brebis : prix des porcs 70 sous, des brebis 39 sous. Item il fut pris par le même G.A. de Garro qui le mit à Bayonne fidéjusseur pour Guillaume A. de Luc et ses compagnons, lesquels pour cela lui demandent 1000 sous.

\section{(XVI)}

De la paroisse de Bassessarri (Bassussarry qui dut être d'abord en composition basque régulière Basasarri).

Pierre d'Ossadges (doit correspondre à un nom comme Otsatz) perdit du fait des servants d"Amigot de Garro I bœuf que retint contre son gré ("ipso invito" : sans doute... le gré du propriétaire) la dame de Rutia (avec aphérèse et mécoupure romanes habituelles c'est la maison Urrutia d'Isturitz anoblie en 1435 puisqu'il s'agit de la compagnie de Garro, plutôt que l'une des maisons de ce nom en Cize ou Baïgorry). Item il perdit du fait de P. Sanz d'Araidu et ses frères 2 bœufs et des outils : prix des outils 3 sous, et prix des bœufs 66 sous.

Johan de Faurgues perdit 1 bouf du fait de Garcia Baque et ses frères et trois paillets (balles de blé) et 4 soldées de pains et 1 charrette ("currum") : prix du bœuf 20 sous, prix des paillets 6 sous, prix de la charrette 4 sous.

Aimée ("Amata") de Larrer (ce nom pourrait représenter Larrairi ou un autre composé de larre "lande") perdit du fait de G. Baque et ses frères 2 bœufs : prix 40 sous. Item elle perdit par les mêmes une charrette et un paillet qu'elle estime 3 sous.

"Angeler" ( $s$ 'agit-il d'un surnom d'origine en basque "Angeluar", roman "Angloy" ?) perdit du fait de $G$. Baque et de ses frères une charrette et un paillet : prix 8 sous.

Ceux-là ayant juré chacun à son tour donnèrent leur témoignage sur les choses susdites et dirent pour eux-mêmes et pour certains de leurs voisins absents qu' il furent pris par Amigot de Garro et rachetés à (le texte dit "par") lui-même et son père pour 4 livres. 


\section{(XVII)}

De la paroisse de Suraide ("Souraïde").

Johan de Suraide perdit du fait de Garcia Amalt d'Espelete et ses compagnons, à savoir S. Arnalt fils d'Amalt Blanc, Johan Ortiz et quelques autres 120 brebis : prix 9 livres.

Seignoret prévôt d'Ustaritz perdit 2 mâts avec des cordages du fait de Martin Bracs, Johan Ortiz, Dominique Haretha (si ce nom n'avait été écrit d'abord Harraca, il rappellerait le toponyme médiéval Harretxe) et Senescala (ce titre doit être un surnom) compagnons de Garcia Amalt et Amigot de Garro : prix 18 livres morlanes.

\section{(XVIII)}

De la paroisse d'Orroingna (graphie qui correspond à l'actuel Urruña: Umugne).

Deux taxeurs jurés : P. de Horsebau (forme romanisée de Horzabal ou Orzabal) et A de Sancto Vincentio (les maisons nobles "Saint-Vincent" étaient à Lécumberry en Cize et c'est peut-être ici un nom d'origine).

Pierre de Horsebau perdit 5 porcs et un porc (sic) du fait de $S$. A et d'autres compagnons de $G$. d'Espelete : prix 40 sous.

Amalt de Saint-Vincent fut obligé par Johan de Herismendi (Harizmendi voir plus haut rubrique VIII) et d'autres servants de G.A. de Garro au rachat : 11 livres et 5 sous. Il perdit aussi du fait des mêmes 76 porcs : prix 11 livres.

Pierre Arnalt de Le Lane (pour Larrea) perdit avec son père 24 vaches du fait de Loup Aner : 20 livres. Item il perdit du fait des compagnons de Sanz de Lisserague 3 porcs : prix 30 sous.

Pierre Arcidz (probablement pour le nom d'origine "Artix") perdit deux vaches du fait de Sanz Tyso (semble un toponyme comme on le voit plus loin) et ses compagnons : prix 30 sous.

Johan de Horsabaus (sic) et Dominique Johan perdirent du fait de Martin de Saxo et Johan de Thais 36 porcs : prix 7 livres. Item Sanz Arnalt et les autres servants de G.A. de Garro l'obligèrent à se racheter pour 8 livres et 8 sous. (Suit un segment non relié au reste nommant peut-être un témoin: "Acearium parvulum sororium ipsius Johannis de Horsebaus", qu'il faut entendre comme "Aznar le (tout) petit beau-frère du même Johan de H...").

Marie Sanz perdit du fait de Garcia Sanz et Martin de Thala (peut représenter Chala pour $S a l(h) a)$ une maison, un moulin et des outils : prix mille sous.

Dominique Pierre perdit du fait des servants de Martin "Enecotz" et Sanz de Tyso et Sanz de Lagornaga 28 porcs : prix 6 livres. Et il perdit un bœuf du fait d'Aner d'A mots (nom d'un quartier de Saint-Pée-sur-Nivelle) servant de Martin "Enecoidz" : prix 20 sous.

Item Arnalt de Saint-Vincent perdit 33 porcs du fait de G. de Sancto Stephano (il s'agit de la salle de Saint-Esteben d'Arbéroue ou de la maison infançonne du même nom à Bustince en Cize) : prix 100 sous.

La dame Gracie de Laralda (Larraldea) perdit une maison avec ses outils du fait de Loup Aner et les compagnons de G. d'Espeleta : prix 50 livres. 
sur-Nivelle). Deux taxeurs jurés : Guillaume Arnalt de Feuti (pour Heuti) et Fortin Ortitz.

Guillaume Arnalt de Feuti à qui Egide d'Ordaidz (c'est, sur les termes urd- "plat, plateau" et l'oronyme aitz le toponyme très répandu Urdaitz, représentant sans doute ici le monastère navarrais voisin ou un autre nom d'origine) doit 6 livres pour les pacages des porcs (sic : phrase inachevée). Item Aner de Bertin doit au même 100 sous qu'il paya pour lui. Il demande les dûs susdits.

Fortin Ortiz perdit du fait de Garcia Almoravitz (sic) et de l'armée du roi de Navarre une maison et d'autres choses: prix 100 sous.

Garcia Sanz perdit du fait de l'armée du roi une maison avec ses outils : prix 100 sous. Item Dominguet perdit du fait de Johan Ortitz et ses autres compagnons 27 porcs : prix 100 sous.

Arnalt del Haaz perdit du fait de Garcia Almoravi (sic) et l'armée du roi une majson avec ses outils: prix 4 livres.

Arnalt d'Armola (maison dite actuellement Armora) perdit du fait de G. Almoravi (sic) et G.A. de Garro une maison avec ses outils : prix 8 livres.

Aneco d'Ordoiz (sans doute même nom que plus haut, avec une ouverture vocalique banale, et une assimilation vocalique qui l'éloigne du modèle) perdit du fait de l'armée du roi lui présent une maison avec ses outils : prix 4 livres.

"Maria del Fleis" perdit du fait de l'armée du roi lui présent une maison avec ses outils : prix 60 sous.

Garcia Amalt perdit du fait de l'armée du roi des étoffes avec d'autres choses : prix 10 sous.

$(\mathrm{XX})$

De la paroisse de Sancti Martini d'Arribera Longa (ce nom roman "rive longue" était donné à Larressore, du basque Larrasoro, et Halsou, de part et d'autre de la Nive). Deux taxeurs jurés: G.A. d'Uhalda (Uhaldea maison infançonne de Halsou) et Guillaume de Locata (maison infançonne dite en 1505 Locata jaureguy, modeme Loketa).

G.A. d'Uhalda perdit du fait de l'armée du roi lui présent une maison avec ses outils, des cuves et du cidre : prix 20 livres.

Guillaume de Lochata (sic) perdit du fait de l'armée du roi lui présent du cidre, une cremaillère ("cremalium") et d'autres outils : prix 60 sous.

Guillaume Sanz de Hiriguian (pour Hirigoien) perdit du fait de l'armée du roi du froment, de l'avoine et des étoffes: prix 30 sous.

Pierre de Narbayz (les maisons Narbaitz connues étant en Basse-Navarre c'est peut-être un nom d'origine) perdit du fait de l'armée du roi lui présent trois maisons : prix 100 sous.

Fortin d'Alduyda (maison homonyme des "Aldudes", l'actuel Aldaia pouvant en être issu quoiqu'il soit plus naturel de penser à un ancien Aldabea) perdit du fait de Dominique d'Estremil 2 bœufs : prix 50 moins 4 sous (sic). Item il perdit du fait de Michel fils de Gracie Chemen et Loup le blanc (sic : "Lupum suria") 16 sous et 8 deniers.

Sanz de Halsu juré au nom de son père perdit du fait de l'armée du roi lui présent du blé, des pommiers, des cuves et des coffres : prix 60 sous.

Marie Guillaume de LandaIdeta (actuellement Landaldea) perdit du fait de l'ar- 
mée du roi lui présent des coffres, des abeilles et des pommiers : prix 70 sous.

Comtesse de Hiriguian perdit du fait de l'armée du roi lui présent du blé et des étoffes.

Arnalt de Heruspa (pour Harizpea) perdit du fait de l'armée du roi lui présent 1 vache, du blé, des brebis et des cuves : prix 70 sous.

Garcia de Hyriart (Hiriartea) perdit du fait de l'armée du roi lui présent 20 conques de mil, une cuve et du cidre : prix 20 sous. ltem le même ayant juré ("juraduz" sic) pour Gracie de Hyriart sa sœur qui ne pouvait venir dit qu'elle perdit du fait de l'armée du roi lui présent une maison, du cidre et des vases: prix 30 sous.

Amalt Bemard de La Cata (voir plus haut Locata) perdit du fait de l'armée du roi lui présent 6 sous en numéraire et des pommiers : prix 9 sous.

Garcia de Garat (maison Garatea) perdit du fait de l'armée du roi lui présent du blé, du cidre et des outils : prix 9 sous.

L'église de Saint Martin d'Arribera Longa (l'église de Larressore où se trouve la maison noble Saint-Martin) perdit du fait de la même armée un livre et un vêtement : prix 20 sous. Elle perdit aussi deux grands pots ("ollas" : oulles).

\section{$(\mathrm{XXI})$}

De la paroisse de Bardoz.

Bernard de Bardoz (la salle ou maison noble dite en 1203 et 1256 domus de bardoz) damoiseau (17) perdit du fait de Bernard de Belsunsa 7 boufs : prix 7 livres. Il perdit aussi du fait de Martin d'Arraidu et Aneco d'Arraidu l'arbre du pressoir, les meules et le fer du moulin : prix 6 livres. Jureurs pour cela Guillaume d'Armendariz (désigne sûrement ici la salle du lieu, actuel "château d' Armendaritz" : voir plus loin) et Pierre B. de le Lana (maison Larrea).

Bernard "Tornerius" (nom de métier "toumeur" peut-être employé comme nom de personne) d'Aignoa (nom d'origine Aïnhoa où la mouillure a disparu) fut pris par B. de Belsunsa et Sanz Amalt de Herryeta (pour Harrieta maison franche d'Ayherre anoblie en 1435) et obligé à se racheter pour 18 livres et 5 sous. Jureurs pour cela : Guillaume d'Armendaritz et B. de Bardos.

Guillaume d'Armendariz (il s'agit certainement du seigneur de la salle d'Armendaritz retiré ou réfugié à Bardos après l'intervention des Navarrais, les dégâts concernant un grand domaine, où a même eu lieu comme à Hasparren la politique de la terre brûlée pour ne pas avantager l'agresseur : le nom semble être resté à Bardos où la maison Arbendaritz est citée au XVII' siècle) perdit du fait de G. A de Garro et Loup d'Erro et des leurs ses pommeraies, noyers, maisons, moulins et granges et le père du même perdit deux chevaux du fait de Garcia d'Arraydu et de ses frères. Item Guillaume lui-même brûla une autre maison, craignant que le roi de Navarre ne l'occupât : prix de cette demière maison 35 livres ; prix de tout le reste mille sous et 36 livres. Jureurs pour cela : Bernard de Bardoz et Pierre Bernard de le Lana.

\section{(XXII)}

De la paroisse de Sansa (pour Azantza principale maison noble de Cambo servant à nommer ici le village). Jurés (sic). Deux taxeurs jurés : Guillaume d'Armendariz et Pierre B. de le Lana. 
Sanz de le Lana (pour Larrea cette fois à Cambo) perdit du fait d'Amigot de Garro et Sanz de Cambo (originaire du lieu mais partisan navarrais comme dans d'autres cas) deux maisons, des cuves et du cidre : prix 40 livres. Item il perdit du fait d'Amigot de Garro et Sanz de Cambo 73 porcs : prix 20 livres.

Bemard de Cruchiague (Kurutxaga) perdit du fait d'Amigot de Garro et Sanz de Cambo une maison, une borde ("bordam") et 7 cuves, des arbres, des noyers : prix 35 livres. Il perdit aussi du fait d'Amigot et Loup Aner 110 brebis et 2 vaches : prix 7 livres. Et il perdit du fait des mêmes 43 sous.

Sanz d'Urcjndoi (cacographie pour la maison infançonne Urkudoia) avec son père perdit du fait de l' armée du roi de Navarre, le roi étant présent, 111 porcs : prix 7 livres. Son père perdit aussi du fait du fils de Garcia "Chemen" d'Oarriz (Oharriz dans le Bastan) 16 sous et 8 deniers.

\section{(XXIII)}

De la paroisse de le Saca (nom donné anciennement à Itxassou). Deux taxeurs jurés : Guillaume d'Armendariz et Pierre B. de le Lana.

Johan de Larrando (pour Larrondo maison infançonne) perdit 22 porcs du fait des servants du vicomte de Begur (Baigorry) : prix 7 livres.

Arnalt Sanz de Savaloa (Zabaloa maison infançonne) perdit du fait des servants du vicomte de Begur 14 porcs : prix 42 sous. Il perdit aussi du fait de Guillaume Sanz et Aneco Sanz deux brebis et 6 chèvres : prix du tout 9 sous.

\section{(XXIV)}

De la paroisse de Saut (la maison seigneuriale de Saut ou Zaldu identifie l'ensemble du "castrum" et la paroisse, la plus importante, hors Bayonne, du Labourd à cette époque : Hasparren) (18)

Arnalt de Saut perdit du fait de G.A. de Garro et Amigot son fils des maisons et leurs outils, une vache et des pommeraies : prix 25 livres.

Bernard d'Ostebil (graphies diverses pour la maison Ustubilea) perdit du fait de l' armée du roi de Navarre lui présent des maisons (19) avec leurs outils : prix 20 livres. II perdit aussi 9 porcs du fait de Pierre de Herriague (pour Harriaga) et du fait de "Domicu" (l'une des formes locales de Dominique) Arressayga (aucune autre mention d une maison Harresiaga "lieu de clôtures de pierres" n'étant connue, il faut peutêtre comprendre Haritzaga bien qu'il n'y ait pas non plus de maison ancienne de ce nom en Basse-Navarre) 4 vaches : prix 4 livres.

Arnalt Guillaume de Bassu (diverses graphies pour cette maison notée en 1193 bassuren puis bassoign, bassuen, baissen moderne Ibasunea) perdit du fait de G.A. de Garro et des siens des maisons avec leurs outils, des vaches, des porcs, et lui-même fut capturé : prix 40 livres.

Arnalt d'Oyharsa (forme déterminée de Oihartz) perdit du fait de Garcia Arnalt de Garro et des siens des maisons, porcs, brebis, vaches : prix 35 livres.

Garcia d'Ansuete (pour Alzueta avec altération courante de -1- en -n-, modeme Alzuieta avec "yod" intervocalique souvent articulé par réduction de diphtongue avec -i- long Alziita) perdit du fait de Garcia Arnalt de Garro et des siens des maisons avec leurs outils : prix 13 livres. II perdit aussi du fait de Johan de Setheriz (Satharitz) 2 vaches: prix 30 sous.

Arnalt "del" Ofalso (cacographie avec aspiration rendue par $f$ pour Olhaso maison infançonne) perdit du fait de G.A. de Garro et des siens des maisons avec leurs 
outils : prix 100 sous. Il perdit aussi du fait d'Amalt de Cyvars (cacographie déjà notée pour un possible Etxebertze : maisons de ce nom à Ayherre, Saint-Martin d'Arbéroue, Ossès etc.) 3 porcs : prix 15 sous.

Pierre de Bidart perdit du fait de G.A. de Garro et des siens des maisons avec leurs outils et un porc : prix 100 sous.

Guillaume de Hifarat (cette graphie romanisée devrait correspondre à un (E)ihar ( $r$ )ate par ailleurs non attesté) perdit du fait de G.A. de Garro et des siens des maisons avec leurs outils et un bcuf : prix 4 livres.

Arnalt de Hiluar (actuellement Elhuiartea) perdit du fait de G.A. de Garro et des siens des maisons avec des outils (et) 4 porcs : prix 4 livres.

Guillaume de Hiriart (Iriartea : une maison de ce nom au quartier Sorano) (perdit) du fait de G.A. de Garro et des siens une maison avec ses outils et 11 bêtes ("pecoribus") : prix 8 livres.

Amalt d'Arteguieta perdit du fait de G.A. de Garro et des siens une maison avec ses outils et des pommiers chargés de fruits (sens apparent de "succissis" : sic) : prix 10 livres.

Arnalt de Larart (pour Larrarte) perdit du fait de G.A. de Garro et des siens une maison et lui-même fut capturé : prix 7 livres.

Guillaume de Baremdeira (pourrait être pour Barrendeiria ou Barrandairia mais semble plutôt une cacographie de Barrandegia : voir plus loin) perdit du fait de G.A. de Garro et des siens des maisons avec leurs outils : prix 50 livres. Il perdit aussi du fait d'Arnalt de Garris (il y avait à Garris une salle qui avait rang de château-fort dont le nom apparaît ici parmi les partisans navarrais) des porcs : prix 25 sous. Il perdit aussi du fait de Bernard de Crincheta (pourrait être pour Kurutxeta ; il y a aussi à Lapiste en Mixe une maison dite en 1350 Trinchayn actuellement Trinchiñea qui pourrait prendre place ici à côté du Mixain Garris) un porc et des vaches : prix 25 sous.

Guillaume de Lavin (semble le nom roman de "la vigne" malgré la forme actuelle Labia plutôt qu un dérivé de labe "four, brûlis") perdit du fait de G.A. de Garro et des siens une maison avec ses outils et des chèvres : prix 10 livres.

Montagne de Landa perdit du fait de G.A. de Garro et des siens des maisons avec leurs outils : prix 12 livres et 10 sous. De même G.A. retient à la même femme une dîme dans la paroisse de Heleta, au prix annuel de 8 sous. Elle perdit de même du fait de Petronille d'Ensiart (Aintziartea maison franche de Hélette anoblie en 1435 : la participation des maîtresses de maison aux rivalités est à remarquer) 11 brebis qu'elle reçut d'elle en commande.

Marie de Hyrigoien perdit du fait de G.A. de Garro et des siens des maisons, une vache, des brebis, un porc : prix 23 livres.

Comtesse de Lavin perdit du fait de G.A. de Garro et des siens une maison avec ses outils et des chèvres : prix 10 livres. Item elle perdit du fait de S. d'Arraidu un bœuf : prix 20 sous. Elle perdit du fait de Martin et Aneco d'Arraidu des brebis : prix 7 livres.

Jourdaine ("Jordane") de Cheverri (pour Etxeberri) perdit du fait de G.A. de Garro et des siens une maison avec ses outils : prix 10 livres.

Marie de Lavin perdit du fait de G.A. de Garro et des siens des maisons avec leurs outils : prix 100 sous. Elle perdit aussi du fait de S. d'Arraidu un bœuf : prix 20 sous.

Bernard d'Olfais (il y avait deux maisons Olhaitz à Hasparren) perdit du fait de G.A. de Garro et des siens des maisons avec leurs outils, des porcs et des vaches : prix 45 livres. Loup Garcia de Sivars et Loup d'Eno et B. de Sivars furent avec le dit G.A. pour causer ces dommages. Item il perdit du fait d'A. Loup servant de Sanz d'Arraidu des porcs : prix 6 livres. 
Sanz de Lagiade (sans doute pour Latxadia actuellement Latxedia) perdit du fait de G.A. de Garro et des siens des maisons (et) des porcs : prix 25 livres. Il perdit aussi du fait de Sanz Fabre ("fabri" génitif de "faber" : voir plus haut) une vache : prix 18 sous.

Guillaume de Barrendeguy (dit Barrandeia qui fut au début de ce siècle la maison du docteur Broussain) perdit du fait de Sanz d'Arraidu des porcs : prix 30 sous. Il perdit aussi du fait de Guillaume de Saint-Esteben une vache : prix 15 sous.

Aner de Firiart perdit du fait de Garcia Amalt de Belsunsa des porcs : prix 12 sous.

Arnalt de Saut, seigneur de ce même lieu, perdit du fait de Garcia Almoravitz et de l'armée du roi de Navarre et Garcia A. de Garro et Amigot son fils une salle à SaintPierre d'Ivaren (c'est-à-dire la salle ou château de Saint-Pée-sur-Nivelle), des moulins, des cuves, du cidre, du vin, un pressoir, du blé et des outils. Item il perdit au même lieu de leur fait 4 autres maisons, 100 brebis, une bête de trait ("jumentum") et quarante pommiers et la moitié d'une vigne : prix de tout cela trois mille cinq cents sous. Item Arnalt perdit du fait du roi de Navarre présent et des siens la salle et toutes les maisons de ce même château (le "castrum" de Saut représentant comme à Ustaritz l'ensemble de la paroisse) avec leurs cuves et leurs outils. Et aussi il perdit ces choses du fait du roi parce que, le roi lui-même venant en ce lieu personnellement, il fut nécessaire qu'Arnalt lui-même les fît brûler en voyant qu'il ne pouvait se défendre contre lui et craignant que le roi lui-même fortifiât ce même château. Il perdit aussi du fait de G.A. de Garro et les siens un moulin à Saut, deux mille pommiers et une borde : prix des dommages du roi (sic) 50 livres ; prix des dommages de G.A. de Garro avec une autre maison qu'il lui brûla à Buynot (peut-être pour Bunus) deux mille sous. Item il perdit du fait du sénéchal du roi de Navarre et G.A. de Garro trois hommes morts une autre fois à Saut. Jureurs pour cela : Johan de Saut, Arnalt de Lobers et Pierre de Paganduru.

\section{(XXV)}

Frère "Aldabertus", prieur de l'hôpital de Fontarrabie, demande au nom du mème hôpital 4 vaches que les servants de Martin "Anecoids" lui volèrent. Item il demande à Dominique Estremil servant du vicomte de Baigur 4 livres. Item il demande à Garcia Semeniz 60 sous.

Ces choses sont demandées sauf le droit d'ajouter, diminuer, déclarer et de poser la somme des dépenses et des dommages.

\section{(XXVI)}

Qu'il soit gardé en mémoire que Garcia Arnalt de Bensunçe (sic) prit à Hurt (Lirt) Pierre Martin de Pontons citoyen dacquois, et eut de lui tant en deniers qu'en d'autres choses pour une valeur de 35 sous morlans; et de Johan de Cabanes citoyen dacquois 18 paires de souliers (c"est sans doute le sens de "sotularium") dorés de Burgis (Bruges ou Burgos?) et deux adosses ("adossas" : peut-être des vêtements) dorées de Stella (Estella). toutes choses que, avec quelques autres comme des cordes de soie ("de serica") il estime à 27 sous morlans. Johan de Pui Berd citoyen de Pampelune reçut de Bives Dantes citoyen(ne) dacquois(e ?) 40 sous morlans que payèrent pour elle ("illa") le dit Johan P. Arnalt lo Ros (surnom "le roux") et Pierre "Boneu". Sanz d'Arraido (sic) prit Guiralt Johan de Corcoste et Bernard de Moras citoyens dacquois 
et Bemard s'enfuit ("affugit"), et le dit Sanz tint captif en Arbéroue G. Johan pendant 10 jours et il reçut de lui 6 livres morlanes tant en deniers qu'en autres choses sans toutes celles qu'il lui remit. Pierre Sanz d'Arraido spolia à Paradis ("Paravisum" : la forme du nom suggère l' ancien hôpital dit Parebis et son quartier à Sourä̀de : voir note 15) Garcia Arnalt de Veira citoyen dacquois au vu des frères et des sœurs de ce même hôpital et lui enleva 4 livres tournoises et 18 deniers morlans." 


\section{NOTES}

I. Archivo Gencral de Navarra, cajón $5 \mathrm{n}^{\circ} 39$. I, II, III

2. Ricardo CIERBIDE. "Encuesta cuadrilingüe de 1249 y el occitano de la cancillería de Navarra", Actes du $\mathrm{N}^{\prime}$ Congrès de l'Association Internationale d'Etudes Occitanes (Vitoria-Gasteiz 22-28-VIII1993), Vitoria 1994, tome II, p.701-714. Le commentaire linguistique du Professeur R. Cierbide porte sur la partic navarraise de l'enquête (section III du document) rédigée en navarro-castillan auquel se mêlent des passages d'occitan et même de vieux français (voir la deuxième partic). L'auteur y rappelle d'abord le contextc historique du conflit, auquel ne fut pas étrangère la guerre entre lc roi de France Louis IX (saint Louis), dont Thibaut était le vassal comme comte de Champagne, et Henri III roi d'Angleterre et duc d'Aquitaine (ct à ce titre lui aussi vassal du roi de France). La guerre des princes coalisés contre Louis IX se termina par la victoire de celui-ci en 1242, et la trêve qui s'ensuivit. Celle-ci fut rompue en Gascogne (dont le Labourd faisait partie) par les entreprises du parti anglais puis par la riposte foudroyante de l'armée que Thibaud conduisit en personne, dont le texte énumetre les dégâts. La paix fut conclue le 29 octobre 1248, et le document rédigé au début de l'annce suivante, relatant un ensemble de rivalités qui s'étaient étenducs sur une douzainc d'années.

3. Les parisans et combattants navarrais le plus souvent cités, generalement par le nom de leur majson, sont les frontaliers du Labourd, habitants d'Ossès et d'Arbéroue au premier chef, qui avaient bien des relations avec les Labourdins, et aussi bien des contentieux revélés par les comptes annuels navarrais, soigncusement tenus à partir de cette même période : incursions des troupcaux el saisies, coupes de troncs dans les forĉts du Bägura etc. Les Cizains et Bägorriens, présents aussi et cités pour les seigneurs principaux (Lacarre, Ahaxe, Alzu, vicomte de Baigorry ...). apparaissent beaucoup moins.

4. Cf. J. BIDACHE, Le livre d'Or de Bayonne. Pau 1896, voir principalement les listes d'habitants censitaires des chanoines et de l'êvêque datées de 1266. p.199-262.

5. "Gentilhomme" traduit le mot lasin miles, "soldat" en latin classique, le seul, a deux exceptions près (cf. note 17). que le texte utilise pour nommer la qualitt de "noble", ignorant les termes locaux d'origine hispaniquc. infançon ou hidalgo. Si la fonction guerrière du noble est ainsi indirectement rappelée, il s'en faut de bcaucoup que les combattants. même les plus fréquemment cités. à l'exception de certains chefs de compagnics. appartiennent tous à des maisons connues pour nobles à cette epoque ou plus tard. Un rc̀glement nouvcau de l"appel aux armes, peut-être en souvenir de cette période et de ces événements, sera édicté sous Thibaud II en 1258 : cf. J.-B. ORPUSTAN "La vallée d'Ossès de 1258 à 1418 ". Bulletin du Muscée Basque n²5. 1976.

6. Bien que revendiquant pour le roi-duc les terres de Mixe et Ostabarrel que le roi de Navarre a envahics pour les remcttre sous son autorite. I'enquête tient Luxe, le principal seigneur de Mixe et en même temps scigneur de Lantabat et d'Ostabat, pour un vassal du roi de Navarrc. Le seigneur de Garris cst aussi cité parmi les partisans navarrais.

7. C'cst unc allusion au siège de Garro, maison noble et fortifiéc (castrum) situke à Mendionde (Grécicttc) à quelques pas de la frontière navarraise de l'Arbéroue, et qui semble avoir été, à part le raid navarrais de Thibaud. Ic fait de guerre principal de ce conflit. Cf. J.-B. ORPUSTAN : "Garro : un nom dans 1"histoire", Bullerin du Muske Basque n'137, 1" semesure 1994, p.25-40.

8. Cl. J.-B. ORPUSTAN : "L'anoblissement de 128 maisons d'Arberoue en 1435". LAPURDUM 1. Biartitz 1996. p. 199-221.

9. Ce passage ajoutc à la plaintc des marins proprement dits, celle de nombreux autres habitants, soit bayonnais. soit labourdins, soit béarnais et chalossais du moins d'après leur nom d'origine.

10. Le nom d' ancien français malto(s)te daté de ce milicu du XIIl' siècle, mais probablement bien plus ancien. repris tel quel dans le texte latin, litteralement "Ievée faitc à tort" au sens de "mauvais" impôt, c'est a dirc injuste. a ćté donné plus tard à l'impôt que Philippe le Bel et ses successeurs levèrent en France pour financer la lutic contre... les Anglais.

11. L'incendic des maisons de Mixc signaléc ici a peut-ĉtre laissé une trace dans la toponymie locale il faliait en effet un "incendie" extraordinaire, hors des accidents courants à cette époque dans des maisons construitcs de charpentes et colombages (modèle qui se voit encore à l'intérieur des murs de pierre qui ont servi plus tard à renforcer les édifíces). pour avoir laissé à unc maison de Bcyric un nom purement latin. ct précisément celui de Combusta "brûleec" que répètent tel quel tous les documents postérieurs jusqu'au $\mathrm{XV}$ ' siècle compris. Si le nom a subi une légère déterioration dans l'usage moderne par simple assimilation vocalique d'abord (Combosta en 1551). Composta actucllement avec un assourdissement de consonne devant nasale en principe contraire à la phonétique basque et quit ne s"explique que par analogie ("compotc. compost" ct même... "Compostellc") pour un nom depuis longtemps incompréhensible, il n'a, dans ses ori- 
gincs conservées dans une longue tradition ecrite, strictement aucun rapport avec... quelque route compostcllane que ce soit. Mais le rattachement de cet étrange nom latin au raid de Thibaud, dont la brutalité en Mixe cst particulièrement dénoncée. $n$ 'en reste pas moins une simple hypothèse certes invérifiablc. mais non invraiscmblable.

12. Le nom de maison Marithurri (avec une premìre vibrante simple) est resté nom d'état civil jusqu'à I'ćpoque moderne. La vibrante double ne dit rien, vu les cacographies nombreuses dans le textc pour Ies toponymes basques, quant à la forme primitive, et le scgment marr- reste de toutes manières impossible à identificr (à la rigucur une alteration d'un barr- lui-même peu cxplicable dans ce contexte). Il ne s'agit pas pour autant d'une quelconque "Marie" chrćtienne. dont la présence dans les noms des maisons médicvales basques (et nobles toujours) est parfaitement catalogué. C'est pourquoi il faut bien envisager un rappon possible avec l'ĉtre que la mythologie populaire ancienne a reconnu sous le nom de Mari, et cette "fon-

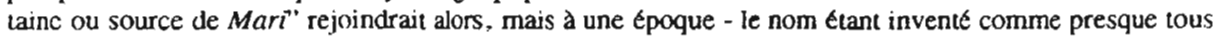
les autres bien avant ce XIII' siecle où il est documente - qui ne foumit guère d'informations sur les croyances populaires, bien des Laminosin, Laminithurri et autres "gouffres" et "sources des lutins"...

13. La confusion cntre haritz "chêne pédoncule" et haitz "rocher", résultat de l'affaiblissemcnt de la vibrante simple intervocalique, n'est pas apparue en labourdin avant le XIX' siècle. Pour tous les noms antérieurement documentés, et tout particulièrement dans la toponymie médiévale, haritz se distingue sans exception de haitz (ct des formes apparentées qui n'en sont, certaines súrement d'autres probablement, que

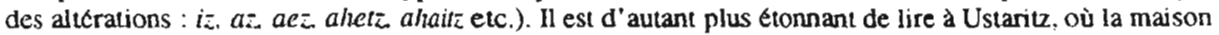
nobie principale Haitz n'a varié ni de forme ni sans doute de prononciation depuis le XII' siecle, un Hariza ou c'cst unc des nombreuses erreurs graphiques relevées dans le document, cc qui parait le plus probabile. ou il s'agit récllement d'un toponyme sur haritz, soit le mot simple détermine, ce qui est possible quoique rarc ("Ic chêne"), soit d'un dérivé raccourci, mais alors nom d'origine extérieur à Ustaritz.

14. Dans l'usage de la chancellcrie anglaise certaines paroisses du Labourd étaient nommées par le nom de la maison noble principale (Cambo, Hasparren, Macaye) ou unique (Espeletue). L'enquête que le roi d'Angleterre fait faire en Labourd en 1311 précise a propos d'Espelette el de Macaye : "Le seigneur d'Espcletta a des pâturages et une paroisse entière sienne nommée Espeletıa (...) Le seigneur de Paganduru a sa propre paroisse de Maqueya (... l." (traduit de l"original en latin). Cf. J. BALASQUE, Esudes historiquer sur la ville de Bayonne, Bayonne 1862-1875. T. Il p. 693-700.

15. Un prieuré de ce nom se trouvait à Saint-Léon près de l'actuel cimetière de Bayonne : Edouard DUCERE, Dictionnaire historique de Bavonne, Bayonne 1991, Laffitte Reprints 1976. Il y avait aussi un "hôpital du Paradis" ou Parebis à Souraïde. Hors du Labourd une maison de Barcus en Soule portant cc nom cst citce depuis le XIV" siècle.

16. Ce Biudz médiéval de Mouguerre a êté compris ct traduit à tort tardivement (XVIIl` siècle) par lc latin vetus "vicux". La voyelle -u- semble unc vocalisation romane, ce qui peut renvoyer au radical hasquc bil cn toponymie au sens de "arrondi, groupe, colline" : voir par exemple "Viodos" en Soulc résultant de Bildo:

17. Le mot domicellus d'où procède Ic français "damoiseau" a cté utilisé plus haut pour un noblc de Mixc ou d'Ostabartct. mais c'est ici l'unique cmploi du texte pour un noble labourdin. Or l'enquête de 1.311 nomme ainsi les soixantc ou soixante-dix maisons nobles anciennes du Labourd. Celle de 1316 pour la réforme du for de Mixe donnc son equivalent gascon donjet à vingt-cinq maîtres de maisons nobles qui $n$ " ont pas droit au titre de "monseigneur" : voir J.-B. ORPUSTAN : "La réforme de la coutume de Mixe par Amanicu d'Albret. vicome de Tartas, en 1316". Le pavs de Mixe, lzpcgi 1992, p.71-87.

18. Comme Macaye par la maison noble Paganduru et Cambo cellc d'Azantza, la paroisse enticre dc Hasparren. oủ se trouvaient plusieurs maisons nobles anciennes, cst nommee par le "castrum" de Saut ou Zaldu (voir note 14). C'est sans doute la maison nommée actuellement Zalduzahar ou "Vieux Saut". qui ne se trouvc pas sur la hautcur occupée par les rines du château de Saut, peut-ĉtre installé là après Ics destructions du XIIF siccle.

19. Le pluricl "les maisons" pcut correspondre au fait que des maitres de maisons possédaient effectivement par héritage plusieurs maisons. comme c’est le cas précisément du seigneur de Saut de Hasparren tgalcment seigncur de la salle d'Ascain. Mais il s'agit plutôt dans la plupart des cas des bâtiments ou maisons annexes de plus nu moins grande importance (a l'cxception des moulins toujours désignés comme tcls ct appartenant aux nobles) dites au XVIIE siècle "petites maisons". bordes ou métairies, que les maisons principales possćaicnt comme on le voit par excmple à cette epoque pour les maisons de Mendiondc. 


\section{$2^{*}$ partie : les réclamations des Navarrais et Bas-Navarrais.}

\section{Avant-propos}

A la suite et en opposition aux réclamations des Bayonnais et Labourdins sujets du roi d'Angleterre et duc d'Aquitaine (voir la première partie), texte latin parsemé de quelques termes romans, mais aussi de nombreux toponymes (noms de maisons ou de pays et villages) et de rares surnoms basques, la dernière section de l'enquête de 1249 qui mettait fin aux hostilités entre les Labourdins et les Navarrais est rédigée dans le navarro-castillan de la chancellerie de Pampelune mêlé de gascon et même de vieux français (1). Cette dernière partie est présentée ici en traduction française comme la première.

Le document original, écrit dans la même écriture dite parfois "gothique" des chancelleries du XIII siècle, soignée et parfaitement lisible dans l'ensemble, differe pourtant de la section précédente par plusieurs traits qui touchent la forme comme le fond.

1) Le trait principal est le mélange linguistique : on doit l'attribuer aussi bien à l'état de la chancellerie navarraise, où la maison de Champagne a renforcé la présence du français, qu'à la diversité culturelle du territoire, avec ses terres sous influence castillane au sud, gasconne et, depuis peu, française au nord. Comparée à la première section, qui suit dans l'ensemble la division hiérarchique et territoriale (d'abord le comte de Leicester, puis la communauté bayonnaise, en une section pourtant un peu complexe, puis le vicomte de Tartas pour les terres de Mixe et Ostabarret, enfin toutes les paroisses du Labourd touchées par l'intervention navarraise), cette seconde partie présente une composition beaucoup moins bien organisée. Il est manifeste que les auteurs ont suivi un modèle unique pour les deux enquêtes, probablement mis au point lors des réunions préparatoires, mais que les Navarrais s'en sont accommodés avec une fantaisie certaine, sans compter par exemple, comme les Labourdins, tous les détails des dommages en argent. En revanche, le lecteur bénéficie cette fois d'une chronologie, peut-être un peu approximative pour des faits mineurs remontant parfois à plus de dix ans, mais bien commode pour reconstituer la suite des événements, compte tenu des faits d'histoire connus par ailleurs, comme la défaite des armées du roi d'Angleterre à Saintes (voir Annexe 1).

Le premier plaignant, comme il se doit, est le roi de Navarre lui-même, expliquant comment il a trouvé dans le changement de camp du seigneur de Gramont, passant au parti anglais après avoir prêté serment à plusieurs reprises aux rois de Navarre, et les divers désordres qui s'en sont suivis, le motif d'une intervention personnelle largement justifiée par le refus de tenir les promesses de revenir à une situation que l'on dirait aujourd'hui" normale" et par la gravité même de la rébellion. Les premières démarches de conciliation au moment 
du siège de Viellenave, malgré l'importance de la délégation aquitaine pour le parti anglais, prélats en tête, n'ayant pas été suivies d'effet, la poursuite de l'offensive navarraise est présentée comme un acte de droit et de justice. Ensuite, pendant symétrique aux plaintes bayonnaises, viennent les réclamations, "neuves" et "vieilles", de la capitale de la châtellenie bas-navarraise, SaintJean-Pied-de-Port, puis le texte alterne, sans intitulé régulier et dans un désordre manifeste, les plaintes des vallées frontalières du Labourd (Arbéroue et Ossès d'abord, les plus abondamment citées) et celles des communautés, établissements religieux et habitants navarrais (Pampelune, Roncevaux, Salazar, Bastan...). Il est vrai que la Basse-Navarre et la Navarre n'étaient pas, comme le Labourd, partagées en "paroisses", mais en terres et vallées.

2) L'impression néanmoins, et ici la forme révèle sans doute le fond, est que la chancellerie a voulu accumuler les griefs, soit pour faire pièce "coûte que coûte" à la plainte des Labourdins et Bayonnais, soit pour montrer que l'acte n'est qu'une simple formalité voulue par les termes de la trêve aux hostilités, puisqu' aussi bien Thibaud a réussi son entreprise : sauf le territoire proprement labourdin, le château de Garro compris (qui sera reconstruit après cet épisode), la terre navarraise ne changera plus de camp jusqu'à l'invasion castillane de 1512, non seulement les vieux territoires de Cize, Baïgorry, Ossès et Arbéroue qui ont fourni le gros de l'armée navarraise, mais aussi Iholdy et Armendaritz, l'Ostabarret, le pays de Mixe et les territoires de Gramont. De ce point de vue la réussite de Thibaud confirme son pouvoir navarrais d'abord contesté, et sans doute aussi l'alliance au trône de France et contre le parti anglais, qui finira moins d'un demi-siècle plus tard par la réunion temporaire des deux couronnes.

Au plan du détail, et comme pour les Cambo ou Ezpeleta labourdins, la dénonciation de Navarrais ou Bas-Navarrais par d'autres Navarrais du moins d'origine (comme Nagithurri d'Ossès, famille pourtant active contre les Labourdins fortement dénoncée dans la première section, et d'autres exemples) montre d'une part que l'origine commune et les liens familiaux pouvaient être contrecarrés par des appartenances à des factions ennemies, et ici des Etats, soit installation dans le territoire voisin si proche, soit allégeance particulière et personnelle selon le système féodal ; d'autre part, car l'appartenance à la faction adverse n'est pas toujours avérée et certaines réclamations se situent dans le cadre des relations de vallée à vallée et même de maison à maison, que l'enquête n'a pas dû être examinée sur ce point de très près ni par la partie adverse, ni par la chancellerie de Pampelune. Le fait souligne ainsi, sans doute contre la volonté de la même chancellerie peut-être peu informée encore des réalités d'outre-monts (avant les listes détaillées de maisons bientôt dressées pour les fouages du XIV' siècle), que les hostilités réelles de ces temps étaient des faits d'ordre quasi individuel, le plus souvent à l'intérieur de la châtellenie elle-même, comme beaucoup d'autres documents de cette époque et du siècle suivant le confirment. La cause réelle de ces rivalités était, comme on le sait, l'usage des terres dites "communes" ou "royales" sur les- 
quelles chaque vallée exerçait ses propres droits d'exploitation et de pâturage et les saisies fréquentes de bétail qui s'ensuivaient.

On note que, à la différence du texte labourdin, peu de mentions de noblesse apparaissent, à l'exception de rares "chevaliers du roi de Navarre", ce qui veut dire sans doute qu'ils ont été armés par le roi lui-même. En revanche, le "don" est quasi général, aussi bien pour les marchands et commerçants que pour les maîtres de maisons, même nobles, et plus souvent pour ceux-là que pour ceuxci. Les noms de métier, assez nombreux, donnent une idée, rare pour ces époques, des activités d'artisanat et des circuits d'échanges commerciaux, en particulier à Saint-Jean-Pied-de-Port, entre Bayonne et la Navarre, vers le nord aquitain. En détaillant les pertes subies par les "nefs" aux noms de saints, Sainte-Marie, Saint-Jacques, Saint Michel, Saint André et leurs chargements, ou saisis à l'arrivée au port ou volés dans un naufrage, le texte éclaire le rôle de Bayonne dans les liaisons maritimes, et l'importance des relations marchandes bayonnaises et, par Bayonne, navarraises, avec les pays du nord et notamment avec l'Angleterre (sans oublier le voyage personnel et guerrier du roi de Navarre signalé dans la première partie, probablement entre Provins sa capitale de Champagne et le port de Bayonne).

Les nombreuses saisies de bétail et de leurs gardiens, ceux-ci armés de lances et de javelots, font directement allusion aux périodes de transhumance et au maintien des troupeaux, porcs en grand nombre, bovins, ovins et chèvres, parfois venus de fort loin (abbayes de Leyre et d'Oliva) dans les bordes ou "cabanes" et les vastes zones montagneuses des pâturages d'été et d'automne.

Comme pour la première section, mais d'une façon plus arbitraire vu le désordre du document signalé plus haut, des chiffres romains ont été introduits entre parenthèses pour subdiviser le texte, parfois accompagnés d'indications signalant des articulations secondaires, le tout n'étant ici aussi qu'un artifice pour faciliter la lecture et la compréhension. De même aussi les noms de lieux, et en particulier de maisons (moins systématiquement utilisés ici que dans la première section, en particulier pour le pays d'Ossès, ce qui peut être attribué à l'ignorance de la chancellerie et peut-être aussi à une précaution d'anonymat en cas de représailles), sont reproduits en caractères gras et accompagnés de notes explicatives entre parenthèses selon les mêmes principes. Leur graphie est en général plus proche de la phonétique basque réelle (sauf l'élimination de l'aspiration, trait du roman navarrais puis des dialectes basques péninsulaires) que celle de la première section labourdine. Les citations du texte entre guillemets obéissent au même principe. A la différence de la première section, tous les noms de personnes, prénoms et autres ainsi que les "don, dona" qui les précèdent souvent, ont été reproduits tels quels, vu que le texte en donne en donne en général la forme usuelle navarraise, quelque peu variable, mais sans les modifications introduites par la déclinaison latine. Les chiffres romains ont été transcrits en chiffres arabes. 
(I)

"Celles-ci sont les réclamations que le roi de Navarra (désormais écrit "Navarre") fait au sujet du roi d'Anglaterra (idem "Angleterre") et de ses gens.

Premièrement du château d'Agramont (2), que Vivian d'Agramont reçut du roi don Sancho sous serment et susceptible de lui être remis ("jurable et rendable"), ce dont le roi de Navarre possède des lettres divisées par a-b-c; et après la mort de ce Vivian c'est Arnalt Guillem qui le reçut du roi don Sancho (3), et après la mort du roi don Sancho Amalt Guillem le reçut du roi don Thibalt et il lui rendit l'hommage des mains et de la bouche devant tous les hommes (4) et jura de lui remettre le château toutes les fois qu'il le lui demanderait (à lui-même) ou à celui de ses conseillers qui apporterait ses lettres patentes ("letras pendientes") ; et le roi lui demanda le château, et il le lui remit une fois et don Garcia Semeneitz. le reçut de la main du roi à sa convenance ; et le roi de Navarre se rendit dans le château pour le lui remettre et il lui fit serment et hommage des mains et de la bouche de garder toujours ces dispositions devant de nombreux chevaliers, et le roi en possede des lettres patentes et des témoignages vifs de suffisamment de chevaliers. Puis le sénéchal de Vascoinna (désormais transcrit "Gascogne") vint trouver cet Arnait Guillem d'Agramont et il lui donna de l'argent du roi d'Angleterre de sorte que le château lui fut remis par le roi d'Angleterre et il fit hommage à celui-ci ; et le roi garde ses enfants comme otages en Angleterre.

Et le roi de Navarre se plaint grandement au sujet du bien ("aver") de ses bourgeois de Navarre (ces bourgeois sont en particulier ceux de Pampelune) que saisirent ceux de Bayona (dorénavant transcrit "Bayonne") sur l'ordre du sénéchal ; et le roi le fit demander par 2 ou 3 fois à ceux de Bayonne et au sénéchal par des caviers ("caveros") et par des gens d'église et ils ne voulurent pas le rendre.

Et le roi se plaint à présent du sénéchal qui fit abattre son château d'Arçar (5) pris par force et le mit en pièces et il fit tuer tous les hommes qui étaient à l'intérieur et les massacra, toutes choses que le sénéchal fit avant que le roi entrât dans sa terre ; et quand le roi vit que ces torts lui étaient faits, il s'adressa à lui une nouvelle fois, mais on ne lui défit aucun tort. Alors le roi se mit en marche pour aller sur la terre du roi d'Angleterre et il fit encercler Vylla nueva (sans doute Viellenave où se trouvait le premier château de Gramont) et il la faisait assiéger. Et vinrent à lui l'archevêque de Bordel (Bordeaux) et l'évêque de Basatz (Bazas) et le seigneur de Blaues (Blaye) et le seigneur de Blancafort (Blanquefort) et don Guillem d'Andon (Andoins) et d'autres hommes bons, pour parler avec le roi de la paix. Et le roi leur répondit de lui défaire les torts qu'il avait reçus et qu'il partirait volontiers et qu'il lui en coûtait d'entrer dans la terre du roi d'Angleterre et qu'il accepterait volontiers la réparation par égard pour eux-mêmes; et ils ne firent rien ; à la suite de quoi il fit envoyer une importante mission pour redresser ces choses, au sujet de quoi le roi demandait qu'il lui en fût rendu compte comme il est juste. Car toutes ces choses lui furent faites durant la trêve (trêve entre les rois de France et d'Angleterre : cf. la note 1 de la première partie) laquelle ne devait pas être rompue pendant un an après qu'elle fut déclarée.

Et le roi se plaint encore au sujet de 27 chevaux que le sénéchal saisit un autre jour avec tous leurs harnais et d'autres objets de valeur ("ioyas") que le roi envoyait par terre et lui-même (voyageait) par mer (voir dans la première section la rubrique II).

Et le roi se plaint de Iohan de Camera (Came dont les Navarrais prirent le château) qui lui brûla ses moulins et lui tua un bailli ("bayle") et lui vola sa terre, et le roi le fit montrer au sénéchal de Gascogne et celui-ci lui répondit qu'il ne pouvait y remédier.

Et le roi se plaint au sujet de trois chevaux que saisit un autre jour Amalt Guillem d'Agramont et il les retient au point que l'un est endommagé ("afoyllado"). 


\section{(Ila : Saint-Jean-Pied-de-Port))}

Celles-ci sont les réclamations nouvelles de ceux de Sant Iohan de pie de puertos (Saint-Jean-Pied-de-Port). Pero Guillem le savetier se plaint de Bernart Arotze (ce mot basque peut être compris comme nom de métier "forgeron" ou un nom de personne qui en est issu, comme "faber" etc. dans l'enquête bayonnaise) de Labort qui lui vola deux vaches et un bœuf et de Iohan de la lana d'Utztaritz (maison noble Larrea) qui lui prit une vache.

Pero Lopeitz le muletier se plaint de Ioan (sic) de Camer (Came) qui lui prit une mule et un roussin qui lui avaient coûté 7 livres de morlans.

Arnalt d'Irissarci (sic pour Irissarry) est plaignant contre don Guillem deu Boys et contre don Tomas le doreur ("daurador") et ses fils qui lui prirent 7 livres de morlans, et de Ferrant dou Poy (c'est-à-dire "du Puy") de Bayonne pour 12 sous de sterlings et 4 livres de morlans qu'il dépensa en frais et en mission pour cet argent.

Arnalt Santz et Santz de Sant Miguel (nom d'origine pour "Saint-Michel-leVieux" plutôt que la maison de ce nom de Juxue en Ostabarret) sont plaignants contre des hommes de Bayonne pour 8 sous 8 deniers.

Auger le marchand se plaint de don Blasc d'Armendariç qui lui prit sur le chemin du roi (la grand-route qui se dit aussi en basque errepide) la recette de 20 sous de morlans.

Don Petri Santz d'Urutie (pour Urrutia désignant un originaire de l'une des maisons de ce nom nombreuses en Cize et ailleurs) est plaignant contre don Iohan d'Amendariç qui lui prit 8 porcs au temps où don Franc de Brene était sénéchal.

Don Ramon Santz le magasinier est plaignant contre les 3 frères d'Espelete qui étant avec le roi d'Angleterre lui prirent une vache pleine.

Eneco A. le pelletier est plaignant pour 100 écureuils (peaux) et 5 sous de bordelais et pour quelques chaussures que lui prirent les fils d'Espelete.

Bernart savetier est plaignant contre les hommes de Bayonne qui lui prirent 2 sous de morlans.

Dona Guiralda est plaignante contre don J. de Camer qui lui tua son mari et lui prit ce qu'il transportait.

Bernart d'Ariete (originaire de Harrieta maison noble à Saint-Jean-le-Vieux) est plaignant contre don Guillem d'Armendariç qui lui prit 15 porcs.

Pero le mercier est plaignant contre A. Guillem de Salt de Gascoyne (doit être Zaldu de Hasparren, par opposition à Zaldu de Cibits) pour 10 livres de morlans qu'il lui prit.

\section{(IIb : idem)}

Celles-ci sont les plaintes anciennes de Saint-Jean-Pied-de-Port : don Benedit est plaignant contre les 12 de Bayonne (le conseil communal) pour 4 livres de morlans et 5 sous.

Don Guillem Per d'Arion (toponyme inconnu en Cize) est plaignant pour 2 douzaines de cordouans (mot dérivé de Cordoue réputé pour ses cuirs, désignant souvent des chaussures de cuir).

Dona Amade d'Arrion (sic : c'est la bonne orthographe, sauf la suppression probable de l'aspiration initiale) pour 26 sous de morlans.

Don Guillem Arnalt le pelletier se plaint de don Fort Arnalt d'Erspile pour 25 livres de morlans qu'il lui prit en draps et 4 livraisons de tissu ("liuradas de ropa") et pour l'avoir gardé prisonnier 40 jours. 
Ferrando se plaint de don Arnalt Guillem d'Agramont pour 300 sous de morlans et 2 bêtes que lui enleva le muletier (sic) qui le prit.

Arnalt Bergoyn et Ferrando se plaignent de don Johan des Borcs de Bayonne pour 100 sous de morlans qu'il enleva à leurs parents.

Don Pero Santz se plaint de sire Richat (sic) de Gree et de sire Johan de Gree pour 80 marcs d'argent qu'ils lui enlevèrent à Granasui (sans doute Guemesey ; "Granoni" désigne aussi parfois l'actuelle Pointe de Grave) alors que le roi d'Angleterre avait bonne paix et trêve avec le roi de Navarre.

Don Amalt Guillem pelletier se plaint d'A. Guillem d'Agramont pour 800 sous de morlans que lui emprunta son beau-père.

\section{(Ilc : Ossès)}

Celle-ci sont les plaintes que les hommes d'Osses font des hommes de Labord.

De don J. de Lana (Larrea d'Ustaritz) il se plaignent au sujet de 20 chèvres et d'autre part de Pedro d'Aribeleta qui était serf ("siervo" qui peut être entendu "au service de") des Francs de Breuas (sic: "de los franquos de Breuas", mais il s'agit sans doute d'une erreur du copiste pour le même sénéchal "Franc de Brene" signalé en Ila ; sinon, ces "Francs" restent ici assez incompréhensibles) pour 12 porcs et d'autre part d'Eneco Arnalt et B. Santz serfs (id.) de Seinoret pour 10 porcs et d'autre part d'Eneco A. et A. pour deux vaches et 1 bouf et d'autre part du fils de B. Faor (pour "faur(e)" mot gascon "forgeron" : voir la première section du document) pour 1 bcuf et d'autre part d'Eneco A. pour une vache et d'autre part d'Atznar de Soranoa (quartier de Hasparren) et d'Atznar de Hutze (forme erronée représentant lhitz ou Haitze maisons d'Ustaritz) pour 4 vaches et d'autre part du seigneur de Vados (sic : probablement pour "Bardos") pour 20 porcs et d'autre part de don Santz d'Urstuvil (forme pleine pour Ustubil à Hasparren) pour deux bœufs. Somme : 11 vaches (sic : les bœufs compris) et 42 porcs et 20 chèvres.

\section{(III : Haute-Navarre 1)}

Celles-ci sont les plaintes que les hommes de Maye (Maya) font contre les hommes de Labord de la Lana (6) :

Ceux de Maya se plaignent pour 40 bœufs et vaches que les hommes de Labord de Lana leur ont pris par force et pour 9 veaux et pour 26 clochettes ("esquilas") et 14 mesures ("arrovos") de blé et une cape de stanford (drap de qualité venu à l'origine de la ville anglaise de Stanford) et autre cape de bure ("sayal") et 2 sous et 5 deniers de morlans avec la bourse et 4 sacs qui coutèrent 6 sous de sanchets et 2 lances et 2 javelots ("azconas") et 1 couteau qui valait bien 4 sous, et du seigneur d'Aribileta qui racheta (sans doute : le força à se racheter) un homme de Maya (sic) pour 25 sous de morlans, et des hommes de don Brasc d'Armendariç et de 16 porcs (sic) et de don Guillem d'Armendariç pour un épieu de chasse ("venable") et de don Oger de Salt qui leur retient 2 bêtes sous promesse de 100 sous de morlans.

Don Bernart Peritz de Sarasa (Salazar, vallée navarraise) se plaint des hommes de Bayonne pour 20 porcs, les meilleurs des 101 porcs qu'ils prirent en Batztan et il en fit les réclamations aux hommes de Bayonne et eux prirent les 20 meilleurs et enlevèrent aux porchers leurs lances et leurs javelots et leurs couteaux et leurs courroies et les dépouillèrent jusqu' aux braies (sic : "ata las bragas", c’est-à-dire les culottes...) et le voleur fut Bemart Pes. 
Yenego d'Erro se plaint pour 3 bœufs et deux vaches que lui prirent Eneco Erlanç d'Echague (ce nom apparaît dans la première section parmi les Navarrais) et Sancho Goria (sic pour gorria "le rouge") Gorost apasequo (sic : ce nom peut représenter. comme cela arrive parfois dans ces textes romans médiévaux, l'intrusion d'un génitif basque usuel désignant la maison ou le lieu d'origine, de la maison Gorostabaso ou Gorostapate pourtant non identifée par ailleurs) hommes de don Blasquo de Salt et don Blasquo les partagea.

Miguel Erascotz et Domingo Johanes d'Odariç (Oderiz au val de Larraun en Navarre) se plaignent de Guillem Amalt de Salt et de don Oger son frère qui leur enlevèrent 25 vaches à Jaç. ogayno (sic : peut représenter un toponyme basque, peut-être Jatsu, avec le terme "gain") en carême.

Don Santz d'Alçu et l'alcade d'Aezquoa (Aezcoa vallée de Navarre) se plaignent de Sancho Naguiturin (ici nom déformé d'un partisan labourdin originaire de la maison d'Ossès Nagithurri) qui lui enleva autrefois 30 porcs (6).

Garcia Muquoç se plaint de Sancho Larrea qui emporta un bouf de Maya de la maison de don Domingo Esnos.

Bemart de Fariete (pour Harrieta) se plaint de Guillem d'Armendariç qui lui prit 15 porcs avec leurs compagnons (sic : "compaiñeros" doit nommer ici les porchers).

Ils (les gens de Maya) se plaignent de Seiñoret châtelain (il avait le titre local de "prévôt") d'Utztariç qui emporta de la cabane de San Salvador (nombreuses chapelles et lieux-dits de ce nom) 33 vaches et elles avortèrent toutes et de plus il retint les 3 meilleures et il enleva 5 vachers et il les frappa et blessa et prit les clochettes de toutes les vaches.

Un garçon de Pampalona (Pampelune) se plaint des hommes d'Ax (Dax) qui lui prirent 8 quintaux de lin qui coûtaient 24 livres de sanchets, et il voulait aller à Bordel (Bordeaux) et ils lui rendirent pour le tout 40 sous de morlans et ils le gardèrent prisonnier 40 jours et 40 nuits dans de grands fers (c'est-à-dire "enchaîne").

Ils (sic) se plaignent de don Guillem Bigot et de Guiralt neveu du trésorier qu'ils avaient à Bayonne avec 15 balles de cordouan à la veille des Rameaux et ils entendirent dire qu' on marquait à Bayonne les cuirs de Navarre et ils allaient à Bearritz (forme ancienne correcte pour le moderne "Biarritz") et les hommes de Bayonne arrêtèrent les balles et de la part du commun (c"est-à-dire "la communaute") de Bayonne : et le jour des Rameaux le maire envoya bien 40 hommes qui leur prirent les balles et les emportèrent à Bayonne, et des 15 balles ils en perdirent les 5 meilleures et ils leur retinrent toutes les 10 autres dans lesquelles il y avait 110 douzaines et un quar ("caern") de cordouans dont chaque douzaine coûtait quand elle était à Bayonne 45 sous de tournois.

\section{(IV : Arbéroue 1)}

Celles-ci sont, seigneur, les réclamations que font ceux d'A rberoa.

Don Garcia Arnalt de Belcunçe (sic pour Belzuntz première maison noble d'Ayherre) chevalier du roi de Navarre se plaint de Ramon de Pomars qui lui prit un cheval qui valait 20 livres de morlans à Urgos sur le chemin de Rochamador (Rocamadour dans le Lot) avec le pouvoir de la ville d'Urgos; et d'autre part il se plaint de Ramon de La Reula franca de Bayonne qui lui retient 8 livres de morlans et un mât qu'il lui vendit et il ne veut pas les lui rendre. Et d'autre part il a à se plaindre de Bernart Garcia de Bayonne qui lui retient 36 sous de morlans qu'il lui enleva.

Don Petri Amalt de Bidart (Bidarte à Isturitz ou Apara-Bidarte à Ayherre, maisons anoblies en 1435) se plaint de don Johan Par et d'Amalt Par qui lui prirent 15 porcs qui valaient 10 sous de morlans. 
Amalt Santz de Puillaga (aucune maison de ce nom étrange n'est recensée en Arbéroue, et il est difficile d'y reconnaître une forme semi-romane pour le "lieu de poules", probablement sauvages, qu'indique le premier élément d'Oilloeta-agerre de Saint-Martin d'Arbéroue anoblie en 1435) se plaint d'Arnalt de Sorano qui lui retient un bœuf qui valait 30 sous de morlans.

Sancho Yssuli (altération d'Ixuri ancienne maison infançonne d'Ayherre) se plaint d'Arnalt Santz d'Urstubil et de Guillem de Barendeguj (sic, à Hasparren) et de Garcia Amalt de Sorano qui lui prirent 7 bœufs par la force.

Guillem de Laquoagua (Lakoaga maison de Saint-Martin anoblie en 1435) se plaint d'Arnalt Santz d'Urstubil et de Guillem de Barrendeguj qui lui prirent un bœuf par la force et d'autre part il se plaint de don Sancho d'Açança (maison noble de Cambo) qui lui prit 4 porcs par la force.

Eneco Iriveri (pour Iriberri maison d'Isturitz anoblie en 1435) se plaint de Iohan de Camer et de J. Arbeu (ce nom qui est peut-être un sumom était celui d'un fils d'Arraidu d'Ayherre dans les réclamations des Labourdins) qui lui prirent un bœuf.

Guillem Garcia de Londaitz (maison noble ancienne d'Ayherre) se plaint de Bernart Pes et de Garcia Arnalt d'Alçuburu et de Lop Bernart son frère qui lui prirent 6 brebis par la force.

Dona Jurdana d'Arguain (l'une des maisons Argain de Sent-Esteben, l'une infançonne, l'autre anoblie en 1435) se plaint de Bemart d'Albat qui lui prit 60 porcs.

Bernart de Bidart se plaint de Garcia de Goleyotz (encore une dénonciation de Navarrais, puisque ce quartier est à Saint-Martin d'Arbéroue) et d'Açeari de Isça (pour Ihitz : c'est peut-être la forme basque, en phonétique péninsulaire, pour Juncars d'Ustaritz) pour deux bœufs qu'ils lui prirent par force.

Bernart Guillem de Sant Martin (la salle, seule maison noble ancienne de SaintMartin) chevalier du roi de Navarre se plaint de Rostain du Soler pour 50 livres de morlans pour ses équipements ("garnjments") qu'il lui racheta et d'autre part il se plaint de Seinoret et de J. de le Lane et de Bemart Pes qui lui prirent 80 porcs et d'autre part de Bernart Pes et de Pes de Josse habitant ("vetzino") de Bayonne qui lui prirent un roussin durant les trêves.

\section{(V : Haute-Navarre 2)}

Don Per Semeneitz d'Oarritz (actuellement Oharriz) chanoine de Pampelune se plaint de don Bernart d'Armendaritz qui lui prit 18 porcs à Aynoa (Aïnhoa à la frontière) des porcs de Sainte Marie de Pampelune (c'est-à-dire la cathédrale) et d'autre part il se plaint d'Amalt Guillem d'Aynoa qui lui retient 31 porcs.

Don Aymar Crozat se plaint de don Amalt Guillem d'Agramont qui lui prit par la force 7 marcs et 10 sterlings il y a eu deux ans à la demière Saint Jean (soit en juin 1246) et il dut les lui donner de bonne foi à la dernière (fête de) Noël passée et de ceci i) y a des témoins chevaliers et des citadins ("homes de rua").

Bernart de Camo (nom d'origine : Camou en Mixe ou en Soule) de Ronçavals (Roncevaux) se plaint des hommes d'Ax qui lui prirent 2 balles de poivre ("pebre").

Guarcia (sic) Peritz de Ronçavals se plaint des hommes du seigneur d'Agramont qui lui prirent 6 sous de toumois.

Don Amalt d'Esparça se plaint de don Sancho qui est seigneur d'Espeleta qui retient 5 porcs de Saires et 4 d'Utzcharros (pour Uscarres dans le val de Salazar) et 5 de Ochogavia (Ochagavia) et 6 de don Arnalt lui-même. 
Don Sancho Lopeitz d'Esparça se plaint de don Sancho d'Espeleta qui retient 6 porcs d'Aspartz (sic) et 3 de Navasques (Navascues romanisation phonétique de Nabaskoz) et 2 de Guessa (Güesa en Salazar, en basque Gorza) et 1 de Ciralda.

L'abbé d'Urdais se plaint de Guillem Arnalt de Guissen (forme ancienne de Guiche, en basque Gixun) qui est entré dans sa maison d'Aynoa par la force et prit par la force des biens de la maison pour 20 sous et 6 deniers de morlans.

Dame ("Na") Ramona Lastreira se plaint de Santz de Naguiturri (voir plus haut) et d'Arnalt son neveu pour 15 porcs qu'ils prirent par la force et ils furent pris dans la maison de Heguidoa (il y a une maison infançonne Hegito à Ispoure en Cize, proche des zones de pâturage de l'Arradoy et des monts d'Ossès, et une maison à Mendionde).

L'abbé de San Salvador de Leurum (le monastère de Leyre) se plaint de Seynoret qui lui prit 30 vaches de sa cabane et causa du dommage à ses hommes, et le prix de ces vaches était de 400 sous morlans.

Arnalt Bernart de Vilanova (l'un des nombreux Villanueva navarrais) se plaint de Franc de Brena pour 23 porcs de 3 ans.

Don Petri Santz de Legassa se plaint de don Guillem Arnalt de Salt pour 31 porcs.

Semeno Atznareitz de Larazpe se plaint de Guillem Eirlantz de Gandaratz (les maisons Ganderatz connues sont à Saint-Martin d'Arbéroue) et de Johan Domincuitz d'Etzçan (aujourd'hui Esain) pour 16 porcs qu' on lui prit par la force.

Pascal de Lantz se plaint de don Sancho de Lana (sic) et d'Espaynol et de Johan qui lui prirent 13 mesures ("arrovos") de blé.

Semeno de Lantz se plaint de don Johan de la Lana et de son frère le clerc qui lui prirent 2 porcs par la force.

Pedro d'Escati se plaint du seigneur d'Agramont et de son frère don Auger qui lui prirent un roussin qui valait 4 livres de sanchets et 9 sous de morlans et le couteau et la ceinture et une cape (sic) et 1 surtunique ("sobercot").

Domicu Johanetz de Madoz (au val de Larraun) se plaint de don Guillem Arnalt de Salt qui lui prit 12 vaches pleines ("prenyaderas").

Domicu Beraiscojtz (ce toponyme basque d"où dérive "Briscous" en Labourd est ici nom d'origine) se plaint de don Guillem Arnalt de Salt qui lui prit 10 vaches pleines et don Auger de Salt une (sic).

L'abbé d'Oliva se plaint de Seynoret qui lui prit 12 porcs par la force.

Le prieur de Ronçavals se plaint de don Johan neveu de don Arnalt de Nobeins (pour les formes de ce nom voir la première partie).

\section{(VI : Garro, Ossès 2, et autres)}

Celles-ci sont les réclamations que don Guaissia (sic) Amalt de Garro fait contre les hommes de Labort. Seynoret et ses hommes et Johan de Lana lui enlevèrent 80 porcs. Item Franco de Brena (sic) lui enleva 100 porcs. Amalt de Bassuen (nom d'origine issu d'une maison de Hasparren : voir première partie) et Per Amalt des Puis bourgeois de Bayonne vinrent avec d'autres compagnons de Bayonne et don Amalt de Salt et Johan de Salt et Santz Arnait de Bearritz (et) ils lui brûlèrent la maison d'Osses (8) et scièrent le verger et lui firent du mal pour 100 livres de morlans et tuèrent 3 hommes. Et Santz Amalt de Çepurua (peut-être pour Haizpurua) et Santz de Naguiturri lui emportèrent 20 porcs qui valaient 20 sous de morlans. Eneco Amalt de Sague (voir plus Echague) lui emporta 6 grandes têtes (sic) de bœufs et de vaches. Bemart d'Osses et son fils lui emportèrent 6 têtes de boufs et de vaches. Amalt Santz d'Ustubil et les hommes de don Arnalt de Salt tuèrent le frère de don Guaissia Arnalt de Garro alors qu il n'était pas en guerre et se trouvait en Baztan. Don Auger de Salt 
a tué le fils de sa sœur qui était du roi (de Navarre). Amalt Santz d'Ustubil et Per Amalt d'Arriaga (Harriaga maison infançonne de Mendionde) tuèrent le gouverneur ("alcajt") du château de Rocafort (à Saint-Martin d'Arbéroue) avec un autre guerrier ("peon"). Don Amalt de Salt et ses compagnons tuèrent le cheval d'Amigot et 1 "cavier" (on peut se demander, vu le contexte, si le mot "cavero" dérivé du latín caput ne commence pas à être confondu avec le terme "cavalier", comme cela arrive à l'époque moderne) et lui prirent un roussin qui valait 5 livres de morlans et les armes et les garnitures ; et ceux de Bayonne vinrent brûler Garro (le château de Mendionde) et don Gaissia Amalt prit un hornme et don A. de Garroia (ce mot semble la forme basque déterminée du nom "Garro" lui-même) le libéra pour 100 sous de morlans et il ne peut les récupérer. Per Johan de Beor lui doit 100 livres de morlans pour un homme qu'il libera ("manlevo"). Et tout ceci fut fait pendant les trêves du roi.

Baldoyn le clerc du roi de Navarre se plaint d'hommes d'Ax qui lui volèrent sa malle qui valait bien 7 livres de tournois.

Les hommes d'Osses se plaignent de Yenego A. de Sague et de Guillem de Sague pour 6 vaches et 18 bœufs.

Don Gassia A. de Belçunçe se plaint du seigneur d'Agramont et de Per Martin de Miramont (maison noble d'Amorots en Mixe ou de Bardos en Labourd) et de Condet de Miramont et de Guillem d'Aguerrea (de même maison de ce nom de Bardos ou d'Amorots) et de Per Gassia de Miramont et de Bernart d'Agramont qui lui enlevèrent 27 têtes de bœufs et de vaches et 6 hommes "derdemudos" (sic : le mot d'espagnol moderne "tartamudo" a le sens de "bègue" qui ne convient évidemment pas ici) pour 500 sous morlans.

Dona Sol a à se plaindre de don Per A. de Salt et de ses fils pour 40 vaches qu'ils lui enlevèrent.

L'hôpital d'Irissairi (pour Irissarn') a à se plaindre de Pedro d'Aiza et de Johan d'Oçaçaneta (noms navarrais) pour 5 vaches.

Dominguo d'Arizcon (pour A rizcun en Navarre) a à se plaindre de Guillem A. de Salt pour 80 porcs qui valaient 8 sous (sans doute chacun).

Dona Maria de Chalatz (pour Echalaz en Navarre) a à se plaindre de Santz de Naguituri ( $\mathrm{sic}$ ) et de Johan de Luidudo (nom altéré qui représente peut-être Alduide pour "Les Aldudes") qui lui prirent 31 porcs et d'autre part 40 porcs qu il menèrent à Agramont.

Gil d'Orseis (le nom d'Ossès apparaît ici proche de l'étymon basque Orzaiz) se plaint de Amalt Johan et de Sancho Landa frères et d'Eneco A. d'Echau et de Hancho (sic sans doute pour "Sancho") Sele qui prirent 17 bœufs et 7 vaches par la force. Ceux d'Oses (sic) ont à se plaindre de Guillem le fils du chapelain d'Ustaritz pour 100 sous de morlans qu' il leur prit par la force.

Arnalt Brasc se plaint de Sans Guaisia de Çavaloe (Zabaloa maison infançonne d'Itxassou) qui lui a volé une vache.

Issemen de Larragua (pour Laharraga maison d'Ossès) se plaint de B. de Meçcarat (voir la première section : doit être pour Amezkarate) et de B. Gaissia pour 7 sous de morlans.

Arnalt d'Arulose (sans doute une cacographie pour Arlausa nom de maisons d'Eyharce en Ossès ayant évolué en l'actuel Arrossa) se plaint de Pes d'Urguri (sans doute pour Urgorri) et de J. d'Oleritz (peut-être originaire d'Oloriz en Navarte) pour 8 porcs qu'ils lui prirent par la force.

Gayssia Guillem de Murue (une maison Murı ou Murru existait à Ossès) se plaint de Santz d'Etsague pour 7 porcs qu'il lui vola et l'un des porcs fut mangé à Laralde (écrit "al aralde" ? pour Larralde : la maison ancienne de ce nom la plus proche est à Macaye). 
Sanç d'Oses se plaint de sire ("den") J. de la Lana et de Pez le fils de Naregure (nom probablement altéré d'une maison du Labourd, rappelle Nagore en Navarre) pour 30 sous de morlans qu'ils lui prirent par la force.

Isemen (sic) de Larraga se plaint d'Aner de Sorane (Sorano à Hasparren) pour une vache qu'il lui a volée.

\section{(VIIa. La nef "Sainte-Marie")}

Mémoire de ceux de la nef Sainte-Marie d'Espagne ("la nau sancta maria despaynna") qu'a volée sire Pes de Laudoar en Gironde ("Gironda"); et don Arnalt Bernart jure et dit qu il avait dans la nef Sainte-Marie son valet (ou garçon : "macip") et on lui fit entendre que sire Pes de Laudoar de Bayonne lui avait pris son avoir de 44 douzaines de cordouan, et ils (sic) les rachetèrent 23 livres moins 12 deniers de morlans que son valet a payés à Bernart Bernardon de Bayonne ainsi que son valet le lui fit entendre. Témoins ou jurés qui entendirent que don Bernart Bernardon se tint pour payé de l'argent susdit : don Belenguer et Salvador Motça (surnom basque courant au Moyen Age : "le court"), mais ils ne savent pas de combien de deniers il s' agit. Et item il perdit dans la nef Saint-Jacques ("la nau Sant Jacme") selon ce que son valet lui fit entendre la valeur de 45 marcs de sterlings employés en draps qui lui furent enlevés en Angleterre au port de Plemua (c'est-à-dire Plymouth). Et on lui prit à Bayonne 110 sous 6 deniers de morlans en parts de maltôte (taxe indue : voir la première partie). Et item ils prirent son valet Guiralt de les Cumbes en Ax et les lui firent racheter 8 livres 12 deniers de morlans ainsi que le valet le fit entendre. Témoins de ce qu'il perdit dans la nef Sant Jacme au port de Plemua : Guillem de Sant German et don Arnalt Bernart le jeune jurés qui garantirent l'affaire à plusieurs reprises à la cour du roi d'Angleterre ; mais ils ne furent pas sur place et ne savent combien valait ce bien ni s'il fut pris.

Salvador Motça jure et dit que sire Pes de Laudoar lui prit son bien dans la nef Sancta Maria de don Johan d'Espainna et on le lui fit racheter 20 livres 4 sous 9 deniers de morlans, (et) 37 sous et demi de tournois à don Pes de Lesquila pour le fret de la nef, qu' il paya sans (compter) les frais et les missions qu'il a fait(e)s qui lui coûtent bien 20 livres de toumois ; et ceci advint en l'ère 1244 de l'Incarnation, au mois de novembre : il n'a pas de témoins.

Don Arnalt Peyre le changeur jure et dit qu'il avait dans la nef Sancta Maria 32 charges de sumac (arbuste à tanin) et 3 charges de (appartenant à) Domingo Bel Bufon, selon ce que son hôte lui fit entendre, à qui il avait envoyé son sumac; et sire Pes de Laudoar les prit, et il les trouva à Bayonne et il les racheta 7 livres de morlans et les paya de sa main à don Guilleumes (sic) Doutej de Bayonne, et de ceci il doit y avoir des témoins à Bayonne selon ce qu'il dit; et il paya pour la maltôte (taxe) des galères ("galees" : petits navires) 40 sous de tournois. Et ceci lui fut pris en l'an 44 au mois de novembre. Pour l'avoir de la nef et celui des galères ce fut avant.

Guillem de Fenes jure et dit qu'il avait dans la nef Sancta Maria 2 balles de cordouan et sire Pes de Laudoar les y prit ; et il trouva son bien à Bayonne et ils les lui firent racheter 11 livres 16 sous 6 deniers de morlans et il les paya de sa main à don Pes dels Puys; et ceci advint en l'an $\mathbf{4 4}$ au mois de novembre ; il n'a pas de témoins.

Belenguer jure et dit que Bernart de Puyvert son compagnon chargea dans la nef Sancta Maria 8 grands sacs ("costals") (pleins) de cordouans selon ce que son compagnon lui fit entendre et sire Pes de Laudoar les prit et Belenguer sait que son bien avait été pris à Bayonne ; et il fut à Bayonne et le trouva et le racheta 21 livres 18 sous moins 3 deniers de morlans et les paya de sa main à don Guillem Arnalt de La Gaillardia qui était des 12 (voir plus haut) et ceci advint en l'an 44 au mois de 
novembre. Et il perdit dans cette même nef 5 douzaines de cordouans et don Guillem Vidal de Perer sait qu" on trouva de ce cordouan chez un cordonnier ("cordoaner").

Miguel de Gandulayn (aujourd'hui Guendulain nom de plusieurs villages navarrais) jure et dit qu'il avait 9 ballots ("boyllons") d'étamine (étoffe) dans la nef Sancta Maria et il trouva son bien à Bayonne et ils passèrent outre et son maître don J. del Salin y envoya son valet à Pere de Mendolorri (sic pour l'actuel Mendillorri en Navarre, qui a acquis une mouillure dans le second terme el( $h$ )orri "aubépine") et le racheta selon ce qu'il fit entendre 10 livres moins trois deniers de morlans et il les paya à don Guillem Amalt de la Gaillardia, sans les frais et les missions qu'il fit, ce qui monte bien à autant ; et ceci advint en l'an 44 au mois de novembre.

\section{(VIIb. Les nefs "Saint-Jacques" et "Vianaise")}

Don Grimalt jure et dit qu'il avait dans la nef Sant Jacme ("Saint Jacques") 2 valets et ils lui firent entendre qu'ils avaient pris son bien et qu' on les avait volés dans 5 ports dans la terre d'Angleterre, et il y avait du sien et de celui de son frère bien 100 marcs et de ses valets tant du leur que de commande bien 100 autres selon ce qu'ils disent ; et ceci advint en l'(an) 44.

Don Domingo de Longuida (vallee de Navarre) jure et dit qu'il avait 6 balles dans la nef "Vianesa" (cet adjectif "de Viane", ville de Navarre, doit nommer une nef appartenant à des marchands navarrais) dans laquelle les biens de Navarre furent laissés à Bayonne et il les racheta 8 livres de tournois et c'est le prévôt qui était au roi d'Angleterre qui prenait la maltôte en ce temps-là et il les paya à don Bernart Guillem de Bayneres (Bagnères) qui donna l'assurance pour lui ; et aussi deux mariniers et le petit prévôt (sic : ancien français "prevostel" diminutif de "prevost") qui l'aidèrent (veut peut-être dire "et qui aidèrent le prevostel") eurent 50 sous de tournois ; et aussi quand il chargea les balles dans la nef il paya au prévôt 22 sous et demi de morlans de maltôte. Somme : 10 livres et demie de tournois et 22 sous et demi de morlans; et ceci advint en l'an 44.

Martin de Berrio (lieux-dits et maisons en Navarre) jure et dit que don Joan (sic) de Camer lui prit 2 balles de cordouan selon ce que le muletier qui les portait lui fit entendre et il fut à Bayonne et il les racheta à ce susdit don Johan (sic) de Camer 12 livres et demie de morlans et don Bernart del Potz paya l'argent à don Johan de Camer devant don Miquel de Maus et devant J. d'Ardir et devant don Guillem Vidal de Perer selon ce qu'il dit et cela advint en l'an 38 (1238).

Don Esteven Amalt jure et dit qu'ils lui prirent à Bayonne pour maltôte de la maison de leurs galères 13 sous 4 deniers de sterlings et il paya cela à don Guiralt Alaman et à don Guillem Arnalt d'Ondres, et ils lui prirent les péages de ce temps 75 sous de morlans pour la maltôte du cordouan qu'il portait. Les sterlings lui furent pris en l'an 35 (1235) et les 75 sous de morlans en l'an 41 (1241).

Johan de Puyvert jure et dit que des hommes d'Ax le prirent et le tinrent 40 jours dans les fers et le tenant dans les fers ils lui endommagèrent 4 grands sacs de lin qui lui avaient coûté 24 livres de sanchets, et il n'eut pas plus de 54 sous de tournois et le lin s'endommagea dans une nef (bateau) qui était à la Pointe ("la pointa" : lieu dit "Punte" sur le cours de l'Adour) et ceci advint en l'an 43.

Don Aznar de la Rocha jure et dit que Johan Logros (surnom roman qui deviendra aussi un fameux nom de maison en Cize : Logras) de Bayonne et Lorençet son fils lui doivent 9 livres de vieux sanchets pour des tissus ("sayals") et des cordages qu'il eurent et de ceci ils lui firent promesse ("homenage" : voir plus loin) qu'ils l'auraient payé dans 15 jours, et ils ne l'ont pas payé. 
Don Garcia d' Olcoz (nom ancien du quartier d'Occos en Baïgorry et d'un village de Navarre) jure et dit que don Guillern Arnalt d'Eutej (peut-être nom d'origine rappelant celui de la maison Heuti de Saint-Pée-sur-Nivelle) lui prit quatre mesures de froment selon ce que Johan d'Ualde le muletier qui portait le froment lui fit entendre sur le chemin où il le portait à Fonta rabia (Fontarrabie) en l' an 47.

Esteven Guillem jure et dit que le prévôt de Bayonne lui prit 25 sous de morlans de maltôte pour le cordouan et ceci advint en l'an 44.

Don Lop de Loli jure et dit que Lorentz fils de don Per Johan de Magron de Bayonne lui doit 13 livres 14 sous de sanchets pour 3 cordages qu'il eut et dont il lui fit hommage des mains et de la bouche (7) qu'il le paierait entièrement à la Saint André, et il lui en paya 100 sous et Pelegrin Borrel de Bayonne 20 sous de sanchets pour l cordage de mescle ("mescla"), et ceci advint en l'an 43.

Don Garcia Peritz Yvon jure et dit qu'on lui prit à Bayonne 40 sous de maltôte pour le cordouan et c'est Guillem le doreur qui le prit pour le prévôt et autres 7 sous de maltôte pour faire la maison de leurs galères; et ceci advint en l'an 43.

Don Bernart de Sant German jure et dit que don Johan Marin (peut-être nom de métier) d'Estela (Estella en Navarre) avait reçu de lui en commande 33 marcs et demi de sterlings et il les employa en draps et ils les mit (les draps) dans la nef Sant Jacme selon ce que Johan Marin d'Estela lui fit entendre ; et ce bien lui fut pris en Cornoaylla (Cornouaille) dans la terre du roi d'Angleterre, et il en reçut 4 marcs et 1 ferton (petite monnaie d'argent valant le quart d'un marc), et ceci advint en l'an 39. Et de cela est témoin jureur don Gil Martin qui sait avec certitude que ce bien lui fut pris dans la terre du roi d'Angleterre.

Don Gil Martin jure et dit qu'on lui prit dans la nef Sant Jacme qui fut volée au port de Plemua 7 stanforts ("estanfortz" : pièces de tissu de laine qui tirait son nom de la ville de Stanford) de Raç (probablement "d"Arras") dans une balle qui lui coûtèrent 16 marcs de sterlings, et ceci advint en l'an 39.

Guillem de Sant German jure et dit qu'on lui prit à Bayonne 74 sous de morlans de maltôte du cordouan (sic) (pour) le prévôt (ou : "le prévôt lui prit" bien que le verbe soit au pluriel), et autres 60 sous de morlans pour dona Andregaylla de Fenes que luimême paya de sa main quand le roi d'Angleterre partit de Bayonne.

Esteven de Fenes jure et dit qu' on lui prit à Bayonne 32 sous de morlans de maltôte du cordouan (pour) le prévôt (idem) quand le roi d'Angleterre partit de Bayonne.

Don Per Arnalt le changeur jure et dit qu'il confia ("comanda") à don Garcia (son) valet 6 cordages et ils les vendit et acheta 4 stanforts de Bruges et 1 "peyscan" (ou "peysoan") selon ce qu'il lui fit entendre, et il les mit dans la nef Sant Jacme et ils lui furent volés au port de Plemua et ceci advint en l'an 39.

Don Simon de Conches jure et dit qu'il perdit dans la nef Sant Jacme 25 marcs de sterlings employés en draps qu'il mit lui-même de sa main dans la nef et ce bien lui fut pris dans la terre de Devensire (Devonshire) au port de Plemua ; et ceci advint en l'an 39.

Felip Martin jure et dit qu'il perdit en la nef Sant Jacme 37 marcs de sterlings employés en draps qu'il mit lui-même de sa main dans la nef, et ce bien lui fut pris dans la terre de Devensire au port de Plemua ; et ceci advint en l'an 39.

Don Esteven d'Ortes jure et dit qu'il perdit dans la nef Sant Jacme 30 marcs de sterlings employés en draps et son valet mit les draps dans la susdite nef, selon ce qu'il fit entendre; et ce bien lui fut pris dans la terre de Devensire au port de Plemua ; et de ceci sont témoins qui jurèrent et savent avec certitude que le valet le mit ainsi et que don Esteven le perdit : don Simon de Conches et Felip Martin qui étaient sur place : et ceci advint en l'an 39 ; et d'autre part on lui prit à Bayonne 
12 sous de morlans de malıôte pour faire la maison de leurs galères et ceci advint en I'an 43.

\section{(VIIc : commerçants navarrais)}

Don Johan Marra jure et dit qu'il confia 100 marcs à don Guilleumes d'Eutey de Bayonne sur l'assemblée communale ("contra el comunal") de Bayonne de telle manière que, quelque accord ou quelque accommodement qui serait conclu sur le bien qui restait à Bayonne, les hommes de Bayonne avaient arrêté avec les hommes de Navarre qu'il en serait fait de ce bien selon l'accord; (et) qu'ainsi en répondit don Johan Marra de ces 100 marcs qu'il confia à don Guilleumes d'Eutey. Don Arnalt la Ceilla et don Arnalt Peyre changeur jurent et dirent qu'ils furent au lieu où don Guilleumes d'Eutey paya la taille ("se taylla") pour 100 livres de toumois pour les 100 marcs de sterlings, disant qu'il était garant pour don Johan Marra, et ils restèrent en telle condition à titre de garantie ("en voz de marca") pour libérer les prisonniers que, d'après ce qu'ils disaient, le seigneur de Garro détenait. Et si à la vue du sénéchal les prisonniers étaient laissés (libres) sinon que les susdites 100 livres de tournois resteraient à titre de garantie pour libérer les prisonniers. Et don Arnalt la Ceilla libéra les 2 prisonniers pour 110 sous de tournois de rançon et 80 sous de tournois de mission, et comme les autres prisonniers étaient relâchés pour moins de 100 livres de tournois, ils avaient à rendre le surplus des 100 livres ; et ils convinrent de ceci de bonne foi.

Joan d'Uritz (village de Navarre) jure et dit que Pere Rosset le maire de Bayonne lui enleva 16 sous 8 deniers de tournois de maltôte pour faire la maison de leurs galères; et ceci advint en l'an 43.

Miquel d'Un castel (sic pour Uncastillo) jure et dit que les péagers de Sant Thomas prirent à Julian son frère à Sant Thomas de Conturberi (Canterbury) selon ce que Julian son frère lui fit entendre parce qu'il ne voulait pas entrer dans le district ("la iura" : l'espace sous la juridiction de la ville) pour payer le péage de son bien et qu'il lui faisait faire le tour à 4 lieues de distance de la ville de Sant Thomas 60 sous de sterlings en l'an 4l. Et d'autre part Pere de Rosset qui était maire de Bayonne prirent (sic) à Miquel d'Un castel 15 sous de toumois de maltôte pour la maison de leurs galères ; et ceci advint en l'an 43.

Don Johan Peritz jure et dit que les gens de Maçanges (sans doute Messanges, dans les Landes) lui prirent 55 livres de tournois dans 1 vaisseau qui cinglait de Bayonne pour la Bretagne ("Bretaynna" peut représenter la "Grande Bretagne") et le vaisseau fut volé et se brisa sur la côte de Maçanges et il n'y eut point d'épave ; et il le prit à grand tort et il alla les réclamer à don Rostain qui était en ce temps sénéchal et il n’a pu encore les recouvrer; et ceci advint en l'an 43.

Don Garcia Santz de Çandueta (Zandueta en Navarre) jure et dit que les gens de Maçanges lui prirent 8 marcs de sterlings et 40 sous de tournois dans 1 vaisseau de Bretagne qui se brisa sur la côte de Maçanges et il n'y avait point d'épave ; et ceci advint en l'an 43.

Domingo Ortitz jure et dit que Johan de Bernardis celui d'Ax lui doit 48 sous de morlans pour trois fourrures et un vêtement ("vestit") de lapin qu'il eut de lui et il lui avait promis sans tromperie qu'il les paierait dans 8 jours et de ceci sont témoins don Bernart de Lay et Peyron de Rigada et Domingo Eregue (sic pour erregue, sumom "roi" devenu par la suite nom de maison) selon ce qu'il fit entendre ; et il fait plainte de cela ; et ceci advint en I'an 43.

Don Amalt Johan jure et dit qu' on lui prit à Bayonne 38 sous 1 denier de morlans de maltôte pour le cordouan comme péage : et d'autres 39 sous et demi de morlans de maltôte pour faire la maison de leurs galères ; et ceci advint en l'an 43. 
Don Aznar de la rassojnna (sic pour Larrasoaña au val d'Esteribar en Navarre) jure et dit que le comte maréchal (sic "lo compte mariscalt") lui prit 1 cheval et après il s'entendit avec lui pour 26 marcs et dit qu'il le paierait en Angleterre et qu' il lui ferait une lettre que lui apporterait son valet ; et il lui fit une lettre avec son sceau pendant et il y envoya son valet et il lui prit les lettres et il ne le paya pas, sauf 13 marcs de sterlings selon ce que le valet lui fit entendre, et il réclame pour les 13 marcs qui restent et pour la dépense que fit le valet en 1 an en suivant le comte ; et ceci advint quand le roi d'Angleterre fut à Sayntes (Saintes).

Dominicu Varacutz d'Odeyn jure et dit que Guillem Arnalt de Sant (sans doute pour "Saut") lui prit 22 vaches en "caromie" (peut-être "à la Chandeleur", ancien français "calamai") en l' an 47, et Ogiers de Sant (idem) une vache et il fait serment que chacune valait 20 sous de morlans.

\section{(VIIla Basse-Navarre : Ossès 3)}

Simen d'Orses jure et dit qu'Arnalt de Sorane lui prit 5 vaches, et Guillem le fils du curé ("labat") d'Ustaritz des planches qui valaient bien 10 livres de morlans et les vaches lui furent prises par 4 (sic) fois en l'an 45 et 46 et 47 , et elles valaient bien les 3 vaches 20 sous de morlans chacune et les deux autres chacune 15 sous de morlans. Et Bernart de Mescare et Bernart de Garsis lui prirent 7 sous de morlans à Bayonne.

Garsias Guillem d'Orses jure et dit qu'Eneco Rolantz d'Eschaugue et Guillen d'Eschaugue et leurs cousins lui prirent 7 vaches qui valaient 101 sous de morlans à ce qu'il dit en l'an 45 au mois d'août et 6 chèvres qu'Eneco Rolantz lui prit qui valaient 10 sous de morlans et 1 porc que Santz d'Eschaugue lui prit qui valait 4 sous 6 deniers de morlans, et une vache qu'Ausamos (sic, sans doute une cacographie) lui prit qui valait 14 sous de morlans en l'an 41 . Amalt d' Orisbusti (sic : aucune maison ancienne d'Ossès ne se rapproche de ce nom qui semble une cacographie, peut-être pour... Orpuzzan cité au siècle suivant) d'Ousers (sic) et Arnalt d'Erlause (voir plus haut) témoins jurèrent et dirent qu'ils savaient bien (le fait) des vaches et qu'elles furent prises, sauf l'une dont ils ne savaient rien, et ils savent (le fait) du porc et des chèvres mais il n'en savent rien du prix ni de la valeur.

Arnalt d'Iriverri (quartier et maisons Iriberri) d'Orses jure et dit que Bernart d'Orçaintz (sic : forme proche de l'étymon d'Ossès) d'Onnaçu (c'est à peu près la forme basque et étymologique d'Oneis en Mixe) et Pedro Bernat son fils d'Onnaçu lui prirent 1 bœuf en l'an 47 au mois d'août qui valait 20 sous de morlans. Témoins jurés de cette chose (en vieux français dans le texte comme tout ce passage : "iure de ceste chose") : Martins d' Uaurcengo (très probable cacographie pour un génitif locatif basque correspondant à Ugarzango "du quartier d'Ugarzan"), Garsias Guillen de Murusco (maison ancienne de ce nom disparue avant le XIVt siècle, si ce n'est encore un génitif erroné pour Muru encore cité au $\mathrm{XV}^{\circ}$ ) ; mais ils ne savent pas le prix.

Lop Santz d'Orses jure et dit qu'Arnalt de Saut lui fit du dommage en planches ("tables") et millet "jusques" (sic) à la valeur de 30 sous de morlans en l' an 47 au mois d'août. Il n y a pas de témoins (cette demière phrase est en latin).

Arnalt de Rause (voir ci-dessus les formes pleines Erlausa, Arlausa) d'Orses jure et dit que Ferrant de Brene et Petri Harambileta (la maison de ce nom anoblie en 1435 est à Ayherre, mais il y a confusion avec Aribileta cité plus haut dans le même contexte) et Johan d'Ondezitz (sic pour Underitz de Mouguerre) et leurs compagnons lui prirent 8 porcs qui valaient 32 sous de morlans, et Eneco Rolantz d'Eschaigue (sic) lui prit 19 chèvres qui valaient 31 sous de morlaṇs et pour faire cette prise fut (présent) Johans (sic) de la Regue (probablement forme francisée de Larraga pour 
Laharraga: maisons de ce nom à Ossès et Armendaritz), et ceci advint quand le roi de Navarre fut en guerre ("fu a ost") en Gascogne. Témoins jurés de ceci : Pedro d'Orses et Garsias Guillen d'Oses (sic) qui approuvèrent et dirent ce que celui-là dit (sic : "distrent cel que cil dist").

Pedro Osois d'Orses jure et dit qu'Eneco Rolans d'Eschaugue et Garsias Sens (sic) de Jacsu (déjà en prononciation française : pourrait être pour Jatxou en Labourd, mais semble plutôt désigner Jaxu en Cize) et Pedro de Jassu ( $\mathrm{sic}$ ) qui est mort lui prirent 10 porcs qui valaient 40 sous de morlans en I'an 46 au mois d'octobre, et Sanz (sic) d'Eyars (pour Eiharz quartier du pays d'Ossès actuellement à Saint-Martin d'Arrossa) témoin jure et dit qu'il ne sait rien de ces porcs sauf que les parents de ce Pedro de Jacsu qui est mort l'avaient prié qu'il s'en prît (on peut comprendre ainsi le "portachast" du texte mis sans doute pour l'ancien français "porsachast") à ce Pedro Osois et qu'il pardonnât au mort ce vol où il avait été car il l'a al légé par sa mort (si l'on peut entendre ainsi "quar il legei a sa mort") comme le dirent ses parents.

Martin d'Uartegon (sic : pas de maison de nom, sans doute une cacographie pour un nom vu plus haut) d'Orses jure et dit que Garcia Guarre (pour Agerre maison de Bardos) et Arnalt Santz et Bernart de la Sague (pour Latsaga, maison de Bardos) homme du seigneur de Vardos (c'est-à-dire "Bardos") qui lui prirent 20 porcs qui valaient 4 livres de morlans à "Caresme prenent" (sic : carême prenant) passé en l"an 47 ( $d^{\prime}$ où se déduit que l'enquête d'Ossès est faite au début de 1248). Sont témoins de ceci Symon de La Harragua d'Orses et Lop Santz d'Orses qui jurèrent ce qu'il dit. Mais ils ne savaient pas qui étaient les hormmes ni rien de la valeur.

Berasco d'Orses jure et dit que Sancho Santz de Naguiturri (voir plus haut) et Domingo Berari (aucune maison de ce nom : le nom le plus proche est Irari en Baigorry) lui prirent 11 porcs qui valaient chacun 4 sous et 6 deniers de morlans, et trois de ces hommes sont vassaux du seigneur de Saut (à Hasparren) et l'autre (sic !) est vassal d'Espaynol de le Lana (à Ustaritz); et 2 bœufs qu'Eneguo (sic) Rollan (sic) d'Eschaugue et Sancho de la Landa (sic : sans doute pour le précédent "Lane" dont c'est la forme basque et étymologique) lui imputent (? "amiet lui") qui valaient 34 sous de morlans, et les porcs lui furent pris à la Saint Michel en l'an de 48, et les boufs quand le roi de Navarre alla en guerre ("d'ost") à Vilanova (Viellenave) ; et on lui demande s"il avait des témoins et il dit que toute la terre (d'Ossès) le savait mais qu'il ne savait nommer personne.

Sancho Ochoa d'Orses jure et dit que Johan de la Lana d'Ustaritz lui prit 30 sous de morlans en la terre de la bort (sic : Labourd) à Pâques fleuries ("Pasca florida" : nom ancien du dimanche de Quasimodo octave de Pâques, qui se dit en basque bazko zahar "vieille pâque") en l'an de 47 ; il n'a pas de témoins.

\section{(VIIIb Basse-Navarre : Arbéroue 2)}

Celles-ci sont les réclamations de ceux d'Arberoa.

Bernart Guillem de Sant Martin d'Arberoa (voir IV : Arbéroue 1) jure et dit qu 'il fut garant pour le seigneur de Garro de telle manière que s`il conduisait le seigneur de Garro à Bayonne qu'il serait quitte et il l'y conduisit et ils ne voulurent pas le prendre et ceux de Bayonne le prirent et le mirent en prison aux fers à Bordiaus (Bordeaux) pour 1 an et puis il convint qu'il se rachèterait pour 76 livres 6 sous de morlans et son justaucorps (vêtement rembourré porté sous la cotte de mailles) et son chapeau et ce qu il avait perdu (? l'expression "ses perti" semble une erreur de graphie) et 1 palefroi ("palafre") que Pere d'Iorse lui prit : pour le palefroi sont témoins Garcia Arnalt de Belçinçu (sic pour Belžmz) et Garcia Baque et non pour l’argent. 
Sancho d'Urquido de Helieta (Urkudoi de Hélette : nom d'origine semble-t-il pour cet habitant) en Herberoa (sic) jure et dit que don Pere de Ceurt (pour Zuhurte maison infançonne de Macaye) en Labor (sic) lui prit 75 sous de morlans quand on le tint pris dans la tour de Bayonne parce qu'il sortit à l'appel ("la pelit") pour la guerre en l'an 44.

Amalt d'Aguarrete (peut représenter la maison dite plus tard Agorreta à SaintMartin d'Arbéroue ; il y a aussi une maison ancienne de ce nom, justement, à Bardos) d'Erbero (sic) jure et dit que Seynoret lui brûla ses maisons et Santz d'A ristoitz (pour Hariztoi maison infançonne de Bardos) et Guillem d'Arbinoritz (pour Albinoritz maison de Bardos) lui prirent 28 porcs et ses maisons valaient 6 livres de morlans et les porcs 4 livres 4 sous de morlans, et ceci advint pendant la guerre.

Martin d'Arroses (pas de maison de ce nom : sans doute nom d'origine) jure et dit qu' on lui prit à Bayonne 11 sous de morlans de maltôte pour faire la maison de leurs galères et ceci advint en l'an 42 ; et aussi des hommes du roi d'Angleterre de Gujnçaliseu (sans doute pour Winchelsee port anglais en relation avec Bayonne) et de la côte lui prirent dans la nef Sancta Maria de Laredo (ville de Biscaye) dont le patron était Johan de Beta de Bayonne 27 tonneaux de vin ainsi qu' on lui fit entendre et ces vins valaient vingt et 9 livres de parisis (ce doit être le sens de "parensins"), et ceci advint en l'an 46 en carême.

\section{(IX. Haute-Navarre 3 : Pampelune)}

Sancho Gil jure et dit qu'il vendit à sire Jofre de Maude Vile 1 cheval pour 18 marcs et de cela il lui prit 5 marcs et demi et il se plaignit au maire du roi d'Angleterre (sic) et il ne put avoir son droit, et ceci advint quand le roi d'Angleterre alla à Sayntes et sire Jofre alla au combat sur ce cheval.

Bertolomeu de Ronçavals bourgeois de Pampalona jure et dit que les gens du roi d'Angleterre lui prirent au port de Plemua en draps une valeur de 11 livres de sterlings qui étaient à don Thomas Iurdan et ceux qui le prirent étaient Gualter le Flamand ("le flamenc") d'Antonie et Daniello Breton et leurs compagnons en l'an 39. Témoins ayant juré : Pere Johan de Morlans (c'est-à-dire Morlaas en Béarn où se faisait aussi la monnaie locale) qui dit qu'il vit bien quand on lui prit son bien mais il ne sait pas combien.

Lorentz le fils de don Pere Guillem de Pampalona jure et dit qu'il avait dans la nef Sanct Jacme 9 draps de Bruges entre lui et son compagnon et ils leur en prirent 4 selon ce que lui dirent les marins qui gardaient les draps et 12 sous de toumois que Pere de Roset (sic) lui prit à Bayonne.

Autztorc Arroer (sic pour ces étranges noms de personne) jure et dit que ceux de Bayonne lui prirent 20 sous 10 deniers de morlans pour 50 douzaines de cordouans pour la maltôte et ceci advint au temps où ils prirent la maltôte aux autres; et ils lui prirent 51 douzaines et 8 peaux de cordouan dans la nef Sant Miquel en Angleterre ainsi que ses valets le lui firent entendre; et on lui demanda si les valets étaient en Navarre et il dit que non ; et on lui demanda ce que valaient ses cordouans et il dit qu'ils valaient bien 51 livres de sterlings car c'est ainsi que fut vendu le restant qu'il mena par terre. Ensuite Ramon d'Urditz (variante probable d'Urdaitz ce qui signale un maître de navire d'origine navarraise en principe) qui était le maître ("maiestre") de la nef et qui devait garder le bien lui prit 2 douzaines qui valaient 40 sous de sterlings. Il $\mathrm{n}$ ' a pas de témoins.

Johan Matheus jure et dit que lui et ses parents avaient donné leur avoir à don Enequo Crique et comme il le leur fit entendre il le mit dans la nef Sant Jacme qui fut 
perdue ả Plemua en Angleterre et il y perdit bien jusqu’à la valeur de 90 marcs comme le valet le fit entendre. Témoins : Bartolomus de Ronçavals et Pere Johan de Morlans qui dirent qu'ils savaient bien qu'il avait du bien dans cette nef mais ils ne savaient pas combien.

Johan Murgue (ce pourrait être la romanisation du nom basque de lieu Murgi, village d'Alava et maison à Ossès, mais semble plutôt un nom de "Franc" navarrais originaire de France, moderne "Mourgue") de Pampalona jure et dit qu'l des chevaliers du comte d'Ayrefort lui prit un roussin à Seintes (sic) ils lui en donnèrent 1 mauvais et il s'en plaignit au roi d'Angleterre et il ne peut avoir son droit et il perdit bien 8 livres de tournois.

\section{(X. Arbéroue 3)}

Pere Heruans de Bidart (voir IV) d'Esberoa (sic) jure et dit que Jehans d'Esparre et Arnautz, (sic) d'Esparre lui prirent 9 porcs qui valaient chacun 6 sous de morlans ; et ils lui furent pris en l'an 43 au mois d'octobre. Témoins qui jurèrent ces paroles et témoignèrent : Sancho d’Içuri (sic) et Guillem Arsis de Londatz (sic). (9)

Santz d'Içurri (sic) d'Esberoa jure et dit qu'Amaltz Santz d'Ituvil (sic pour Ustubil) lui prit 7 bœufs qui valaient 7 livres de morlans, et ces bœufs lui furent pris en l'an 43 le jour de Pâques fleuries ("pasque florie" : voir ci-dessus) ; et ceux qui furent prendre ces bœufs furent Guillem de Barrendeguj et Garsias de Heriart (Hiriarte) de Sorane ; et il se plaint (aussi) de Seynoret et de ceux de la Lane et de don Santz de la Lane et d'Espaynol de la Lane et de Pedro Bernart de la Lane qui brûlèrent sa maison avec tout son pain et sa garde-robe (sens de "sa robe") et avec toutes ces choses qui valaient 1000 sous de morlans. Témoins qui jurèrent et dirent ces choses : Guillem Garsis d'Aitar et Pedro Arnalt de Bidart, sauf qu'ils ne savent pas la valeur de la maison ni des choses brûlées.

Guillem Garsis de Londiritz (sic pour Londaitz) d'Esberoa jure et dit que Garcia Amalt de Hyherauçu (nom sans doute altéré) et Lop Arnalt son frère lui prirent 5 brebis en l'an 42 au mois de décembre ("detzenbre"). Témoins qui jurèrent ces mêmes (choses) : Garcia Vaque et Sancho d'Içurri.

Guillem Domicu de Chegoiane (maison Etxegoien d'Ayherre, Saint-Martin ou Saint-Esteben, toutes trois anoblies en 1435) d'Arberoa jure et dit que Guillem d'Armendaritz et son frère don Sancho Arnaltz et Amalt de Saut et son père et Johan de la Lane et Santz de la Lane lui brûlèrent sa maison avec toutes ses brebis et avec toutes ses choses qui valaient bien 15 livres de morlans en l'an 43 au mois de septembre. Témoins qui jurèrent et virent ces choses: Garcia Vaque et Sancho d'Içurri.

Guillem de la Coague (pour Lakoaga) d'Esberoa jure et dit qu'Arnalt Santz d'Ustuvil et Guillem de Barrandeguj et Garcia Amalt d'Iriart lui prirent 4 bœufs qui valaient 4 livres de morlans en l'an 42 entre la Pentecoste et la Seint Johan. Et Pierres Bernart de la Lane et Santz de la Lane lui prirent 3 porcs qui valaient 18 deniers de morlans au terme ci-dessus indiqué. Témoins qui le jurèrent et le virent : Garcia Vaque et Sancho d'Içuri (sic).

Garcia Amalt de Belcinçu (voir plus haut) jure et dit qu'il allait au pèlerinage à Rocamador ; Raimos de Pomeros et ceux d'Usdos avec lui prirent son péage et ensuite lui prirent son cheval duquel il ne voulut avoir 9 livres de tournois. Et Amalt Guillem d'Agramont lui prit 11 puis 18 tant vaches que boufs au temps où le roi de Navarre vint à la guerre en Gascongne ; et il racheta 6 hommes pour 20 livres de morlans. et Amiec (sic : peut représenter l'équivalent de l'Amigot gascon) Arnalt Guillent d'Agramont fit ces choses (avec) Pierres Martin de Miramont, Guillem d'Aguerre (qui 
prit) le cheval et Arnalt de Çalane (maison noble de Camou en Mixe) et Pedro Garssias de Bidageign (maison noble de Biscay en Mixe : la mouillure finale, aujourd'hui disparue, est à remarquer dans ce texte écrit en vieux français). Témoins qui jurèrent et entendirent ceci : Garcia Vaque et don Pere de Mehari (pour la salle de Méharin).

Enequo de Sancta Maria (maison noble) de Heleta en Arberoa jure et dit que Seynoret lui prit 120 et 13 (sic) porcs. A cette prise participèrent Amalt Santz d'Ustubil et Amalt Guillem sire de Vasson (pour Bassuen de Hasparren : voir la première partie) et don Santz de Briscorz (sic : Briscous) et Arnalt Garsis d'Arteguieta (maison de Hasparren : aujourd'hui Artaieta) et Bernart Pedro de Belçuncu (sic : il y a aussi un Belzuntz dans le parti labourdin) qui demeure à Bayonne, et les porcs furent pris en l'an 43 aux environs de la sient (sic) Michiel (à la Saint Michel le 29 septembre commençait le pâturage libre des porcs dans les forêts communes). Témoins qui jurèrent et entendirent ceci : Guillem Arnalt de Heleta et Ramons (sic) d'Issurri.

Guillem Amalt de Heleta d'Esberoa jure et fait dire à Pedro de Garat (maison de Hélette anoblie en 1435) que Seynoret et Amalt Santz d'Ustuvil et Amalt Guillem sire de Vasson et don Santz de Briscoitz et Arnalt Garcia d'Arteguieta et Bernart Pedro de Belçinçu lui prirent 7 porcs en l'an 44 aux environs de la seint Michiel. Témoins qui jurèrent et entendirent ceci : Johanes de Sancta Maria de Heleta et Arnalt Ramon d'Issurri.

Don Garcia d'Arraidu (pour le rôle de cette maison dans la guerre contre les Labourdins : voir la première partie) d'Erberoa (sic) jure et dit que les hommes de Bayonne depuis que le roi don Thibalt fut roi (10) lui tuèrent son frère avec 14 hommes et ceci advint en l'an 42, et Seynoret lui brûla ses maisons qui valaient mille sous de morlans et la maison de son frère et ce qu'elle contenait qu'il évalue à 200 sous. Il a pour témoins Guillem Gaissia de Limidart (nom probablement altéré) et Pere Arnalt de Bidart qui dirent que $c^{\prime}$ est vrai.

Arnalt Aramon (forme à prothèse pour "Ramon") Issulicho (sic : intrusion d'un génitif basque d'origine en - $k o$ plutôt qu un diminutif, pour ce personnage qui semble déjà cité comme témoin, et qui paraît le désigner comme maître de la maison noble Ixuri d'Ayherre) jure et dit que don Pere Amalt de Salt et le seigneur d'Armendaritz lui brûlèrent ses maisons et ce qu'elles contenaient qu'il estime à 700 sous de morlans. Il a pour témoins don Garcia d'Arraidu et Saut (sic, sans doute pour "Santz") de Issuli qui virent cela mais ils ne savent ce qu'il y avait à l'intérieur, en l'an 42.

Garcia Lopiz de Beldarais (Bildaraitz hameau de quatre ou cing maisons autrefois indépendant, aujourd'hui intégré à Ayherre) jure et dit que Seynoret et ceux de Salt (veut dire "ceux de Hasparren") et ceux d'Armendaritz et Bernart Pes lui brûlèrent ses maisons avec ce qu' il y avait dedans et son gendre qui y fut brûlé, et il estime la maison avec ce qu'il y avait dedans à 300 sous morians, en l'an 42 . Il a des témoins : Santz de Issuli et Guillem de Ioy (nom sans doute altéré) qui disent qu'il en est ainsi.

Bernart d'Aguerre (l'une des maisons d'Ayherre ou Saint-Esteben anoblies en 1435, plutôt que la maison noble ancienne de Hélette qui pourrait être nommée au paragraphe suivant) jure et dit que Seinoret et ceux de Salt et ceux d'Armendaritz et ceux de la Lana lui brûlèrent ses maisons et ce qu'il y avait dedans en l'an 42 et il estime la maison (sic) à 200 sous de morlans avec ce qu'il y avait dedans. Il a des témoins : Santz d'Issuli, Guillem d'Oiosen (mot peu lisible et altéré : c'est apparemment le même témoin que ci-dessus).

Peirona d'A nerart (nom altéré par le copiste ou le recopieur, qui doit représenter Anciart pour Aintziarte maison de Hélette anoblie en 1435) jure et dit que Seynoret avec sa compagnie lui brûla ses maisons et ses, bordes et son aire à battre le blé ("trillar") avec les cuves et 80 porcs qu'elle estime à mille sous de morlans; et elle 
racheta son fils qu'ils lui prirent pour 200 sous de morlans en l'an 42. Elle a pour témoins Santz de Issuli et Amalt de Agarrea (pour Agerrea) qui virent cela.

\section{(XI. Cize et autres)}

En Petri Santz d'Urrutia de Cissa (plusieurs maisons nobles - le en gascon désigne un notable - en Cize, la plus connue étant celle précisément de "Saint-Jean d'Urrutia" qui a donné son nom à "Saint-Jean-le-Vieux") jure et dit que Johan d'Ondritz lui prit 8 porcs qui valaient 40 sous de morlans en l'an 43 aux environs de Noël.

Don Aymar Crozat de Pampalona jure et dit qu'il envoya avec Bernart de Montaner à Bordel (Bordeaux) 7 marcs de sterlings et 10 deniers et ainsi que Bernart de Montaner le lui fit entendre don Amalt Guillem d'Agramont lui prit ces sterlings. Et ensuite il vint avec don Helies Davi (sic) et don Arnalt Guillem était présent et il lui fit demander par don Helies qu'il lui rendît les sterlings ; mais (il demanda) qu'il lui fixât un terme pour amour de lui, et il lui fixa un terme jusqu'à Noël passée de l'an 47 , et il ne lui a pas rendu les sterlings et ce vol fut fait aux environs de la saint Jean en l'an 47. Il a pour témoins don Bernart de Hatsa (le seigneur d'Ahaxe) et don Navarr (sic) de Hassa (sic), Pes d'Ones (sans doute Oneix en Mixe) qui dirent à don Arnalt Guillem d'Agramont que pour l'amour de don Helies David il devait rendre cet argent, mais ils disent qu'ils ne savent pas combien d'argent.

Ceux-ci sont ceux de Cisa (sic) :

Lope Santz Corroça dit et jure qu'Arnalt border (ce mot est sans doute le nom de métier "bordier") d'Ustaritz lui prit 1 vache en l'an 43. Témoins : Lope Ochoa qui jura qu il vit emporter la vache.

Amalt Lopis de Sant Johan jure et dit qu'en Brasc d'Armendaritz lui prit 15 porcs en l'an 44 et il dit qu'ils valaient 7 sous (sic) de morlans. Témoins : Lop Achaatz son père et Lop Santz Çorrotça (sic) qui virent emporter les porcs et dirent qu'ils valaient tant et plus (sic : pour "encore plus").

Peiron mercier de Sant Johan jure et dit qu'Amalt Guillem de la Barra de Salt en Tascama (sic : mot sans doute altéré) lui prit un roussin qui lui coûta 60 sous de morlans et 60 sous en deniers et en achat ("enpleite" : le sens est peu clair) qui valait 60 sous et 20 sous que lui coûta la mission en l'an 47. Témoin Eneco Santz qui jure et dit qu'il était présent sur le lieu à Salt, mais il ne sait pas ce que valait ce qu'ils prirent.

Arnalt Santz de Sant Johan jure et dit qu" 1 homme de Bayonne Pes de Badet le blessa et il y eut un jugement sur cela et celui qui le blessa fut taxé ("peito") de 366 sous pour prix de la violence ("calonia") par don Pes de Rosset qui était alors maire ; et de cet argent celui qui fut blessé devait avoir 8 livres 3 sous de morlans; et don Pere (sic) de Rosset lui prit de force ces 8 livres 3 sous, et ceci advint en l'an 41 .

Pes d'Argena (s`il s'agit d'un Cizain ce pourrait être une cacographie pour Argaba maison infançonne d' Uhart-Cize) que Pes de Hurt (pour "Urt" en basque Ahuri) lui prit 8 charges de sumac et il supporte un dommage de 20 sous morlans, et la mission pour le réclamer lui coûta 20 sous de morlans. Témoins : en Johan Santz de Garritz témoigne que Pes de Hurt lui prit 8 charges de sumac, et pour la mission il n'en sait pas le montant.

Aner d'Estrena jure et dit qu'en Guiralt de Hon (peut-être pour Ihune maison infançonne d' Uhart-Cize) doit pour 2 charges de poix qu'il lui emporta à Pampalona 26 sous de sanchets. Il $n$ 'y a pas de témoins.

Amalt d'Aassa (Ahaxe) de Sant Johan jure et dit qu'en Santz de Assa (idem) seigneur d'Espeleta (11) le mit garant pour 700 sous de morlans et il l'a laissé prolonger et il a demandé sa part ("su heretage" qui n'est pas au sens propre un "héritage") pour cette garantie. Il a pour témoins Johan de Garris (sic), Bernart Artus, Amalt Haissia de Luc (pour "Luxe" en Mixe), en l'an 47. 
Adam de Sant Johan jure et dit qu'en Johan de Camer lui prit 1 roussin qui valait 60 sous de morlans. Témoins Arnalt de Hassa, Arnalt Guaissia de Luc, en l'an 43.

Maria Guarceitz de Vila nova (soit le hameau d'Iriberri en Cize soit la maison infançonne du même nom à Bascassan) jure et dit que le seigneur de Paganduru (à Macaye) prit à son mari sur le chemin de Bayonne 12 sous de morlans et 8 mesures de mil avec 2 ânes, et qu'il racheta et les ânesses (sic) et le mil avec une vache pleine et elle estime la vache 20 sous de morlans et ceci advint en l'an 38.

\section{(XII. Haute-Navarre 4 : Bastan, Roncevaux, Larraun, Maya)}

\section{Ceux-ci sont de Lerin Bastan :}

Pere Santz de Lagassa de Lerin jure et dit pour son père èt pour lui que Guillen Arnalt de Salut (sic, pour "Sault") lui prit 31 porcs qui valaient 9 livres sanchètes en l'an 44 environ à la Sant Miquel.

Esteven de Lagassa jure et dit que don Blasco d'Armendaritz lia les mains à son fils dans la montagne et lui emporta 21 porcs, et Martin Eniegueitz et toute la terre le savent selon ce qu'il nous dit et ceci advint en l'an 47.

Baldoujn jure et dit qu' ils lui prirent en deçà d'Ax une mallette à la sortie de la ville et ce qu il y avait dedans valait bien 7 livres de tournois et ils firent ceci de nuit en l'an 45 .

Ceux-ci sont ceux de Ronçavals :

Domingo Pascal de Ronçavals jure et dit .que Pierres d'lorse lui prit 8 juments pleines et 3 roussins et 2 poulains de chevaux et une pouliche qui valaient 40 livres de morlans en l'an 45 environ à la Sant Andreu (au 30 novembre la Saint André marquait la fin des pâturages libres); et il dit sous serment qu'il prise autant ce qui en est issu que l'autre château nommé auparavant (passage peu clair en vieux français). Témoins furent Arnalt Santz de Soraburu (maison noble de Saint-Esteben en Arbéroue) et Pierres Arnalt son frère et Pierre de la Lane (pour ce témoin sans doute cizain on peut penser à la maison noble Larrea d'lspoure) et Arnalt Bernart de Sant Johan qui entendirent qu'il vint manifestement à ce Pierre (sic) de Iorse qu'il les avait pris pour marque des porcs (passage également obscur) et le sire de Hasse (Ahaxe) voulut lui rendre ses porcs par preuves et sur ce ils se mirent à se quereller et les juments ne furent pas rendues et pour le prix il ne voit pas bien ce que les juments valaient.

Sanchetz Ortitz du Val d'Agueil jure et dit qu'Amalt Peire de Saut lui prit l boe uf pour raison d'herbage ( $c^{\prime}$ est-à-dire saisie sur les lieux de pâturage) en l'an 47 au mois de mai et ceux de Ronçavals avaient payé l'herbage et il dit que le bøuf valait 23 sous de morlans.

Bernart de Caumoz qui est à Ronçavals jure et dit que ceux d'Ax lui prirent et enlevèrent 2 charges de poivre et ils prirent son corps (c'est sans doute ce que veut dire. avec une cacographie, "pristrent son cos", sic) et le tinrent tant en prison qu'il dépensa 4 livres 13 sous de morlans; et puis ils donnèrent son poivre à Bernart dou Lac de Bayonne et il convint de racheter son poivre 23 sous 7 deniers de morlans. Domingo Pascal le sait qui fut présent, mais il ne sait pas bien quelle fut la dépense.

Pere Tastif jure et dit que n'Ogiers d'Agramont lui prit son roussin et sa selle et tout son harnois qui valait bien jusqu'à 100 sous de sanchets en l'an 48 .

Domicu d'Ayçua qui demeure à Ronçasvals jure et dit que Bemart d'Aroçe et Arnalt d'Irundaritz (maison de Mouguerre) lui prirent une vache en l' an 36 qui était à la "vacherie" (sic, sans doute la "cabane" ou "borde" de montagne et non "l'étable") de Bernart de Lomberi (représente un Irumberri, maison noble en Cize notamment). 
Garcia de Biscarret (le village navarrais proche de Roncevaux) jure et dit que Johan de Larrando et Anso Erlans de Çepuru (sans doute pour Larranda et (H)aizpuru à Ustaritz) lui prirent 30 porcs au val d'Erro (en Navarre) et les menèrent au pouvoir d'Arnalt de Salt ; et d'autre part Jaun (ce mot basque remplace ici les "en", "sire" et "don" romans habituels) Petri Johan d'Albeintz (maison d'Arcangues), Ochoa Falsart (pour Haltzarte), Garcia Bergara, Anso Domicuitz qui sont dans la lettre du roi. prirent 54 porcs qu'ils menèrent à Agramont et de ces porcs les 53 étaient à dona Maria d'Echalatz (en Navarre) et à sa fille, 10 à G. le porcher, 8 à Santz de Biscarrz et 8 à Eneco Ortitz d'Ureta (en Navarre), et ils valaient bien pour chaque porc 8 sous. Ceci advint en l'an 47 au mois de février. Témoins jurés : don Arnalt de Biscarret et Ocho de Biscarret son fils.

Ceux-ci sont ceux de La Raun (pour l'un des Larraun en Navarre) :

Domingo Yvaynes de la Raun jure et dit que don Guillem Arnalt de Salt lui prit 22 vaches pleines et don Ochier de Salt une en carême et ceci advint en l'an 44.

Ceux-ci sont ceux de Mayer (Maya) jurats :

Ramon de Mayer jure et dit que Santz de Lane prit à ceux de la terre de Maya (sic) 14 bœufs et 12 vaches en l'an 46 au mois d'avril ; il ne sait pas le prix des bœufs et des vaches et il leur prit 18 mesures de froment et une vache qui avait coûté 17 sous 8 jours avant.

Durant de Mayer jure et dit que Santz de Lane leur (sic) prit 14 bœufs et 12 vaches et 14 mesures de froment ; et ensuite don Bernart de Mandaritz (sic pour Armendaritz) 14 porcs et Guillem Arnalt de Salt 4 porcs qui valaient chaque porc 8 sous de sanchets et une vache qui avait coûté 17 sous 8 jours avant en l'an 47 au mois d'avril et les porcs furent pris en l'an 47 au mois de novembre.

Qu’il soit en mémoire que don Martin jure et dit qu'il avait envoyé Johan Martin son neveu en Flandres et il arriva au port de Plemua en Angleterre dans la nef Sanct Jacme et on lui prit son bien pour une somme de 60 marcs et plus ; ceci advint en l'an 39 ainsi que le firent entendre les exécuteurs (testamentaires) là où fut tué Johan Martin son neveu.

Don Per Guillem Gosser jure et dit que son valet lui fit entendre que quand il vint dans la nef Sant Andreu de don Garcia de Lissaga (pour Elizaga nom de nombreuses maisons, en Labourd à Saint-Pierre d'Irube et ailleurs) ils trouvèrent les galères du roi d'Angleterre à Sant Mayeu. Nicholas de Antont était le maître (sans doute le commandant) des galères et il lui prit son bien : 120 hermines qui coûtèrent 38 sous de sterlings et d'autre part une robe qui valait 26 sous et demi de sterlings dans la ville de Mayagatz, 7 livres de tournois que lui prit Helias Aspes et 15 sous de bordelais et 10 sous de morlans. Et quand il sortit de la prison il lui en coûta 60 sous de morlans pour le rachat. Ceci advint quand le roi de Navarre fut à la Pointe (sic: voir plus haut), et la première perte eut lieu quand le roi de Navarre s'en alla (c'est ainsi qu“il faut entendre sans doute le mot "fu" qui termine la phrase).

Don Pere d'Ayeta jure et dit qu'il avait dans le nef Sant Jacme 10 draps de Santhomer (Saint-Omer) et deux tierçains (sans doute le sens de "terç" : petit tonneau, comme unité de mesure) de draps blancs qui coûtèrent 15 livres de sterlings et ceci fut pris au port de Plemua ainsi que son valet le lui fit entendre en l'an 39, et 50 sous de morlans et 6 sous de sterlings de maltôte.

Don Andreu Climent jure et dit qu'il avait dans la nef Vianesa a Bayonne 15 mesures ("costals") de cordouans et on lui fit un dommage de 20 marcs ; ceci advint en l'an 44 , et ils payèrent 66 sous de morlans de maltôte. 
Martin de Montaner jure (et) dit qu' on lui prit à Bayonne 39 douzaines et 1 caern de cordouans ce qui lui fit un dommage de 25 livres de tournois et on lui prit par mauvaise raison 40 sous de tournois pour péage ; ceci advint en l'an 44.

Don Guillen Bigot et Guiralt jurèrent et dirent que le maire de Bayonne don Lorentz de Puiaga (sic pour Puiana ou Pouyane) lui prit 110 douzaines et 1 caern de cordouans qu'il mit en son pouvoir. Ceci advint en l'an 44 ; et ils avaient coûté 64 sous de toumois la douzaine et ils donnèrent 40 sous de maltôte aux galères, et il leur en coûta bien 100 livres en missions. Il y a des témoins pour les 110 douzaines et 1 caem de cordouans qui ouirent l'hôte de Bearritz là où le cordouan fut pris, ainsi que le maire de Bayonne et ses hommes qui auraient... (ici un mot illisible) le cordouan : don Martin et don Andreu Climent qui étaient là où ils pouvaient le savoir (passage obscur : "que eran dor lo conoissiren"). Cette saisie ("tolte") fut faite en l'an 44 le jour de Pâques fleuries (voir plus haut) et ils lui prirent une balle de drap qui avait coûté 12 livres et demie de sterlings. Le maire de Bayonne don Pere Ramon de Veneça (pour Bénesse : la phrase inachevée veut dire sans doute que c'est le maire au moment de la rédaction en 1248).

Don Johan Bigot jure (et) dit qu' on lui avait pris 10 livres de morlans de maltôte.

Don Gil Bigot jure (et) dit qu'on lui avait pris $\mathbf{4 0}$ sous de maltôte pour les galères.

Bernart Montaner jure (et) dit qu'Arnalt Guillem d'Agramont lui prit 6 livres de tournois et 7 marcs de sterlings et on lui prit 5 chevaux en 5 semaines ce qui lui fit un dommage de 200 morlans et il dépensa pour les chevaux 8 livres de tournois ; ceci advint en l'an 47 au mois d'août.

Sancho Gros jure (et) dit qu' on lui prit 5 conques de froment qui valaient 10 livres de morlans; et de cela on lui donna 50 sous de morlans. Ceci advint quand le roi d'Angleterre était en guerre avec le roi de France.

Don Pontz Peritz jure (et) dit que les bourgeois de Bayonne prirent dans la nef Sancta Maria à Royam (sans doute Royan) son bien à son valet Thibalt et il racheta son bien pour 33 livres de tournois à Bernart d'Usot, ce fut en l'an 45.

Durant Martin jure (et) dit qu'il avait dans la nef Sant Jacme 9 draps de Santhomer qu'on-lui prit au port de Plemua, qui valaient 10 livres et 16 sous de strelings. Ceci advint en l'an 39.

Don Johan Gros jure (et) dit qu'on prit à son compagnon à Royam 20 livres de morlans

Johan Folques jure (et) dit qu'on lui prit en Loreront (sans doute Oléron) 52 charges de sumac et il le racheta pour 10 livres de poitevins ("peitevins" monnaie du Poitou) qu'il eut de Rostayn del Soler et ensuite on lui rendit le sumac pourri ; ceci advint quand le roi fut à Sayntes (sic).

Garcia de Lort garantit et dit sur sa garantie (sic) que Guillem de Saumat prit sa fille à Bayonne et il la racheta pour 7 livres de sanchets et ce fut en l'an 45 au mois de septembre. Il paya cet argent par 1 More qu'il acheta à Guillem de Saumat et il le perdit en Navarre.

Gaissia Arnalt de Garro jure et dit que Pere de Rosed (pour Arrauset) qui était maire de Bayonne et ceux de Salt et les 4 frères de Lana, le seigneur de Nobeis (voir plus haut). don Pere de Subist et d'autres bourgeois de Bayonne lui ont fait un dommage qui vaut 43 fois 1103 sous de morlans (sic) pour le rachat de ce qui fut racheté et pour les maisons qu ils lui détruisirent et pour les vergers qu'ils lui coupèrent à lui et à ses parents, sans compter la mort des hommes au nombre de 41 . Et nous lui demandons quand cela lui fut fait et quand il avait subi ce dommage ; et il nous dit que c'est quand il était vassal du roi d'Angleterre et depuis." (12) 


\section{NOTES}

1. Pour le commentaire de certains aspects linguistiques très curieux de cette seconde partic de $1^{\circ} \mathrm{cn}$ quête de 1249, après le texte cn latin mêlé de rares intrusions romanes ct basques (celles-ci sculement en onomastique) de la premiere partie, qui passe tour à tour du navarro-castillan habituel de la chancellerie de Pamplunc à l'occitan gascon ct au vieux français, avec diverses formules bâtardes de ces langues, y ajoutant cncore des formules latines, et bien entendu, une large part d onomastique basque (noms de licux et de personnes), se reporter à l'article de Ricardo CIERBIDE signalé dans la note 2 de la première partic.

2. Les ruines du château de Gramont primitif sont à Viellenave ct occupent le sommet d'une butte qui porte aujourd' hui le nom de La Mulari, nom roman qui semble se refércr à l'ancien moulin sur le cours d'cau qui passe au pied de la bulte. C'cst ce site et cc château qui portaicnt le nom roman ou peut-être romanisé de Gramont dont les traductions latines nombreuses montrent que ce ne fut pas un "grand mont" mais un "mont aigu". La construction du château de Bidache qui prit le nom des seigneurs est postérieure aux evénements relatés dans ce document. et en particulier au siège de Viellenave, c'est-à-dire sans doutc du château lui-même, conduit par le roi de Navarre en personne.

3. Pour le scrment prêté au roi de Navarre Sanche le Fort par Vivien II de Gramont dans son château dc Viellenave le 17 deccmbre 1203, reconnaissant devant témoins sa suzeraineté et hissant le drapcau du roi sur sa tour. se reporter aux articles de Clément URRUTIBEHETY : Bulletin de la Société de Borda p.332-332. Dax 1964, et Bulletin de la Societé des Sciences. Lettres et Ans de Bavonne, $n^{\circ} 129$ p.93-124.

4. Ccttc formule exprime le rituel de l'hommage féodal souvent représenté dans l'enluminure médié. valc, qui cngagcait chaque contractant à rester fidele au scrment prêté cn public et devant témoins : en 1203 ce furent 26 seigneurs de Mixc qui jurèrent à leur tour "de faire tenir à Vivien de Gramont cet engagement et tout ce qui esi écrit dans la leture", la lettre dont précisément Thibaut fait mention dans sa rêclamation. Si Ic châtcau de Gramont a été remis ensuite à un fidèle de Thibaud autre que le seigneur Amalt Guillem, comme le nom du nouveau "titulaire" lc laisse supposer, il aurait eu quelque raison d'accepter la protection anglaisc.

5. Lc chäteau royal d'Arçar, nom basque signifiant "vieux rocher", correspond sans doutc au sitc dc Charritte en Mixe nomme en gascon (c'est la frontière linguistique) "Castel biel" au-dessus d'un coude de la Bidouze : cf. Clément URRUTIBEHETY "La marche de Lauhire", Gure Herria. La cartc de I'IGN "Pcyrehorade 1344 Est" signale à proximite un Errenborda qui est évidemment Erregerenborda ou Errcgemborda que le gascon nomme "borde dou rey", ct un "Chemin du roi" : on ne saurait dire, faute de fouilles. si le site fut abandonné après que les Labourdins ct les Gramontais eurent rasé la fortcressc, ce qui scmble lc plus probablc, ou s'il fut reconstruit et détruit dans un nouveau conflit.

6. Lexpression "Labor de la Lana" ou "Labourd de la lande" ne semble pas désigner ici le Labourd "et" la lande, c'est-à-dire le territoire au sud du département actuel des Landes qui se nommait sous l'Ancien Régime "Ies Lannes", mais le domaine des seigneurs de "la Lane" d'Ustaricz si souvent nommes dans les cntreprises contre lcs Bas-Navarrais, traduction gasconne ct à ce titre quasi officialisée du basque Larrea. nom porté par de nombreuscs majsons médiévales aussi bien en Labourd que dans les autres provinces,

7. Cc Nagithurri installe en Labourd, soit engage au service personnel du seigneur de Saut ou Zaldu de Hasparren sclon le système des relations fécodales, soit marié dans l unc des maisons de Hasparten. a garde lc nom de sa maison d'origine en Osses, alors même que ses homonymes et sans doute proches parcnts sont très actifs dans l'armce navarraise. C'est le même schéma que cclui des Espeleta, mais inversé

8. La maison des Garro en Ossès (ou les Espeleta du parti navarrais avaient aussi une demeurc) a été à l'epoque modeme "La Châtaigneraie" dite en basquc un peu différemment Gażenarena, à laquclle le rang de noblesse de ses possesseurs donnait le titre de "noblc salle", el qui sc trouve au-dessus du quarticr de Gahardu au centre de la vallee. Au Moyen Age, où aucunc maison de ce nom n'apparait parmi les maisons nobles anciennes de la vallée au nombre de sept (sans compter le "palacy" d' Unhaizeta disparu au cours du XII' siecle sans qu' on en sache davantage sur scs scigneurs ni sur son emplacement ancien), la maison de Garro clait peut-čtre ailleurs : il reste toujours au quarticr d'Ugarzan, d'où l'on est cntré dans la vallecc jusqu au XVIIF' siccle en venant de Bayonne ct du Labourd par la route romaine, Garro el Helette. une borde ruinéc qui a gardé le nom de Garroa. C'est par là que la compagnie des Labourdins est venue à coup sür mur brûler la maison de Garro.

9. Ici Ic manuscrit ajoute les noms suivants qui ne sont apparemment pas reliés au paragraphe qui précedc. mais laisscnt cntendrc sans doute que ces trois personnages sont les responsables des cxactions commiscs par lcurs subordonnes: "Amalt de Saut, don Auger de Saut ct don J. de la Lane".

10. Ce rappel de l'arrivê de Thibaud sur Ic trône navarrais. l'annéc 1234. lie effectivemcnt les evéncments rapportés et le debut des hostilites entreprises par les Labourdins contre les Navarrais à unc prise de 
pouvoir ct un acte politiquc, dont on sait qu'il fut d'abord contesté à l'intérieur mêrne du royaume navarrais, ce qui réveilla peut-être aussi à l'extérieur les appétits (ou les craintes : Thibaud était vassal et proche du roi de France) dcs pouvoirs voisins. Il laissc même entendre, au moins aux yeux du lecteur moderne, qu'ils cn furcnt une sortc de conséquence.

11. Voila une filiation qui donne un nouvel excmple des liens familiaux inexuricables entre les deux partis : Ic scigncur d'Espclette dont les Navarrais, les autres "Espelette" compris, ont ravagé la maison et les bicns. est issu des seigneurs d'Ahaxe, alors même que le scigneur d'A Ahaxe du moment à la tête de sa compagnic est très actir dans l'armée de Thibaud.

12. Ces dcux demiers paragraphes sont séparés du restc et cnurc eux par un blanc dans le manuscrit. La đcrnière phrasc laisse cntendre que le seigneur de Garro n'est plus. au moment de la rédaction au début de I'annóe 1249. attaché au roi d'Angleterre par un lien de vassalité. Mais il l'était encore quand on a assiégé son châtcau de Mendionde et brûlé ses biens, ce qui laisse entendre qu'il a été injustement autaqué par les Bayonnais, mais que la contrc-attaque qu'il a mené avec l'aide des Bas-Navarrais etait donc juste. 


\section{ANNEXES}

\section{Repères chronologiques.}

N.B. L'essentiel de la chronologie qui suit est tirée de la partie navarraise de l'enquête. Les interventions du roi de Navarre, prise de l'Ostabarret et de Mixe, siège de Viellenave, destruction de Saut d'Hasparren et raid en Labourd, ne sont pas datées avec exactitude : on peut supposer, indirectement, qu'elles ont eu lieu en 1244.

1192. Le vicomte de Tartas Arnalt Remon, seigneur "naturel" de Mixe et Ostabarret, prête serment au roi de Navarre "de faire guerre et paix pour lui contre tous chaque fois qu "il le lui ordonnera, y compris contre le roi d'Angleterre et contre Gaston vicomte de Béarn".

1203. Au château de Gramont à Viellenave, Vivien Il de Gramont fait le même serment au roi Sanche le Fort le 17 décembre et s'engage à lui remettre à sa demande son château, sur lequel flotte la bannière royale, en présence de 26 chevaliers témoins presque tous mixains.

1228. Pierre-Amaud seigneur de Luxe, seigneur de Lantabat et Ostabat, ayant vu les murs qu'il avait fait édifier autour d'Ostabat rasés sur l'ordre de Sanche le Fort. prête serment et rend. l'hommage rituel à celui-ci au même lieu le 6 juillet.

1234. Mort de Sanche le Fort sans héritier direct. Il a déshérité son neveu et successeur naturel Thibaud IV comte de Champagne et de Brie (1201-1254), né à Troyes, l'un des six pairs laïques de France et le premier des poètes lyriques français ou "trouvères" de son temps. Il est néanmoins reconnu roi de Navarre par l'assemblée des Cortes et devient Thibaud premier de Navarre. Son fils et successeur Thibaud II épousera une fille de Louis IX (saint Louis) roi de France. Tous deux participent aux croisades en Palestine.

1235. Saisie de biens navarrais à Bayonne et perception d"une taxe ("maltôte").

\section{Saisie de bétail de Roncevaux en Basse-Navarre.}

1238. Saisie de biens navarrais par Johan de Camer (Came); ils sont rachetés à Bayonne. Saisie de biens navarrais par le seigneur de Paganduru (Macaye) "sur le chemin de Bayonne".

1239. La nef Saint Jacques et son chargement de biens navarrais saisis au port de Plymouth dans le Devonshire en Comouaille.

1241. P. d'Arrauset maire et des Bayonnais, les seigneurs de Saut (Hasparren), La Lane (Ustaritz), Albeintz (Arcangues) et leurs troupes brúlent les maisons et détruisent les biens de Garro, tuent 41 hommes de l'armée navarraise. Saisie d'argent navarrais à Bayonne. Saisie de bétail d'Ossès.

1242. La coalition des seigneurs poitevins commandée par Henri III d'Angleterre est vaincue par l'armée du roi de France, à laquelle participe le roi de Navarre en personne, aux batailles de Saintes et Taillebourg. Le domaine du roi d'Angleterre en France est réduit à la Guyenne et à la Gascogne.

Les Bayonnais et Labourdins avec les seigneurs de Saut et d'Armendaritz tuent un Arraidu d'Ayherre et 14 hommes, brûlent plusieurs maisons en Arbéroue (Ayherre, Bildaraitz, Hélette). 
1243. Saisie de biens navarrais et emprisonnement de Navarrais à Dax. Maltôte sur les biens navarrais à Bayonne. A Pâques, en octobre et novembre de la même année : saisie de bétail d'Arbéroue, d'Ossès, de Cize par les Labourdins qui brûlent des majsons en Arbéroue. Naufrage d'un vaisseau navarrais à Maçanges et vol des biens qu 'il contenait.

1244. Les Navarrais sont "appelés à la guerre" : époque probable des principales actions de Thibaud contre les Labourdins et les partisans du roi d'Angleterre en BasseNavarre. Saisie de biens navarrais "dans les ports d'Angleterre" (Plymouth est nommé) sur les nefs Saint Jacques, "Vianese" : ils sont retrouvés à Bayonne. Maltôte sur les biens navarrais à Bayonne. En novembre saisie de bétail d'Arbéroue par le seigneur de Saut, et "vol" de la nef Sainte Marie en Gironde.

1245. Saisie de biens navarrais vers Dax. Saisies de bétail d'Arbéroue, Ossès, Cize, Lerin

1246. Saisie de biens navarrais sur la nef Sainte Marie à Royan. Arnalt Guillem de Gramont saisit des biens navarrais, La Lane du bétail d'Ossès.

1247. Saisie de biens navarrais sur le chemin de Fontarrabie. En avril ("Pâques fleuries") saisie de bétail d'Ossès et de Navarre par Saut, La Lane, Armendaritz.

1248. Saisie de porcs d'Ossès par les Labourdins (Lane, Oger de Gramont etc.). La paix est conclue en octobre.

Début de 1249. Rédaction des réclamations.

Maires de Bayonne cités : P. d'Arrauset ou de Roset (1241-1244); don Lorentz de Puiana ou Laurent de Pouyane (1244) ; don Per Ramon de Bénesse (1248 ?).

\section{Index alphabétique des noms de lieux cités.}

Première partie (réclamations labourdines).

N.B. L'index sépare les deux parties de l'enquête, ce qui permet de comparer les formes que peuvent prendre les mêmes noms selon qu'ils sont écrits par la chancellerie anglaise ou celle de Pampelune. Comme dans la présentation du document et selon les mêmes principes, les prénoms de cette première partie reproduits entre parenthèses après les toponymes sont traduits du latin ; dans la seconde ils sont conservés sous la forme originale.

Agramont/Agremont (château d', seigneur d', Arnalt Guillem d', B. d')

Aignoa (Bemard Tomerius d')

Aiossa (Johan d')

Aldave (Aner d')

Alduyda (Fortin d")

Almoravid/Almoravitz/Almoravi (Garcia)

Alsu (Bernard d')

Alsueta (Sanz seigneur d', cabane d'): en Cize

Alsuete (Garcia d'): à Hasparren

Ambazedor (Johan)

Amots (Aner $\mathrm{d}^{*}$ )

Amor (Pierre Blanc d')

Andon (Guillaume d')

Angleterre (roi d')

Ansuete: cf. Alsuete 
Anurt : cf. Aurt

Aragon (Raymond d')

Aranseta (Daunet d')

Arcangos (paroisse d')

Arçar (château d')

Arcidz (Pierre)

Armendaryz (Guillaume d')

Armola (Arnalt d')

Arotze (Bernard)

Arrade/Arraide/Arraido/Arraidu (Aneco et Martin frères, Garcia, Michel, PetriSanz, Raymond d')

Arrauns (Garcia Amalt d')

Arraused (Pierre d')

Arraute (B. d')

Arrauts (Arnalt d'): cf. Arrauns

Arressayga (Domicu)

Arribera longa (paroisse Saint-Martin d')

Arteguieta (Amalt d')

Aurt Anurt : aujourd" hui Urt, en basque Ahurti

Auryots (Sanz d')

Autefalle (Johan d')

Avorta (vicomte d', Marie d', P. d'): aujourd'hui Orthe

Baded (P. de)

Baigur/Begur (vicomte de)

Baigneires (Bernard, Guillaume de)

Baliros (Arnalt de)

Baratsa (Martin)

Bardos (paroisse de, Bernard de)

Barendeira (Guillaume de) : cf. Barrendeguy

Barrendeguy (Guillaume de)

Basatz (évêque de) : aujourd' hui Bazas

Bassessarri (paroisse de)

Bassu (Amalt Guillaume de)

Bastan (Sanz de)

Bastitam : Bastide désignant Ostabat ou Larceveau.

Bauta (Bernard de) : cf. Arraute

Bedaumes (dame de)

Beelhoritz

Beguios (P.S. de)

Beios

Belhare (Loup Amalt)

Belsunsa/Belsunse (Garcia Arnalt de)

Belus (Bernard de)

Beraids (Semen de)

Berasu (Sanz Johan de)

Bergoin (Guillaume)

Berindoz (Gracia de)

Berria (Marie de)

Berroeta (Otsoeta de) 


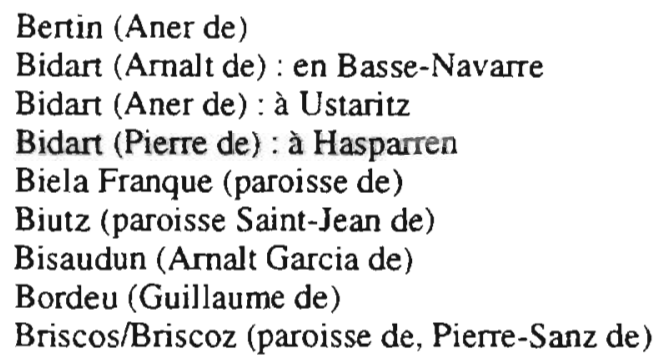

Cabanes (Johan de)

Cambo (Garcia de, Sanz de)

Camer/Camera (château de, bailli de, Johan de) : aujourd'hui Came, basque Akhamar

Caragar/Garagar (Amalt Sanz de. les frères Loup Amalt et Sanz de)

Carreta (Johan Arnalt de, Bernard de)

Casanova (Michel de)

Castaingnada (Bernard de)

Chaga (Arnalt Loup de)

Chava (Sanz de, Sanz Amalt de) : cf. Etsaba

Chavahen (Amalt de)

Cheverri (Jourdaine de) : à Hasparren

Cimbads (Raymond r. de)

Claramonte (Amalt de)

Corcoste (Guiralt Johan de)

Cordaler (Pascal, Dominique, M.)

Comeillan (Marie de)

Crincheta (Bernard de)

Cruchiague/Crussyaga (maison de, Bernard de)

Cyuars cf. Suiars

Desbor (Johan) : la partie navarraise de l'enquête montre que ce nom peut être compris et lu "des Borcs". Dans tous les autres noms la préposition latine ou romane accolée au nom dans la rédaction latine a été détachée et c'est, sauf précision contraire, l'initiale du nom qui fait l'entrée.

\section{Endrein (Dominique d")}

Ensiart (Petronille d')

Ere (Arnalt d')

Errimberi : cf. Hirumberri

Erro (Loup d')

Espeleta (paroisse d', maison d', Sanz d', Garcia d'): en Labourd

Espeleta (Garcia A. d', Guillaume son fils, Sanz Amalt d'): partisans navarrais

Espert (Bernard)

Espila/Espilla (Dominique d') à Armendaritz, (Raymond d') en Basse-Navarre (Cize).

Estela (Johan d')

Estremil (Dominique d')

Estubil (Amalt Sanz d")

Etsaba/Chava (Amalt Loup d') 
Etsau (Sanz Anso Sanz d', Sanz Amalt d', Loup A. d')

Euses : cf. Osses

Exagoe (Amalt Loup)

Faiet (Peirona de)

Faurgues (Fort Aner de, Johan de, Pérégrin de)

Ferriague (Pierre de, Sanz de) : Harriaga à Ustaritz

Feuti (Guillaume Amalt de): Heuti à Saint-Pée

Firiart (Fort Guillaume de) : Hiriarte à Bardos

Fleis/Flis (Maria du, Guillaume Amalt du)

Fort (Arnalt de, Michel de)

Galvensu (Dominique de)

Garagar : cf. Caragar

Garans (R. de, Guillemat de)

Garraut (Bernard Aner de)

Garat (Arnalt Sanz de) : à Briscous

Garat (Garcia de) : à Larressore

Garraut (Bernard Aner de)

Garris (Amalt de)

Garro (château de, Garcia Arnalt de, Amigot et Pierre Estua ses fils, Arnalt B. de)

Garue (Arnalt de)

Gelos (Marie de)

Giestars (Pierre Arnalt de)

Goos (Pierre Amalt de)

Gortairi (Amalt de)

Guerre (Pes de, Navarre de) : pour Agerre à Briscous.

Gusquieguia (Comtesse de)

Haas (Arnalt del)

Hahistura (Bernard de)

Halsu (Sanz de)

Harauriz (Jourdaine de)

Harismendi (Garcia Arnalt de, Johan de)

Hariza (Arnalt Fortin de)

Harraca/Harretha (Domingo ou Dominique de)

Hatcha/Hatche (Bernard de, Amalt Sanz de, ses fils Garcia et Raymond de) : Ahaxe

Heguio (Arnalt de)

Heleta

Herenbillague (Pierre de)

Heriart (Amalt de) : Hiriarte à Mouguerre

Herriague (Daunet de): Harriaga à Mendionde

Herriague (Pierre de) : Harriaga en Basse-Navarre

Herriart/Hyriart (Garcia de, Per de): Hiriarte à Ustaritz

Heruspa (Amalt de) : Harizpea à Larressore

Hesparrena

Hesperu/Hyzpirue (Marie de, Pierre de) : Haizpurua à Ustaritz (Hérauritz)

Hetsa (paroisse de) : Ahetze

Hifarat (Guillaume de) 
Hilvar : cf. Luiar

Hiriague (Amalt Sanz de): Harriaga à Briscous

Hiriart (Guillaume de) à Hasparren

Hiriguian (Guillaume Sanz de, Comtesse de) : Hirigoien à Larressore

Hirumberri/Errimberri (Sorbe de) : Hiriberria à Briscous

Hiryberri (Petri Sanz de) à Ustaritz

Horsebau (Johan de, Pierre de)

Huil de Taichon (Guillaume B.)

Hyhout : Iholdy

Hyriart : cf. Herriart

Hyrigoien/Hyrygoien : (Marie de) à Hasparren : (Arnalt Sanz de) à Macaye ; (Sanz

de, Eneco de) à Ústaritz.

Hyruber (paroisse de)

Hyruberi/Vilanova (Aner de) : Iriberri quartier et maison à Ossès

Hytsa (Arnalt de) : pour Ihitza

Hyzpirue : cf. Hesperu

Inissarri (Pierre Arnalt d')

Inryvaren (Johan d')

Iruber (Martin d")

Iruyta (Pierre Alaman d')

Issuri (Santz d')

Ivaren (paroisse Saint-Pierre d')

Jaldai (dame Valence d')

Jatsu (B. Faber de)

Juncars (Martin de)

Lachalda (Garcia Fortin de)

La Fiite/Le Fyte (Johan de, Raymond Guillaume de)

Ladron (Petrus)

Lagiade (Sanz de)

Lagornaga ( $\operatorname{San} z$ de)

La Lana/Le Lane : (Sanz de) à Cambo ; (Petrus Amalı de) à Umugne ; (B. de, Hispanus de. Pierre B. de) à Ustaritz

Landa (Montagne de)

Landalda (Arnalt de)

Landaldeta (Marie Guillaume de)

Lanson (Garcion de)

Laralda (dame Gracie de)

Larart (Arnalt de)

Larcebau/Larsebau (Aneco de, Guillaume Arnalt de)

Lariat (Raymond de)

Larrande (Pierre de)

Larrando (Johan de)

Larras (Guillaume Amalt de, Pierre Amalt de) : en Labourd à Villefranque

Larrassa (Aneco Sanz de) : en Basse-Navarre

Larrer (Aimée de)

Larressoina (Dominique Pascal de)

Larreula (R. de) 
Lastres (Pierre de)

Lavin (Guillaume de, Marie de)

Laugar (Guillaume Pierre de)

Laurhontan (Guillaume de)

Le Bruguerre (Guillaume de)

Le Carra (Arnalt seigneur de)

Le Cata : cf. Locata

Lecharrague : cf. Lisserrague

Le fonsa (frère Pierre B. de)

Le Furie (Bertrand de)

Leguieta (Pierre Guillaume de)

Lelherreguy (Arnalt de)

Le Peruilla (Salvat de)

Lerin (Michel de, Michel Garcia de)

Le Saca (paroisse de)

Lesalde (Lobet de)

Lescum (Pierre Arnalt de)

Lesgor (Johan de)

Lesquire (Jacob de)

Le Tarsa (Sanz Amalt de)

Leycester (comte de)

Lissabe (A. de)

Lisserrague/Lecharrague (Guiralt de, Semen de) : Leizarraga à Ossès

Locata/Le Cata (Amalt Bemard de, Guillaume de)

Luc (Guillaume Arnalt de, Pierre Arnalt de, Vital de)

Luiar/Hilvar (Amalt de) : Elhuiar à Hasparren

Luxa (P. Amalt de)

Luxerror (P. de)

Maier/Mayer : Mava en Navare

Maignan (Pierre, Michel)

Mangs (Esclarmonde de, Michel de)

Marques (Guillaume)

Marriturri (Johan de)

Mansbarrauta/Mazberraute (seigneur de, Bernard de, Guillem molier de, les frères Arnalt et Guillem Garcie de)

Mascarat (Bernart de)

Maçanges : Messanges

Maverned (Sanz Arnalt de)

Meharren (Loup Arnalt de, P. de, S. Loup de)

Mendilla harsu/Mendilleharsu (Fon Aner ou Amalt de)

Mespa (Arnalt de)

Mixa

Molis (sénéchal Nicolas de)

Monen (Vital de)

Mongelos ( $\mathrm{P}$. de)

Montferrand (château de)

Mosserrole (B. de)

Mugron (Pierre Johan de)

Murua (Guillaume de) 
Naguilla (Bernard de)

Naguyturi/Neguytori (les frères Bernard, Garcia Arnalt et Sanz, Amalt Sanz, Sanz Arnalt de)

Naner (Pero A. de)

Narbayz (Pierre de)

Naubeis/Naubica (Arnalt de, Arnalt Johan de, Guillaume de)

Naubil (Amalt de)

Navarre (roi de)

Oarriz (Garcia Chemen)

Ofalso (Amalt de)

Olfais (Bemard d')

Olhatse (Navarte d')

Onderitz (Amalt d', Johan d')

Orbare (Johan d')

Orcuit (Espagnol d') : Urcuit en Labourd

Orcuit (Bernard d', Amalt B. d', Bernard Guillaume d') : Urkieta maison d'Arbéroue

Ordaidz (Egide d')

Ordoiz (Aneco d')

Organvede (Lope d')

Orinsu (Arnalt d")

Orquieta Hugon (Jordana d')

Orroigna (paroisse d')

Orsahaco/Orzanquem (Raymond d') : Orsanco en Mixe.

Orsasenete (Johan d')

Ortes (bailli d')

Os (Raymon d')

Ossadges (Pierre d')

Ossau (Sancia Arnalt d')

Ossès/Ossees/Ousees/Sees (Amalt d', Garcia Amalt d', Guillaume d')

Ostebares (pays et ville, Raymond d')

Ostebil (Bemard d') : cf. Urstubil

Oyharsa (Amalt d')

Pagandu (Amalt Johan de)

Pagandurua (paroisse de, Messeriat de, Pierre de)

Pagasu (Guillaume A. de)

Pampilona/Pampilina : Pampelune

Paradis/Paravisum (Bernard B. prieur du, hôpital du)

Perer (Assarida de)

Peruil (Pierre Bernard de)

Pinu (Johan de)

Plaieds (Amalt de)

Polencs (Pierre de)

Poyes (Grazide de)

Prad (Amalt de, Johan de)

Pui (Bertrand de, Bénévent de)

Puiana (Laurent de)

Puis (Garcia Arnalt del, P. dels)

Pusque (Dominique) 
Ratsu (Guillaume de) : Erratzu en Navarre

Rauset (P. de) : cf. Arrauzed

Re Labord (A. de)

Rocafort/Roquefort/Rupe Fort (château de)

Rutia (dame de) : Urrutia à Isturitz

Sainte-Marie (Arnalt de)

Saint-Esteben (G. de)

Saint-Félix (maison de, V. de)

Saint-Girons (Gracie de)

Saint-Jean (Johan de, Fort Aner de, Martin de)

Saint-Jean-de-Luz

Saint-Jean du bout du Pont de Bayonne (précepteur de)

Saint-Jean (Pied-de-Port)

Saint-Léon (à Bayonne)

Saint-Nicolas (Pierre de)

Saint-Martin (Raymond de) : à Villefranque

Saint-Martin (Pierre B. de) : en Cize (Lécumberry)

Saint-Pierre (Johans de)

Saint-Vincent (Arnalt de) : à Urrugne

Salies/Salias (Jordane de, Julien de)

Samacoids/Samacos (Guillaume Bernard seigneur de)

Saraspe (Garcia de)

Sansa (paroisse de, maison de) : Azantza pour "Cambo"

Sansu/Santz (Aneco de, Johan Sanz de, Pierre de)

Sateriz/Saterids/Setheriz (Aneco de, Johannes de, P. Sanz de)

Saubaignag (Pérégrin de)

Saut (paroisse de, château de, Arnalt de, Johan de, P. Arnalt de) : pour "Hasparren"

Savaloa (Amalt Sanz de)

Saxo (Martin de)

Sees : cf. Ossès

Seingnossa (Pierre de)

Senguinet (Arnalt de)

Senseres (Pierre de)

Seubist (Mathieu de)

Sombilh (Johan de)

Sorarburu (Arnalt Sanz de, les frères Brasc et Bernard de)

Sordua (Johan de)

Sorrain (Amat de)

Sorrossa (les frères Loup Sanz et Petriz Esquerra de)

Sort (Guillaume de)

Sosaute (Amalt Garcia de)

Stella (Bartolomé de) : cf. Estela

Sufaratsu (B. de, Sanz de)

Suiars/Syvars/Cyvars (Arnalt de, les frères Loup Garcia et Bernard de)

Sumset (Guillaume de)

Surayda (paroisse de, Aner de, Johan de)

Surueta (Marie Johan de) 
Taron (Johan de)

Terreberd (Raymond Guillaume)

Thais (Johan de)

Thaler (Garcia Sanz de, Martin de)

Tismar (Guillaume Pierre de)

Tissaul (Bemard de)

Tremolet (Guillaume de, Raymond de)

Torobyz (Auria de)

Tyso (Martin Enecoitz de, Sanz de)

Uhalda (G.A. d') : Uhaldea à Larressore

Uhalda (Garcia Amalt d') : id. à Ustaritz

Urcjndoi (Sanz d') : pour Urkudoi à Cambo

Uztaridz/Ustarydz/Ustaryz (château d', paroisse d', Sanz d')

Uxainda (Aneco d')

Uxavide (Aneco) : presque sûrement le même que le précédent

Villa (Pierre de, Vital de)

Villanova (Aner de) : cf. Iriberri, à Ossès

Villanova (Arnalt Loup de) : cf. Hiriberri, à Ustaritz

Viura (Sanz de)

Yruber (Martin d', Pierre d'): cf. Iruber

Yssuri : cf. Issuri

\section{Deuxième partie (réclamations navarraises)}

Aassa (Arnalt d"): pour Ahatsa "Ahaxe", cf. Assa, Hatsa

Açança (Sancho d')

Aezquoa (alcalde $d^{*}$ )

Agarrea (Arnalt d') : Agerrea en Arbéroue (Hélette)

Agramont (château d', Garcia Arnalt seigneur d', son frère Auger ou Ogiers d', Arnalt Guillem ou Guillent d', Bernart d', Vivian d')

Aguarrette (Amalt d')

Aguerre/Aguerrea (Guillem d'): à Bardos ou Amorots

Aguerre (Bernard d') : Agerrea à Ayherre ou Saint-Esteben

Aitar (Guillem Arsis d')

Aiza (Pedro d')

Albat (Bernart d')

Albeintz (jaun Petri Johan d')

Alçu (Santz d')

Alçuburu (les frères Bernart et Lop Bernart d')

Anerart (Peirona d')

Andon (seigneur d')

Anglaterra (roi d')

Antonie (Guillem le "flamenc" d")

Antont (Nicolas)

Arberoa/Herberoa/Erbero/Esberoa

Arbeu (J.)

Arbinoritz (Guillem d")

Arçar (château d') 
$\operatorname{Ardir}\left(\mathrm{J} . \mathrm{d}^{\prime}\right)$

Argena (Pes d')

Arguain (Jurdana d')

Aribileta (Pedro d')

Ariete/Fariete (Bernard d') : Harrieta en Cize

Arion/Arrion (Amade d', Guillem Per d')

Aristoitz (Santz d')

Arizcon (Domingo d')

Armendariç/Armendaritz/Mandaritz (seigneur d', Blasc ou Brasc ou Blasco d', Bernart d', Iohan d', les frères Sancho Arnaltz et Guillem d')

Arotze/Aroçe (Bernard d')

Arteguieta (Amalt Garsis d')

Arraidu (Garcia d')

Arriaga (Pes Amalt d') : chute navarraise de l'aspiration pour Harriaga

Arroses (Martin d")

Arulose (Amalt d') ; cf. Erlause

Ax

Ayçua (Domicu d')

Ayeta (Pere $\left.d^{*}\right)$

Aynoa

Ayrefort (comte d')

Badet (Pes de)

Barendegui/Barrendeguj (Guillem de)

Basatz (évêque de) : Bazas

Bassuen/Vasson (Arnalt Guillem sire de, Arnalt de)

Bastan/Batztan

Bayneres (Bernart Guillem de)

Bayona

Bearritz (Santz Arnalt de)

Belçunce/Belcunçe/Belçuncu/Belcinçu (Arnalt Pedro de, Garcia Arnalt de)

Beldarais (Garcia Lopiz de)

Beor (Johan de)

Beraiscojtz (Domicu) : roman Briscous

Berari (Domingo)

Bergara (Garcia)

Bernardis (Johan de)

Berrio (Martin de)

Beta (Johan de)

Bidageign (Pedro Garssias de)

Bidart (Bernart de, Petri Arnalt ou Pedro Arnalt de, Pere Heruans de)

Bigot (Guillem, Johan, Guiralt. Gil de)

Biscarret (Amalt de, Garcia et son fils Ochoa de)

Biscarrz (Santz de)

Blaues (seigneur de) : Blane

Borcs (Johan des)

Bordel (archevêque de) : Bordeaux

Bordiaus : probablement forme française ou francisante du précédent

Borrel (Pelegrin)

Boys (Guillem deu) 
Brena/Brene/Brevas (sénéchal Franc de, Ferrant de)

Bretayna

Briscoitz/Briscorz (Santz de) : cf. Beraiscojtz

Bruges

Çalane (Amalt de)

Camer/Camera (Iohan de) : Came

Camo (Bernart de)

Çandueta (Garcia Santz de)

Caumoz (Bernart de)

Cavaloe (Sans Guaissia de)

Cepuru/Çepurua (Santz Amalt ou Anso Erlans de)

Çeurt (Pere de)

Chegoiane (Guillem Domicu de)

Ciralda

Cissa : Cize

Conches (Simon de)

Comoaylla

Çorrotça/Corroça (Lop ou Lope Santz) : la première partie montre qu'il ne s'agit pas d'un surnom mais d'un nom de lieu

Crique (Eneco)

Devensire : Devonshire

Doutej (Guilleumes) : cf. Eutej

Echague/Eschaigue/Eschaugue/(Eneco Rolantz ou Eneguo Rollan ou Eneco Erlantz d', Guillem d')

Echalatz (Maria d')

Echau (Eneco A. d')

Erascotz (Miguel)

Eregue (Domingo)

Erlause (Arnalt d')

Erro (val d', Yenego d')

Erspile (Fort Arnalt d')

Escati (Pedro d')

Esnos (Domingo d')

Espainna/Espaynna (Johan d', la nef Sancta Maria d')

Esparça (Arnalt d')

Esparre (Johan d', son fils Amautz d')

Espeleta/Espelete (Santz d'Assa ou Sancho seigneur d', les trois frères d')

Estela (Johan Marin d')

Estrena (Aner d')

Etsague (Santz d')

Etzçan (Johan Domicuitz d')

Eutej (Guillem Amalt d')

Eyars (Santz d') : Eihartz en vallée d'Ossès

Falsart (Ochoa)

Fariete : cf. Ariete

Fenes (Andregaylla de, Esteben de, Guillem de) 
Folques (Johan)

Fontarabia

Gandaratz (Guillem Erlantz)

Gandulayn (Miguel de)

Garat (Pedro de) : à Hélette

Garris/Garritz (Johan de, Johan Santz de)

Garro (Guaissia Arnalt de)

Garroia (A. de) : ce nom est probablement le même que le précédent en forme basque déterminée avec un "yod" intervocalique encore présent dialectalement jusqu' au XVII' siècle

Garsis (Bemart de)

Gascoyne/Vascoinna (sénéchal de, Salt de)

Gironda

Goleyotz (Garcia de)

Gorost apasequo (Sancho Goria de)

Gosser (Per Guillem)

Granasui : pour Guernesey ou Grave.

Gree (Johan de, Richat de)

Guarre (Garcia) : pour Aguerre à Bardos

Guessa

Guinçaliseu : pour Winchelsee

Guissen (Garcia Amalt de, Guillem Arnalt de)

Harambileta (Petri) : cf. Aribileta avec le prénom en espagnol

Hassa/Hasse/Assa/Aassa (sire de, Bernart de, Navarr de, Santz d'Assa seigneur d'Espeleta) : cf Aassa, Ahaxe en Cize

Heguidoa (maison de)

Heriart de Sorane (Garsias de) : Iriante de Sorano (Hasparren)

Hon (Guiralt de)

Hurt (Pes de)

Hutze (Atznar de)

Hyherauçu (Garcia Amalt de)

Içuri//çurii/Issurri//ssuli/Yssuli//ssulicho (Amalt Ramon ou Aramon d', Ramons d., Sancho ou Santz d')

Iorse (Per ou Pierre ou Pierres d')

Ioy (Arnalt) : cf. Oiosen

Irissairi/lrissarci (hôpital d', Arnalt d')

Iriveri (Eneco) : Iriberria d'Isturitz

Iriverri (Arnalt d') : à Ossès

Irundaritz (Arnalt d')

Isça (Aceari d')

Ituvil : cf. Urstubil

Jaço. gayno

Jacsu (Garcias Sens de)

Jassu (Pedro de)

Josse (Bernart Pes de, Pes de) 
La Barra de Salt (Arnalt Guillem de)

Labort

Lac (Bernart dou)

La Ceilla (Amalt)

Lagassa de Lerin (Esteven de, Santz de)

La Gaillardia (Miguel de)

La Harragua/Larragua/La Regue (Johan de, Issemen ou Symon de)

La Lana (Pierre de) : Larrea en Cize

La Lana/Le Lana (Bernart de, Espaynol de, Iohan de, Pedro ou Pierres de, Santz de) : Larrea à Ustaritz

La Lande (Sancho de) : cf. le précédent

Landa (les frères Arnalt Johan et Sancho de)

Lantz (Pascal de)

La Pointa : La Pointe de Grave

Laquoaga/La Coague (Guillem de)

Laralde

La Rassojnna (Aznar de)

La Raun (Domingo Yvaynes de)

Larazpe (Semeno Atznareitz)

Laredo

La Reula franca (Ramon de)

La Rocha (Aznar de)

Lanagua : cf. La Haragua

Larrando (Johan de)

Larrea (Sancho)

La Sague (Bernart de) : Latsaga à Bardos

Lastreira (Ramona)

Laudoar (Pes de)

Lay (Bernart de)

Legassa (Petri Santz de) : cf. Lagassa

Lerin

Les Cumbes (Guiralt de)

Lesquila (Pes de)

Limidart (Guillem Gaissia de)

Lissaga (Garcia de)

Logros (Johan)

Loli (Lop de)

Lomberi (Bernart de) : Irumberri

Londaitz/Londiritz (Guillem Garcia ou Garcis de)

Longuida (Domingo de)

Loreront

Lort (Garcia de)

Luc (Amalt Gaissia ou Guaissia de)

Luidudo (Johan de)

Maçanges (port de)

Madoz (Domicu Johanetz de)

Magron (Per Johan de)

Marra (Johan)

Maude Vile (Pere Johan de) 
Maus (Miquel de)

Maya/Maye/Mayer (Durant de)

Mayagatz (ville de)

Meçcarat/Mescare (Bernart de)

Mehari (Pere de)

Mendolori (Pere de)

Miramont (Condet de, Per Gassia, Per ou Pierres Manin de)

Montaner (Bernart de)

Morlans (Pere Johan de)

Muquof (Garcia)

Murgue (Johan)

Murue (Gayssia Guillem de)

Murusco (Garcias Guillem de) : probablement le même que le précédent

Naguiturri/Naguiturin (Amalt de, Sancho ou Santz de, Sancho Santz de)

Naregure (Pes)

Navasques

Nobeis/Nobeins (seigneur de, Arnalt de)

Oarritz (Per Semeneitz de)

Oçaçaneta (Johan)

Ochogavia

Odariç (Johanes d')

Odeyn (Dominico Varaculz d')

Oiosen (Guillem d')

Olcos (Garcia d')

Oleritz (J. d')

Oliva (abbé d')

Ondezitz (Johan d'): cf. Ondritz

Ondres (Guillem Amalt d')

Ondritz (Johan)

Ones (Pes d')

Onnaçu (Orçaintz d')

Orçaintz (Bernart d')

Orisbusti (Amalt d')

Orseis/Orses/Osses/Oses (Bemart d', Garcias Guillem d', Gil d', Lop Santz d', Pedro d', Pedro Osois d', Simen d', Sanç d', Sancho Ochoa d')

Ortes (Esteven $d^{*}$ )

Paganduru (seigneur de)

Pampalona (Per Guillem de)

Par (Johan, Arnalt)

Perer (Guillem Vidal de)

Plemua : aujourd'hui Plymouth

Pomars (Ramon de)

Pomeros (Raimos de) : peut-être le même que le précédent, aujourd'hui Pomares

Potz (Bernard del)

Poy (Ferrant dou)

Puiaga (Lorentz de) : pour Puiana maire de Bayonne

Puillaga (Amalt Santz de) 
Puis (Per Annalt des)

Puyvert (Bernart de, Johan de)

Raç (de) : pour "d"Amas"

Rause (Amalt de) : cf. Erlause

Rigada (Peyron de)

Rocafort (château de)

Rochamador

Ronçavals (Bertolomeu de, Domingo Pascal de, Guasia Peritz de)

Rosset/Rosed (Pere ou Pes d'): pour Arrauset maire de Bayonne

Royam : Rovan

Sague (Eneco Amalt de, Guillem de, Yenego A. de)

Saires

Salin (J. del)

Salt/Saut de Gascoyne (Amalt de, A. Guillem de, Arnalt Peire ou Per Arnalt de, les frères Auger ou Oger ou Ochier et Guillem Amalt de, Blasquo de) : Zaldu à Hasparren

Sancta Maria (Enequo de, Johanes de)

San Salvador (cabane de)

San Salvador de Leurum (abbé de): Leyre

Sant German (Bernart de, Guillem de)

Santhomer : Saint-Omer

Sant Iohan de pie de puertos/Sant Johan (Adam de, Amalt Bernart de, Arnalt Lopiz de)

Sant Mayeu

Sant Martin (Bernart Guillem de)

Sant Miguel (Amalt Santz de, Amalt de)

Sant Tomas de Canturberi

Sarasa (Bernar Peritz de)

Saumat (Guillem de)

Sayntes

Sele (Hancho)

Soler (Rostain del)

Soraburu (les frères Amalt Sanz et Pierres Amalt de)

Soranoa/Sorano/Sorane (Aner de, Amalt, Atznar de, Garcia Amalt de)

Subist (Pere de)

Tascama

Tastif (Pere)

Ualde (Johan $d^{\prime}$ )

Uartegon (Johan d')

Uaurcengo (Martin d') : Ugarzan à Ossès

Un Castel (Miquel d')

Urdais (abbé $\mathrm{d}^{*}$ )

Urditz (Ramon d')

Ureta (Eneco Ortitz d')

Urgos

Urguri (Pes d') 
Uritz (Johan d')

Urquido (Sancho d')

Urrutia de Cissa/Urutie (Petri Santz d')

Urstubil/Ustubil/Itubil (Amalt d', Amalt Santz d')

Usdos

Usot (Bernart d')

Utzcharros

Utztaritz

Val d'Agueil (Sanchetz Ortitz de)

Vardos/Vados (seigneur de) : Bardos

Vascoinna : cf. Gascoyne

Vasson: cf. Bassuen

Veneça (Pere Ramon de) : maire de Bayonne

Vilanova/Vyllanueva: Viellenave

Vilanova (Arnalt Bernart de) : en Navarre

Vilanova (Maria Guarceiz de) : en Cize

Yvon (Garcia Peritz) 


\section{Laburpena}

XIII-garren mendean Nabarrako errege Zantxo Azkarra hil eta (1234), haren ilobu Thibalt edo Thibaud Xampañako kondeak ukan zituen Nabarrako korona eta erresuma. Berehala gataskak hasi ziren orduan Angeleterrako erregeren meneko ziren Baiones eta Lapurtarren eta Nabartarren artean : artalde eta abere bahitze larre-mendietan, untzietan zeramatzaten salgai ebaste eta zergatze Baionan eta portu angelesetan... Gauzak oraino gaixtatu ziren, bertze guzien artetik Garroko jauregia, hango jaunak Thibalten zerbitzuan izanez, Baionesek hartu nahi ukan zutelarik. Agaramunteko jaunak aldiz Nabarrako erregeri berak eta aitzinekoek eman hitza janik, Thibalt bere armadarekin sartu zen, Oztibar eta Amikuzen gaindi, Agaramuntiarren Erreitiko jauregiaren setiatzera. Bide nabar edo handik landa, Baxe-Nabartar (gehienik Arberoar eta Ortzaiztarrak, Garazi eta Baigorriko jaun zenbait bere mutilekin lagun) eta Nabartarrek, errege buru, suntsitu zituzten Lapurdiko gaztelu, jauregi eta herri gehienak etxez etxe : Hazpane 'ta Uztaritzetik Urruñara, Milafrangatik Bardozeraino.

Bakea egin zelarik 1248-ko azken egunetan, alderdi bakoitzak eman zituen paperrean gertakari horietan jendeak jasan zituen galtze guziak: jende hiltze, abere bahitze eta ebaste, etxe erretze, salgai eta diru galtze... Hortako 1249 hastapenean egin zen inkesta gelditzen da Erdi-Aroko Lapurdi eta BaxeNabarreko bizi molde, etxe eta jendearen ezagutzeko izan daitekeen lekukotasun baliosena, bereziki bi gaietan : 1) gehienak oraino ezagunak diren ainitz. etxe izen hor agertzen baita, jabe eta egoiliarrekin, lehen aldikotz, 2) baitakigu hortik zer ziren orduko sal-erospenen harat-hunatak, Iruñetik Baionara, Baionatik Angeleterrako portuetara, zer salgeiak (oihal, larru, arrain...), zer etxe eta gauzen balio zuzenak, zer zerabilzaten diru motak, eta holako ainitz xehetasun. Inkesta horren bi zatiak emaiten dira hemen frantseserat itzulirik: Baiones eta Lapurtarrena latinetik, Baxe-Nabartur eta Nabartarrena gaztelera, gaskoin eta frantses zaharretarik.

Jean-Baptiste ORPUSTAN

Université Michel de Montaigne-Bordeaux III UPRESA du CNRS 